\title{
(4)
}

UNIVERSIDAD PERUANA DE CIENCIAS APLICADAS

Facultad de Negocios

Carrera de Administración de Empresas

\section{SERVICIO PROFESIONAL PARA EL CUIDADO DEL ADULTO MAYOR: SENIOR CARE}

\author{
TRABAJO DE INVESTIGACION \\ Para optar por el grado de Bachiller de Administración de Empresas
}

AUTOR (ES):

CANAL ASPICUELTA, MARISOL INGRID (0000-0003-0111-4205)

CHICANA SOTO, YAMINA SOFIA (0000-0002-5515-1418)

PINEDA RODRIGUEZ, CLAUDIA ESTEFANY (0000-0002-2713-5971)

SOSA CARDENAS, JULIA CAROLINA (0000-0002-5753-1107)

ASESOR:

FAVIOLA IVETTE PALOMINO FALCONÍ ～(0000-0002-2033-6914)

Lima, 15 de Julio de 2018 
A nuestros padres y familiares

Agradecimientos

Nuestro más sincero agradecimiento a todas las personas que hicieron posible este logro.

En primer lugar, a nuestros padres que nos impulsaron y alentaron durante todo el tiempo de ejecución de esta investigación. De igual forma, agradecemos a nuestra asesora Faviola Ivette Palomino Falconí, quien nos ha guiado en cada detalle del desarrollo y nos ha mantenido orientadas en el objetivo de este proyecto de investigación. 


\section{RESUMEN}

La idea de negocio propuesta en el presente trabajo consiste en crear una página web y aplicación llamada SENIOR CARE, la cual permitirá a los familiares a cargo de un adulto mayor poder conectar a una red de especialistas en el rubro.

Con el fin de asegurar la tranquilidad de la familia, los enfermeros serán seleccionados bajo un riguroso proceso de selección para asegurar a nuestros clientes que son personas aptas para el cuidado de adultos mayores.

Para que este negocio pueda brindar la seguridad que se requiere contaremos con el respaldo de un área legal y recursos humanos, quienes nos apoyarán en la tarea de contar con el mejor equipo.

La descarga será gratuita desde el AppStore y Play Store, de acuerdo al sistema operativo con el que cuente el usuario y tendremos un diseño Web Responsive que permitirá la correcta visualización desde distintos dispositivos.

SENIOR CARE obtendrá ganancias a través de las comisiones que se cobrarán por la intermediación de un $30 \%$ que se considerarán dentro del cobro realizado al momento de solicitar el servicio.

El precio promedio por este servicio es de $\mathrm{S} / 45$ por un servicio de 3 horas, $\mathrm{S} / 80$ por 6 horas y en el caso de 12 horas el costo será de S/ 150.

Palabras clave: enfermeros, familia, cuidado, adulto mayor, seguridad 


\section{ABSTRACT}

This business proposal aims to create both a website and an application named SENIOR CARE, which will provide relatives caring for older people with a network of specialists in the care sector.

In order to ensure families' peace of mind, nurses will be subjected to a painstaking selection process that guarantees their competence for the care of older adults. To make clients feel safe about our business, a legal department and a human resources department will support us and will be involved in the task of creating the best team.

The application's download will be free of charge from App Store and Play Store, depending on the user's operating system. As for the website, it will have a responsive web design, thus allowing its adequate visualization from different devices.

SENIOR CARE will earn a 30\% commission for mediation services, which will be included in the total amount paid for the service.

The service price is $\mathrm{S} / 45$ for 3 hours, $\mathrm{S} / 80$ for 6 hours, and $\mathrm{S} / 150$ in the case of 12 hours.

Keywords: nurses, families, care, older adults, safe 


\section{Tabla de contenido}

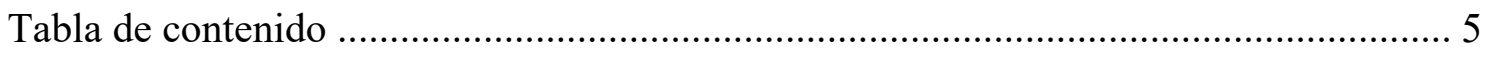

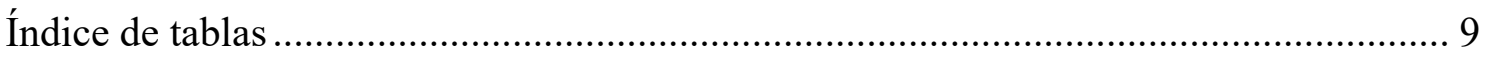

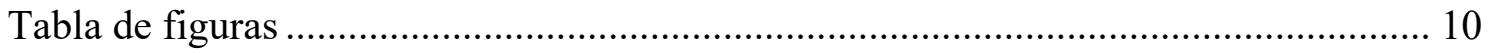

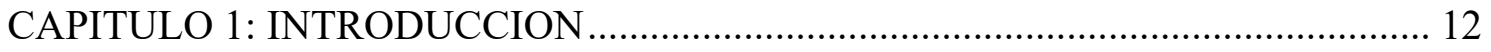

CAPITULO 2: ASPECTOS GENERALES DEL NEGOCIO ...................................... 13

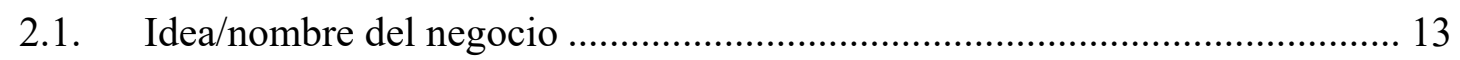

2.2. Descripción del producto/servicio a ofrecer ............................................... 13

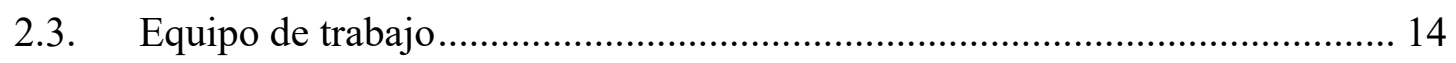

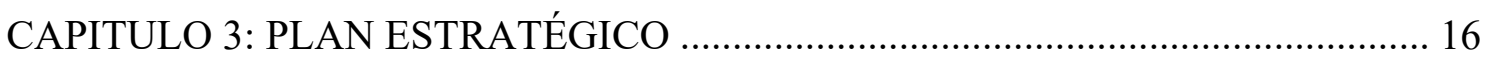

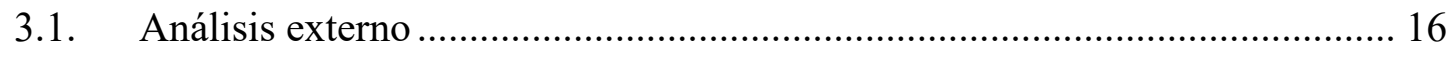

3.1.1. Análisis PESTEL ............................................................................... 16

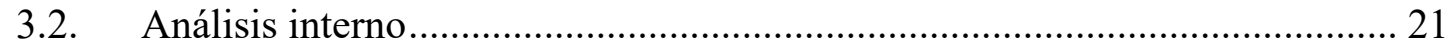

3.2.1. Análisis de las 5 fuerzas de Porter: competidores, clientes, proveedores, productos sustitutos, competidores potenciales.................................................. 21

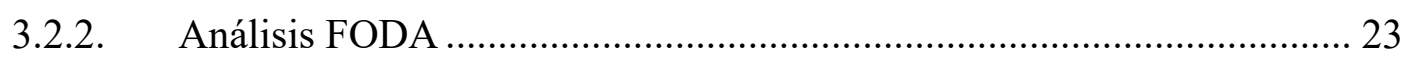

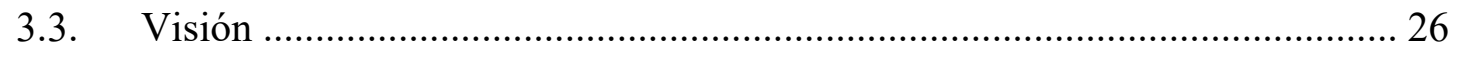

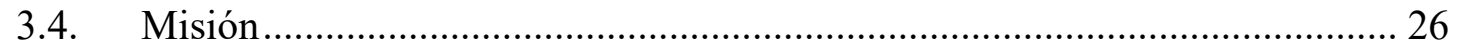

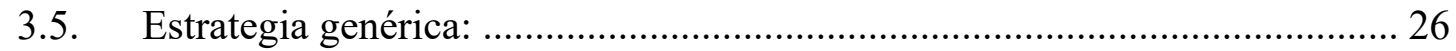

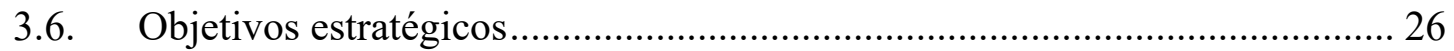

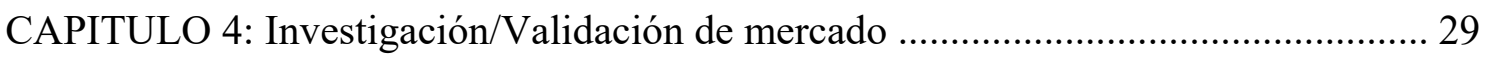

4.1. Diseño metodológico de la investigación/metodología de validación de

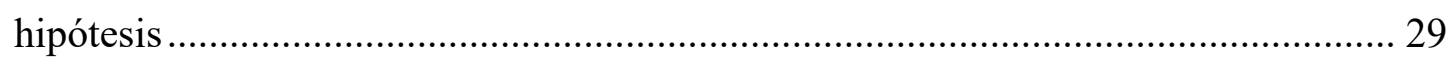

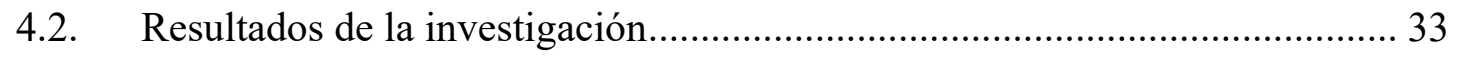

4.3. Informe final: elaboración de tendencias, patrones y conclusiones ............... 40

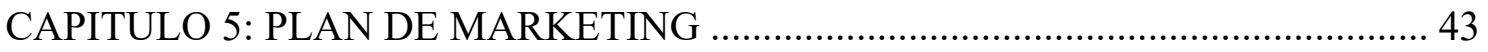

5.1. Planteamiento de objetivos de marketing ..................................................... 43

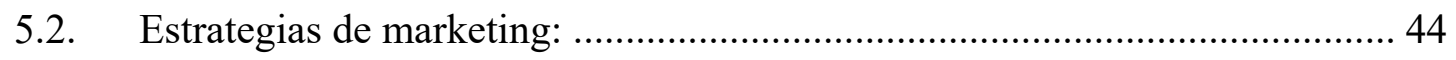

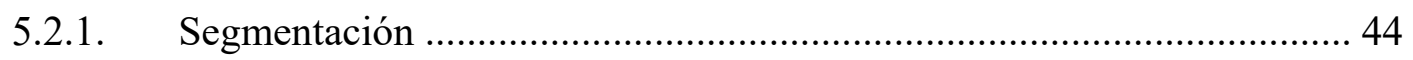

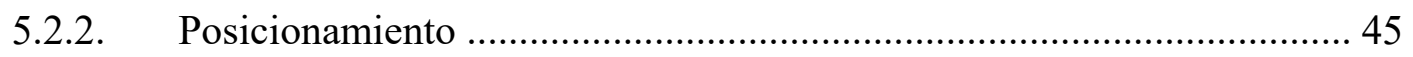

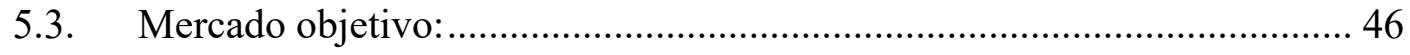




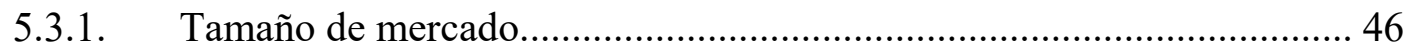

5.3.2. Tamaño de mercado disponible .......................................................... 48

5.3.3. Tamaño de mercado operativo (target)................................................... 48

5.4. Desarrollo y estrategia del marketing mix................................................... 50

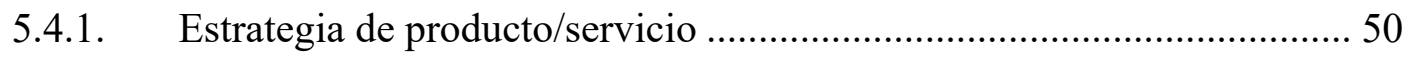

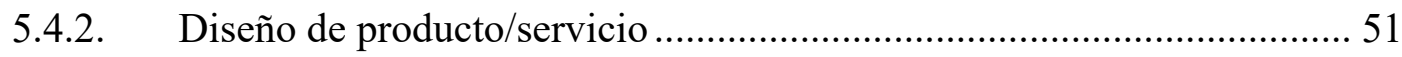

5.4.3. Estrategia de precios (Análisis de costos, precios de mercado) .............. 54

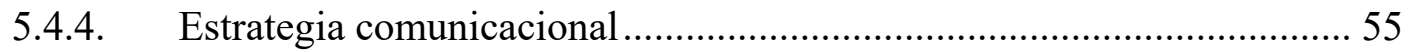

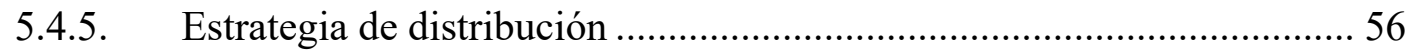

5.5. Plan de ventas y proyección de la demanda ................................................. 56

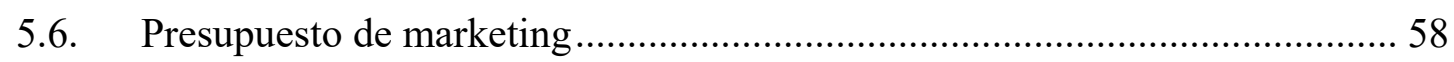

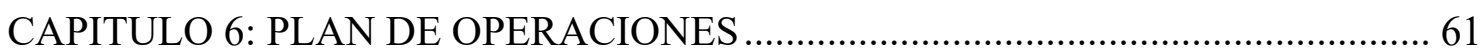

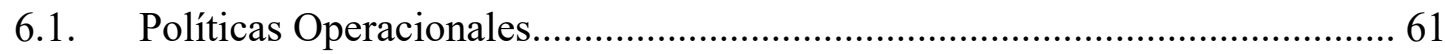

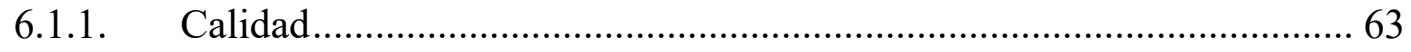

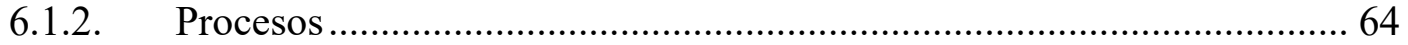

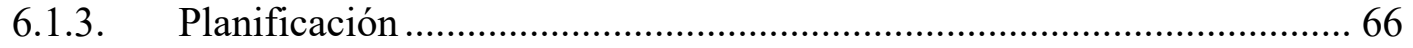

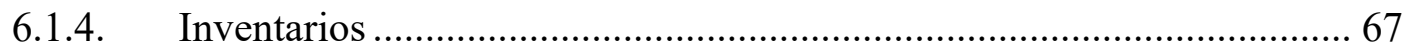

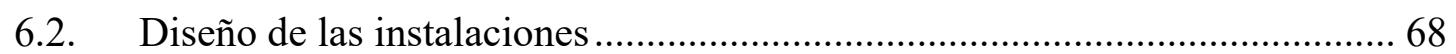

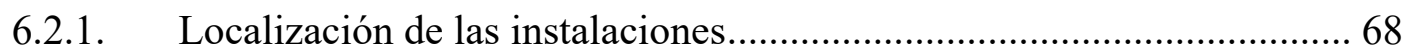

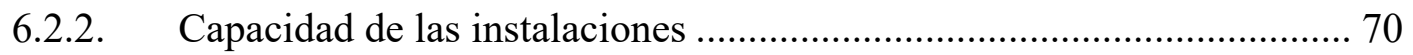

6.2.3. Distribución de las instalaciones ........................................................ 71

6.3. Especificaciones Técnicas del Producto / Servicio ....................................... 72

6.3.1. Diseño del App SENIOR CARE ............................................................. 73

6.3.2. Diseño de la web SENIOR CARE ....................................................... 74

6.3.3. Especificaciones técnicas del App..................................................... 75

6.4. Especificaciones Técnicas del Producto / Servicio ........................................ 75

6.5. Especificaciones Técnicas del Producto / Servicio ....................................... 79

6.5.1. Gestión de compras y stock ................................................................. 79

6.5.2. Gestión de la calidad........................................................................... 79

6.6. Inversión en activos fijos vinculados al proceso productivo .......................... 80

6.7. Estructura de costos de producción y gastos operativos ............................... 80

CAPITULO 7: ESTRUCTURA ORGANIZACIONAL Y RECURSOS HUMANOS . 82

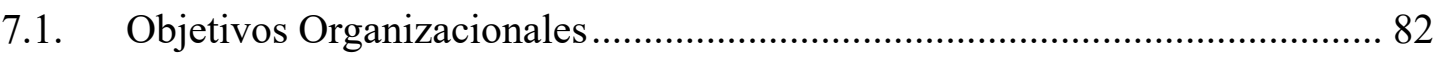

7.2. Naturaleza de la Organización.................................................................... 82 


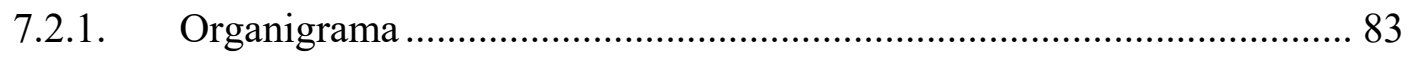

7.2.2. Diseño de Puestos y Funciones ............................................................ 83

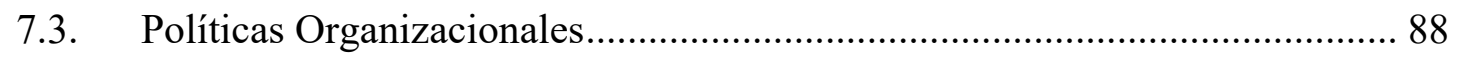

7.4. Gestión Humana ...................................................................................... 90

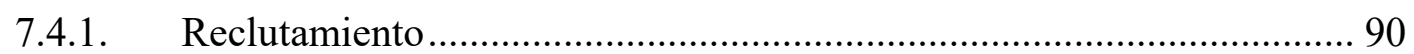

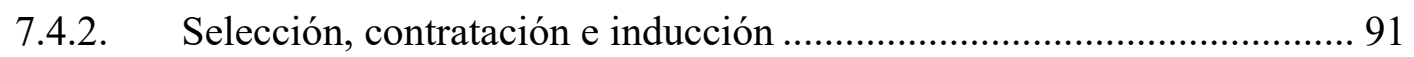

7.4.3. Capacitación, desarrollo y evaluación del desempeño .......................... 92

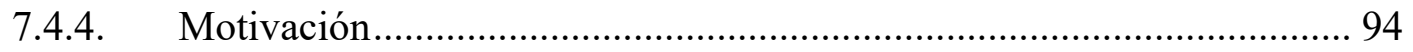

7.4.5. Sistema de Remuneración ....................................................................... 94

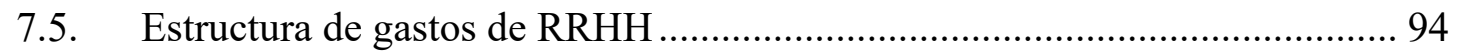

CAPITULO 8: PLAN ECONOMICO Y FINANCIERO ............................................. 96

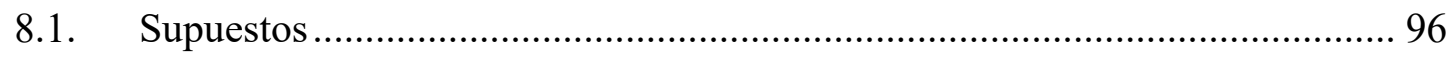

8.2. Inversión en activos (fijos e intangibles) y depreciación ............................... 97

8.3. Proyección de ventas ................................................................................. 100

8.4. Cálculo del capital de trabajo ................................................................... 102

8.5. Estructura de financiamiento: Tradicional y no tradicional ........................ 108

8.6. Estados financieros (Balance General, Estado de GGPP, Flujo de Caja) .... 109

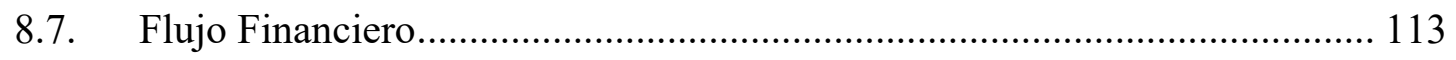

8.8. Tasa de descuento accionistas y WACC ................................................... 114

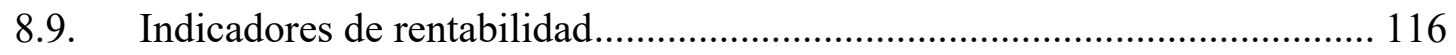

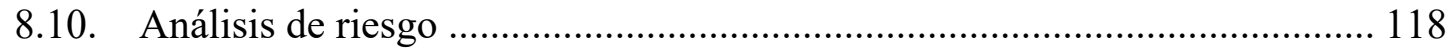

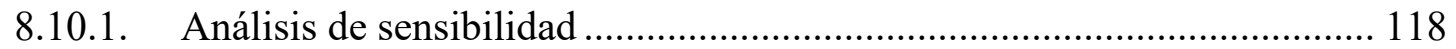

8.10.2. Análisis por escenarios (por variables) .................................................. 121

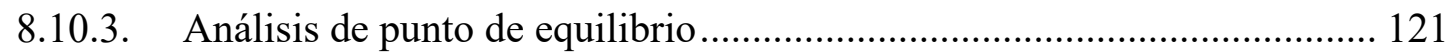

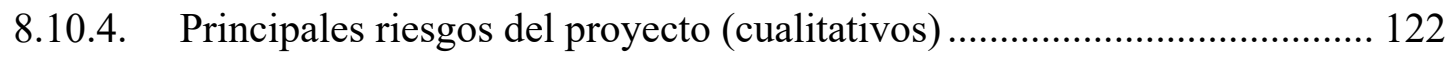

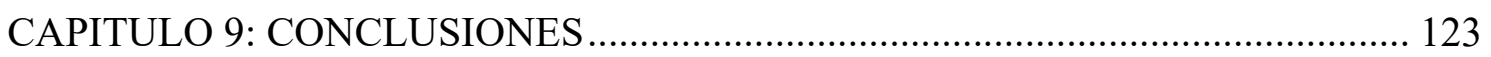

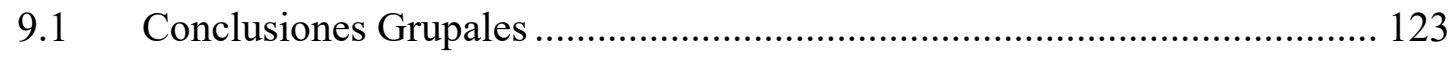

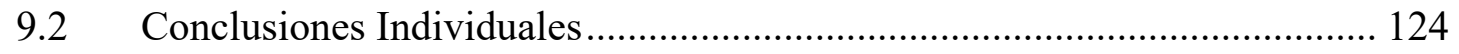

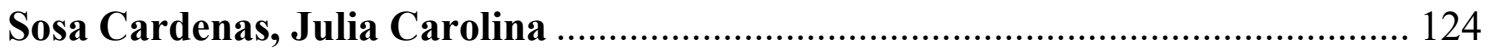

- $\quad$ El proyecto de negocio SENIOR CARE, permitirá a muchas familiar que carecen de tiempo suficiente en brindar apoyo y protección al adulto mayor en casa con la atención que ellos merecen.

- Nuestra propuesta de personal especializado en las técnicas de geriatría permitirá que exista un beneficio en el adulto mayor. 
- Para el desarrollo del negocio SENIOR CARE, se ha plasmado todos los cursos llevados a cabo en la Universidad, que nos han permitido elaborar el presente trabajo final de negocio SENIOR CARE.

- Luego de analizarlo cuidadosamente podemos decir que el proyecto nos ha demostrado ser rentable y crear una oportunidad de negocio personal en el futuro. ... 124

- Para llevar a cabo el proyecto se tomará en cuenta los factores económicos es decir la factibilidad económica y financiera del proyecto.

- El presente estudio se ha abarcado atender las zona 6 y7 de los distritos de Lima Metropolitana, si ponemos en marcha el proyecto se puede cubrir otras zonas adicionales con la finalidad de ir incrementando nuevos clientes potenciales y que el proyecto sea mucho más rentable en el futuro. 


\section{Índice de tablas}

Tabla $\mathrm{n}^{\circ}$ 1: Población adulta mayor por condición de actividad (Fuente: INEI)

Tabla $\mathrm{n}^{\circ}$ 2: Población beneficiaria del programa pensión 65 , según área de residencia

(Fuente: INEI) 19

Tabla $\mathrm{n}^{\circ}$ 3: Matriz FODA (Fuente: Elaboración propia). 24

Tabla $n^{\circ} 4$ : Balanced Score Card (Fuente: Elaboración propia) 26

Tabla ${ }^{\circ}$ 5: Total de población en Lima Metropolitana (Fuente: Elaboración propia) .. 46 Tabla $\mathrm{n}^{\circ}$ 6: Distribución de niveles por zonas APEIM 2017 de Lima Metropolitana (Fuente: APEIM 2017)

Tabla ${ }^{\circ}$ 7: Perfil de personas según NSE 2017 de Lima Metropolitana (Fuente: APEIM 2017) 47

Tabla ${ }^{\circ}$ 8: Tamaño de Mercado disponible (Fuente: Elaboración propia) 48

Tabla $n^{\circ}$ 9: Total de población en Perú Urbano (Fuente: Elaboración propia) 48

Tabla $n^{\circ} 10$ : Estimaciones y proyecciones de la población total por años calendario, según edad, 1950 - 2020 (Fuente: INEI)

Tabla $n^{\circ}$ 11: Tarifario de servicios (Fuente: Elaboración propia) .....................................5

Tabla $n^{\circ}$ 12: Precio venta y comisión por servicio (Fuente: Elaboración propia)........... 57

Tabla $n^{\circ}$ 13: Proyección de la demanda (Fuente: Elaboración propia) ........................... 57

Tabla $\mathrm{n}^{\circ}$ 14: Proyección de la demanda y la demanda esperada para los próximos 5 años

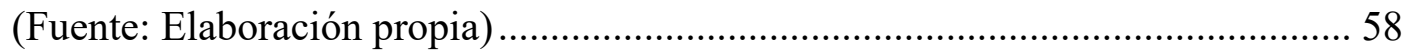

Tabla ${ }^{\circ}$ 15: Presupuesto (Fuente: Elaboración propia) .................................................. 59

Tabla $\mathrm{n}^{\circ}$ 16: Cronograma de las Actividades de Planificación (Fuente: Elaboración propia).

Tabla $n^{\circ}$ 17: Evaluación de los factores para la macro localización (Fuente: Elaboración propia)

Tabla ${ }^{\circ}$ 18: Cuadro comparativo de los cuatro distritos evaluados (Fuente: Elaboración propia)

Tabla $n^{\circ}$ 19: Inversión en activos fijos (Fuente: Elaboración propia). 80

Tabla $n^{\circ} 20$ : Estructura de costos de producción y gastos operativos (Fuente: Elaboración propia). 81

Tabla $^{\circ}$ 21: Estructura de gastos RRHH (Fuente: Elaboración propia) 94 


\section{Tabla de figuras}

Figura $^{\circ}$ 1: Business Model Canvas (Fuente: Elaboración propia) ............................. 16

Figura $\mathrm{n}^{\circ}$ 2: Evolución de la población por rango de edad (Fuente: INEI).................... 18

Figura $n^{\circ}$ 3: Las 5 Fuerzas de Porter (Fuente: Elaboración propia) ............................... 21

Figura $n^{\circ} 4$ : Resultado respuesta 1 (Fuente: Elaboración propia) ................................. 34

Figura $n^{\circ}$ 5: Resultado respuesta 2 (Fuente: Elaboración propia) …............................... 34

Figura $n^{\circ}$ 6: Resultado respuesta 3 (Fuente: Elaboración propia) ................................. 35

Figura $\mathrm{n}^{\circ}$ 7: Resultado respuesta 4 (Fuente: Elaboración propia) ................................. 35

Figura $\mathrm{n}^{\circ}$ 8: Resultado respuesta 5 (Fuente: Elaboración propia) ................................. 36

Figura $\mathrm{n}^{\circ}$ 9: Resultado respuesta 6 (Fuente: Elaboración propia) ................................. 37

Figura $n^{\circ}$ 10: Resultado respuesta 7 (Fuente: Elaboración propia) ............................... 37

Figura $n^{\circ}$ 11: Resultado respuesta 8 (Fuente: Elaboración propia) …............................ 38

Figura $n^{\circ}$ 12: Resultado respuesta 9 (Fuente: Elaboración propia) ............................... 39

Figura $\mathrm{n}^{\circ}$ 13: Resultado respuesta 10 (Fuente: Elaboración propia) .............................. 39

Figura $\mathrm{n}^{\circ}$ 14: Tendencias (Fuente: Diario El Peruano) .................................................. 41

Figura $\mathrm{n}^{\circ}$ 15: Distritos Lima Metropolitana por zonas (Fuente: APEIM 2016: Data

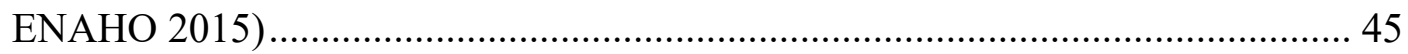

Figura $n^{\circ}$ 16: Distribución de personas según NSE 2017 (Fuente: APEIM 2017) ........ 46

Figura $n^{\circ}$ 17: Evolución de la población por rango de edad (Fuente: INEI) ................... 49

Figura $\mathrm{n}^{\circ}$ 18: Ciclo de vida del servicio (Fuente: Elaboración propia) .......................... 50

Figura $\mathrm{n}^{\circ}$ 19: Vista de App (Fuente: Elaboración propia)............................................ 53

Figura ${ }^{\circ}$ 20: Página Web/ Redes Sociales (Fuente: Elaboración propia) ...................... 54

Figura $\mathrm{n}^{\circ} 21$ : Plataforma virtual (Fuente: Elaboración propia) ..................................... 56

Figura $\mathrm{n}^{\circ} 22$ : Interacciones (Fuente: Facebook Senior Care) ….................................. 59

Figura $n^{\circ} 22$ : Embudo (Fuente: Elaboración propia) ..................................................... 59

Figura $n^{\circ}$ 23: Vista interna de la oficina SENIOR CARE (Fuente: Elaboración propia)

Figura $n^{\circ} 24$ : Vista interna de las oficinas administrativas (Fuente: Elaboración propia)

Figura $n^{\circ} 25:$ Vista interna de la oficina SENIOR CARE (Fuente: Elaboración propia) 
Figura ${ }^{\circ} 26$ : Diseño del App SENIOR CARE (Fuente: Elaboración propia).

Figura $n^{\circ} 27$ : Página web (Fuente: Elaboración propia) .............................................. 74

Figura $n^{\circ} 28$ : Mapa de procesos (Fuente: Elaboración propia) ….................................... 76

Figura $\mathrm{n}^{\circ} 29$ : Flujo de procesos (Fuente: Elaboración propia)..................................... 78

Figura $\mathrm{n}^{\circ}$ 30: Tabla de actividades de la empresa (Fuente: Elaboración propia) ........... 78

Figura $n^{\circ}$ 31: Diagrama PERT (Fuente: Elaboración propia) ....................................... 79

Figura $n^{\circ} 32$ : Organigrama (Fuente: Elaboración propia) ............................................ 83

Figura $n^{\circ} 33$ : Uso correcto del uniforme (Fuente: Elaboración propia)......................... 89

Figura $n^{\circ}$ 34: Proceso de selección y contratación (Fuente: Elaboración propia)........... 91

Figura ${ }^{\circ}$ 35: Evaluación de Desempeño Laboral (Fuente: Elaboración propia)............ 93

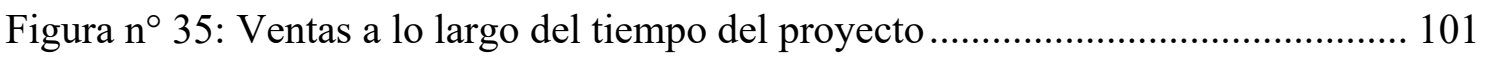

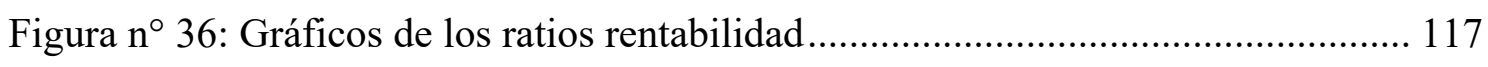




\section{CAPITULO 1: INTRODUCCION}

La presentación del trabajo está enfocada en brindar un servicio innovador en el mercado peruano para el cuidado del adulto mayor. En comparación con otras empresas del rubro brindaremos la facilidad de contratar nuestro servicio a través de una plataforma virtual y una app móvil. SENIOR CARE, nuestra empresa, busca satisfacer las necesidades de nuestros clientes en esta nueva era digital.

Este servicio busca atender las necesidades de los familiares a cargo de adultos mayores, estamos enfocados al segmento socio económico A y B ya que por medio de nuestra investigación hemos detectado que son nuestro nicho de mercado, estando dispuestos a contratar nuestros servicios.

Según el estudio de mercado realizado, se detectó que el principal problema de las familias a cargo de un adulto mayor es no contar con la disponibilidad de tiempo para brindar el cuidado y atención adecuados, ya que cada miembro de la familia realiza diversas actividades durante el día.

Nuestra ventaja competitiva radica en el acceso al servicio desde un medio virtual, además las familias podrán revisar una bitácora en línea que el enfermero irá completando con los acontecimientos más importantes. De esta manera los familiares pueden sentirse tranquilos ya que tendrán conocimientos de lo que sucede durante el servicio contratado.

Se contará con un staff de enfermeros disponibles 24/7, los cuales han pasado previamente por un proceso de selección, cumpliendo perfil requerido para estas labores.

Para ejecutar y validar nuestra idea de negocio se recurrió a diversas fuentes tanto primarias y secundarias, así como también se realizaron investigaciones cualitativas y cuantitativas a través de encuestas y entrevistas, obteniendo datos favorables para continuar con la idea de negocio. 


\section{CAPITULO 2: ASPECTOS GENERALES DEL NEGOCIO}

\subsection{Idea/nombre del negocio}

El cuidado y la seguridad de las personas de la tercera edad es un problema que lo vemos casi a diario en nuestro país, ya sea porque las familias no cuentan con tiempo disponible para atenderlos al 100\%, no tienen la paciencia y/o capacidad necesaria, e incluso existen casos donde estas personas son abandonadas.

Por estos motivos es que surgió la idea de este negocio, el cual consiste en crear una aplicación móvil y página web llamada SENIOR CARE desde la cual las familias podrán conectarse con personal capacitado en la atención de los adultos mayores para los momentos que lo necesiten ya sea por horas, para algunas ocasiones o para días específicos.

Para poder desarrollar esta idea tendremos como herramienta la tecnología, ya que nos da la opción de tener un servicio más global.

\subsection{Descripción del producto/servicio a ofrecer}

SENIOR CARE, es una empresa que se encarga de conectar a cuidadores especializados con las familias que necesitan el apoyo para cuidar a un adulto mayor.

Se obtendrá una base de datos de especialistas a través de los registros que estas personas realicen en nuestra aplicación móvil o página web, e indicarán su disponibilidad de horario y especialidades con las que cuentan.

Una vez registrado aparecerá en la búsqueda de las personas que ingresen a solicitar el servicio.

Asimismo, contaremos con alianzas con instituciones de educación superior especializadas en enfermería, con el fin de poder captar a los egresados.

Desde la perspectiva de los familiares, SENIOR CARE ofrecerá la posibilidad de contactar a los especialistas de nuestra base de datos, de acuerdo a la especialidad que 
necesiten y/o disponibilidad de horarios. Ingresando a nuestra página web/App podrá seleccionar a la persona que se adecue mejor al perfil que requieren y podrán realizar el pago con tarjeta de crédito o débito a través de una pasarela de pago.

Al finalizar el servicio el familiar podrá calificar al especialista, lo cual servirá de referencia para posteriores clientes.

Los servicios que ofrecen cada uno de nuestros cuidadores son:

- Control en medicación, nuestros acompañantes realizarán un seguimiento en la correcta toma de medicinas.

- Comidas según dieta.

- Mantener al adulto mayor con actividad

- Higiene y aseo personal, ayuda para vestirse y en la higiene íntima.

- Supervisión de la persona a cargo / compañía

- Traslado y/o acompañamiento a algún lugar.

Además de los servicios mencionados anteriormente, SENIOR CARE ofrece a los familiares de los adultos mayores un informe detallado de las actividades realizadas durante el tiempo en que el acompañante se encuentre realizando sus funciones mediante una "bitácora on-line" la cual se subirá a la plataforma para que el familiar lo pueda descargar en cualquier momento.

\subsection{Equipo de trabajo}

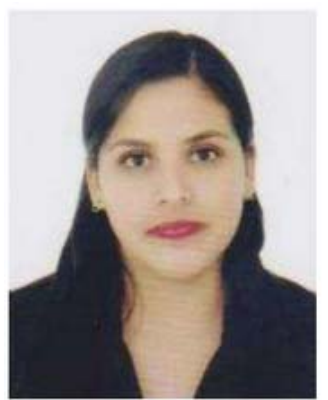

CANAL ASPILCUETA, MARISOL:

Egresada de la carrera de Administración de Hoteles en ISIL, experiencia de 6 años en el área comercial. Actualmente realizando prácticas profesionales en DHL Express en el área de Comercial Corporativo. 
Entre mis habilidades blandas destaco mi adaptación al cambio, vocación de servicio y comunicación efectiva.

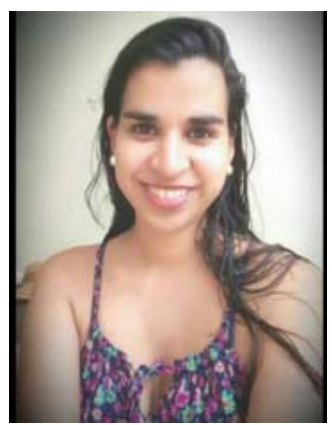

CHICANA SOTO, YAMINA:

Administradora técnica egresada de IPAE, con 8 años de experiencia en el rubro de banca. Actualmente laborando en el área comercial BBVA Continental en la unidad de banca empresas

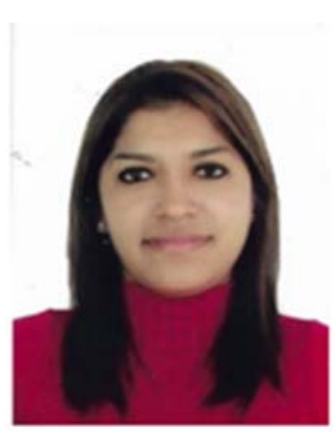

SOSA CARDENAS, JULIA CAROLINA

Estudiante del X ciclo de la Carrera de Administración de Empresas en la UPC, con más de 10 años de experiencia en el rubro de la Administración.

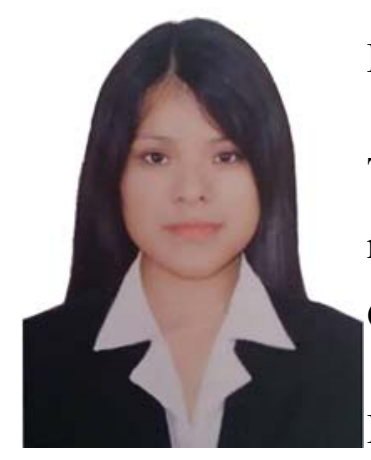

PINEDA RODRIGUEZ, CLAUDIA ESTEFANY

Técnica en Administración de Negocios Internacionales con mención en Finanzas de IFB Certus. Estudiante del X ciclo de la Carrera de Administración de Empresas en la UPC.

Entre mis habilidades blandas destaca mi proactividad, sociable, humildad, empatía y adaptación al cambio 


\section{CAPITULO 3: PLAN ESTRATÉGICO}

Figura $n^{\circ} 1$ : Business Model Canvas (Fuente: Elaboración propia)

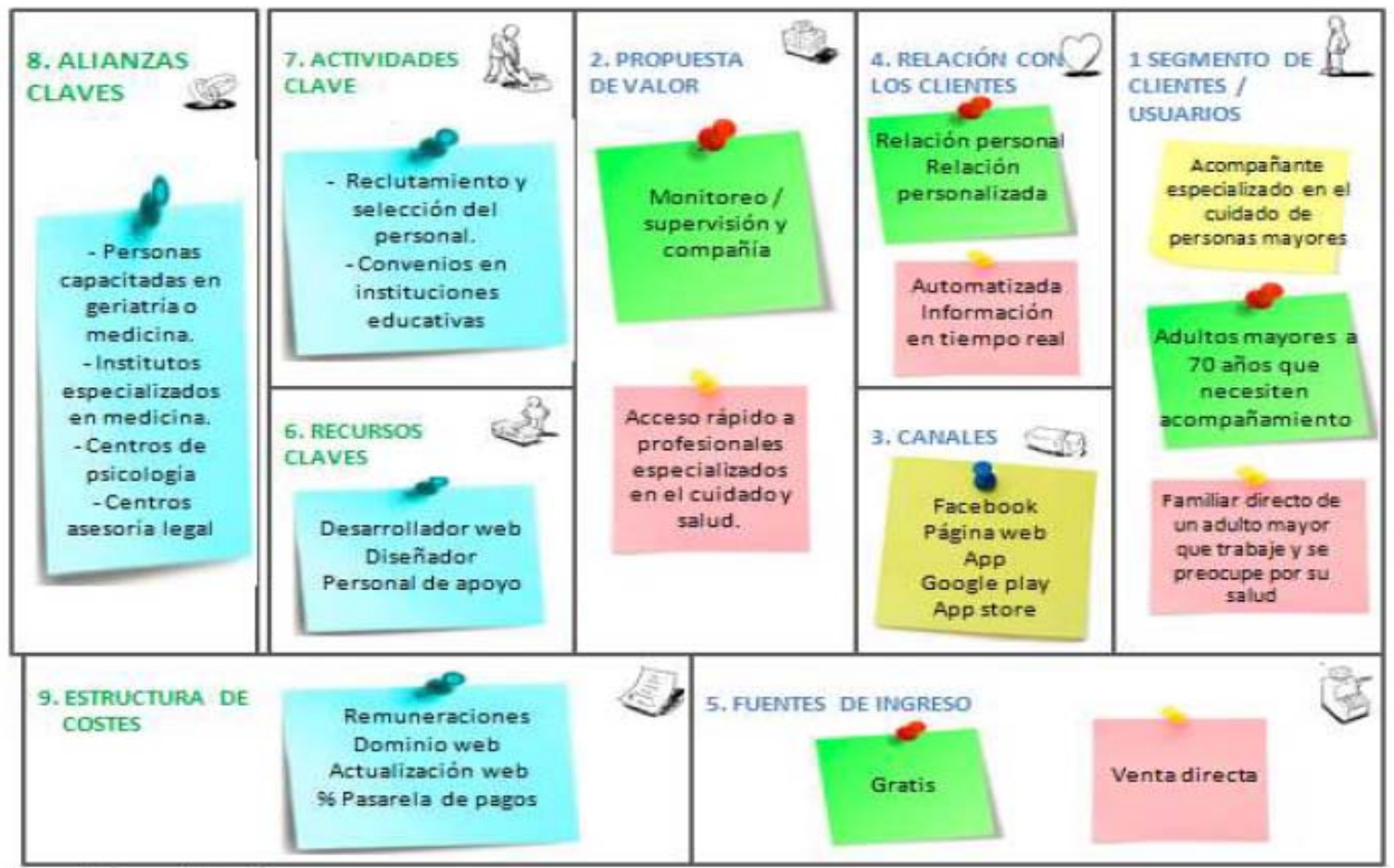

\subsection{Análisis externo}

\subsubsection{Análisis PESTEL}

Político - Legal

- Situación de inestabilidad política crea incertidumbre a la inversión privada, donde el modelo económico se mantiene inestable.

- La reducción de PBI de $4 \%$ a $2 \%{ }^{1}$ va generar un riesgo crediticio mayor en la tasa de interés para las inversiones.

- Se espera que el nuevo presidente Martín Vizcarra, brinde apoyos a las PYMES, a fin de lograr el crecimiento de la economía. Lo que permitirá una oportunidad de negocio.

\footnotetext{
${ }^{1}$ Ref. Crisis Política: ¿Qué impacto tendrá en la economía para el 2018: Diciembre? - Se recuperó el 11 de abril de 2018 de https://gestion.pe/economia/crisis-politica-impacto-economia-2018-223528
} 
Económico

- El estado peruano ha generado cambios en la inversión al sector salud, el $78.3 \%{ }^{2}$ cuenta con algún tipo de seguro de salud, siendo el sector más afectado en el país.

- En el Perú el adulto mayor son los que percibe menor sueldo, es decir su promedio de ingreso mensual es de S/. 492.20 en la selva urbana, en la sierra urbana S/. 575.20 y en la costa urbana S/. 945.60.

- El adulto mayor se encuentra dentro de la Población Económicamente activa (PEA), representando el $58.3 \%$, siendo mayor el de hombres que mujeres $71.7 \%$ y $46.5 \%$ respectivamente. El 41.7\% no representa a la PEA, se puede apreciar el incremento de PEA masculina activa en 4.9 puntos porcentuales

Tabla $n^{\circ}$ 1: Población adulta mayor por condición de actividad (Fuente: INEI)

\begin{tabular}{|c|c|c|c|c|c|c|c|c|c|}
\hline \multirow[t]{2}{*}{ Condición de actividad } & \multicolumn{3}{|c|}{ Oct-Nov-Dic 2014} & \multicolumn{3}{|c|}{ Oct-Nov-Dic 2015 P/ } & \multicolumn{3}{|c|}{$\begin{array}{c}\text { Variación } \\
\text { (Puntos porcentuales) }\end{array}$} \\
\hline & Total & Hombre & Mujer & Total & Hombre & Mujer & Total & Hombre & Mujer \\
\hline Población de 60 a mis & 100,0 & 100,0 & 100,0 & 100,0 & 100,0 & 100,0 & & & \\
\hline PEA & 56,1 & 66.8 & 46,9 & 58,3 & 71,7 & 46,5 & 2.2 & 4,9 & $-0,4$ \\
\hline NO PEA & 43.9 & 332 & 53,1 & 41,7 & 28.3 & 53.5 & $-2,2$ & $-4,9$ & 0.4 \\
\hline
\end{tabular}

P/ Preiminar

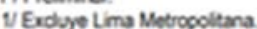

Fuente: Instituto Nacional de Estadistica e Informitica - Encuesta Nacional de Hogares.

Social - Cultural:

- La cultura de la población peruana carece de dos aspectos claves que son la prevención y la calidad de vida.

- En los últimos años el crecimiento de la población adulto mayor se ha evidenciado en un porcentaje según INEI 39.6\% de los hogares en el país cuenta con una persona mayor de 60 años.

\footnotetext{
${ }^{2}$ Ref. ¿Cuál es la situación del adulto mayor en el Perú? Abril. Redacción Perú21.Se recuperó el abril 10, de 2018, de https://peru21.pe/economia/inei-situacion-adulto-mayor-peru-174786
} 
- El 21,5\% de los niños vive en hogares cuyo "jefe de hogar" es un adulto mayor; el $61,8 \%$ son jefes de hogar; el 30,4\% son mujeres; el 54,7\% integra la PEA; el 61,2\% trabaja más de 35 horas a la semana; el 65\% es autovalente; el 30\% es frágil ${ }^{3}$.

- De acuerdo a las proyecciones del INEI, la población adulta mayor alcanzará una cifra de 6,5 millones para el 2050 por lo que, se tendrá que diseñar nuevas estrategias para mejorar su atención.

- En este proceso el envejecimiento de la población peruana adulto mayor la proporción es de $5.7 \%$ en el año 1950 a $10.10 \%$ en el año $2017^{4}$.

Figura $n^{\circ} 2$ : Evolución de la población por rango de edad (Fuente: INEI)

\section{Gráfico Nº1 01}

Perú. Pirámide de la población en 1950

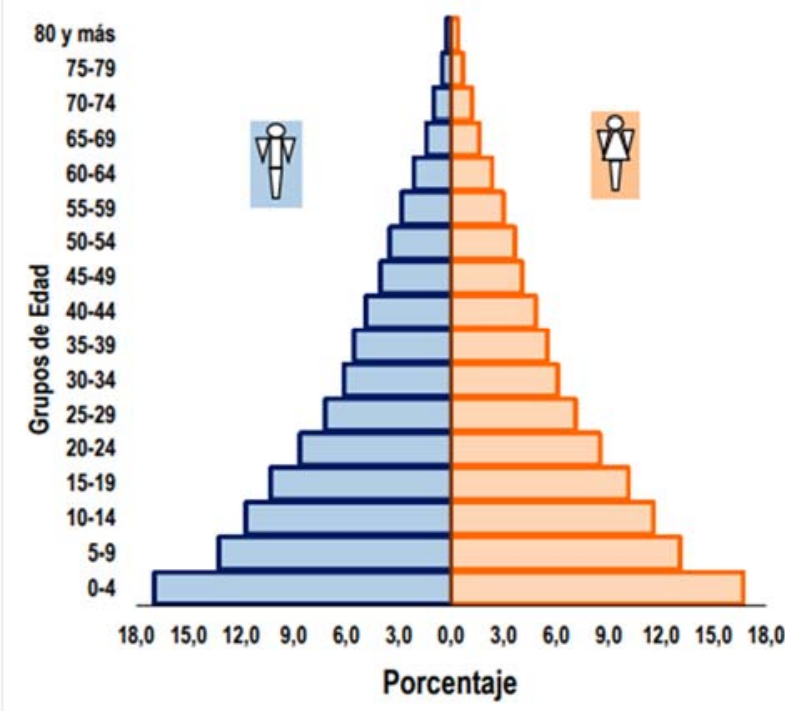

Fuente: Instituto Nacional de Estadistica e Informática.

\section{Gráfico № 02 \\ Perú. Pirámide de la población en 2017}

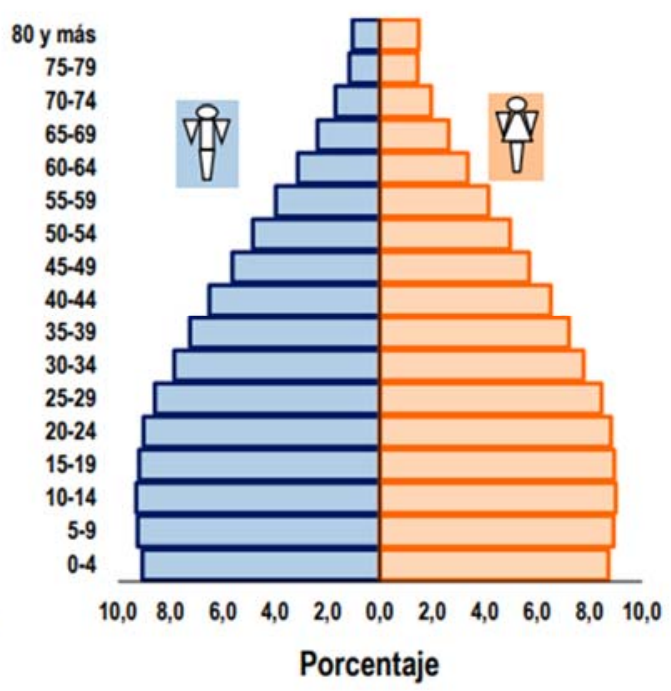

En este sentido, no se trata de hacer más de lo mismo, esta población necesita una atención más personalizada, con un servicio confiable que garantice el cuidado y el buen trato. Consideramos el entorno como una oportunidad para nuestra idea de negocio ya que, el aumento de este segmento será progresivo.

Demográfico:

\footnotetext{
${ }^{3}$ Ref. Adultos mayores en el Perú: Cifras de un segmento poblacional postergado: Agosto. RPP Noticias. Se recuperó el abril 10, de 2018 de http://rpp.pe/lima/actualidad/adultos-mayores-en-el-peru-cifras-de-unsegmento-poblacional-postergado-noticia-829774

${ }^{4}$ Ref. Situación de la Población del Adulta Mayor: Octubre-Noviembre: INEI. Se recuperó el abril 10 de 2018 de https://www.inei.gob.pe/media/MenuRecursivo/boletines/01-informe-tecnico-n01_adulto-octnov-dic2017.pdf
} 
- El adulto mayor limeño cuenta con un promedio de 69 años de edad, y la mayoría vive con la familia (pareja e hijos). En su mayoría la descendencia es hasta la tercera generación es decir el 94\% son padres; el 89\% ${ }^{5}$ son abuelos.

- Sus actividades en su mayoría se basan en el hogar, viendo TV 63\%, quehaceres del día a día 49\%. Pero en el NSE A y B, se encuentran haciendo actividades fuera de casa, ir a misa $45 \%$, visitas a un familiar, ir de compras, restaurantes o cafés entre otros.

- Los adultos mayores demandan servicios de formatos de entretenimiento, especialmente el NSE A, tiene planeado un viaje (60\%).

- El 18.8\% de la población adulta no cuenta con nivel educativo, solo a nivel inicial el $41.9 \%$ estudió primaria, el $23.9 \%$ secundaria y el $15.4 \%$ superior.

- La brecha de estudios entre hombres y mujeres es amplia, el 30.2\% de mujeres no alcanzo educación, mientras que el $6.6 \%$ en comparación de los hombres, la brecha es de 23.6 puntos porcentuales.

- Sólo el 28.3\% de la población adulto mayor se beneficia del programa social pensión 65 , esta misma población va en aumento en $2.8 \%$. Los adultos mayores en el área rural acceden a programas sociales en un 58.2\%, siendo excluida en Lima metropolitana solo el área urbana cuenta con $23.2 \%$ del beneficio.

Tabla $n^{\circ}$ 2: Población beneficiaria del programa pensión 65, según área de residencia

(Fuente: INEI)

Perú: Población beneficiaria del programa pensión 65, según área de residencia

Trimestre: Julio-Agosta-Setembre 2015- 2016

(Porcentaje del total de población de 65 y más anos)

\begin{tabular}{|c|c|c|c|c|c|c|c|c|c|}
\hline \multirow[t]{2}{*}{ Área de residencia } & \multicolumn{3}{|c|}{ Jul-Ago-Set 2015} & \multicolumn{3}{|c|}{ Jul-Ago-Set 2016 P/ } & \multicolumn{3}{|c|}{$\begin{array}{c}\text { Variación } \\
\text { (Puntos porcentuales) }\end{array}$} \\
\hline & Total & Hombre & Mujer & Total & Hombre & Mujer & Total & Hombre & Mujer \\
\hline Total & 25,5 & 24,1 & 26,6 & 28,3 & 27,5 & 29,0 & 2,8 & 3,4 & 2,4 \\
\hline Lima Metropolitana & $2,8 \mathrm{a}$ & $2.7 \mathrm{a}$ & $2,8 \mathrm{a}$ & $4,9 \mathrm{a}$ & $3,9 a$ & $5.6 \mathrm{a}$ & 2,1 & 1,2 & 28 \\
\hline Ares Urbana 1/ & 20.8 & 19,8 & 21,7 & 23,2 & 22,3 & 24,1 & 2,4 & 2.5 & 24 \\
\hline Área Rural & $\$ 6,1$ & 53,1 & 58,5 & 58,2 & 54,0 & 62,0 & 2,1 & 0,9 & 3,5 \\
\hline
\end{tabular}

a. Comprende a estimadores con coefociente de varacion majox a $15 \%$ considerades como referenciales.

1/ Exduye Lima Metocooltana.

PI Preliminar.

Fuente: Instituto Nacional de Estadistica e Informatica - Encuesta Nacional de Hogares.

5 Ref. Perfil del Adulto Mayor: Agosto - Ipsos. Se recuperó el abril 11 de 2018 de https://www.ipsos.com/es-pe/perfil-del-adulto-mayor-2016 
Al respecto, existen muchas familias que optan por llevar a los adultos mayores a su cargo a estas casas albergues, en donde puedan tener una atención como tal. En muchos casos es el factor tiempo que los obliga a tomar esta decisión. Por ende, el entorno puede considerarse como una oportunidad para nuestra idea de negocio, ya que es un segmento de la población en el que, el Estado aún no ha podido concretar lo cual nos permitirá ser una opción en el mercado.

Tecnológico:

- El 79\% de la población de adulto mayor posee internet en el hogar, el $24 \%$ en el trabajo, $6 \%$ en las cabinas públicas y el $4 \%$ en casas de otras personas. Sólo el 18\%, tuvo conexión de inter el año 2015.

- El 37.7\% de hogares cuenta con un teléfono fijo en casa. En la zona urbana el 44\%; mientras que el 1.9\% en el área rural, la brecha de comunicación entre la zona urbana y rural es de 42.1 puntos porcentuales en el acceso de telefonía fija

- El 77.6\% cuenta con algún miembro que tiene teléfono celular; 35.5\% que vive en la zona urbana cuenta con un televisor de cable. El uso de internet en la población del adulto mayor es de $10.5 \%$, la diferencia entre hombres y mujeres en el uso de internet es alta; para el caso de los hombres usan 14\% mientras que las mujeres $7.3 \%$ hacen uso del internet.

- Se hará extensivo el negocio a través del uso de los e-commerce ${ }^{6}$ (NSE A,B). En cuanto a la edad, se evidencia que el promedio es de 25 a 35 años quienes son considerados los de la era Millenials.

- Cabe mencionar, que las App's más utilizadas en el medio de los e-commerce podemos identificar series y películas (73\%), seguido por la mensajería (68\%) entre otros.

- Se planea generar plataformas virtuales para generar mayor accesibilidad para la compra de cualquier producto o servicio, amigables para el uso del adulto mayor.

- Hoy en día, la tecnología es una ventaja frente a los competidores por lo que, consideramos este entorno como oportunidad para el negocio ya que, estos avances

\footnotetext{
${ }^{6}$ Ref. E-commerce en el Perú: desafíos y tendencias para el 2018: Febrero - Ey Perú Library. Se recuperó el Abril 10, de 2018 de https://perspectivasperu.ey.com/2018/02/12/e-commerce-peru-desafios-tendencias2018/
} 
nos permitirán diseñar una página Web/App amigable, de confianza y rápida accesibilidad del servicio, y con las tendencias que los usuarios necesitan.

\subsection{Análisis interno}

\subsubsection{Análisis de las 5 fuerzas de Porter: competidores, clientes, proveedores, productos sustitutos, competidores potenciales}

Figura $n^{\circ}$ 3: Las 5 Fuerzas de Porter (Fuente: Elaboración propia)

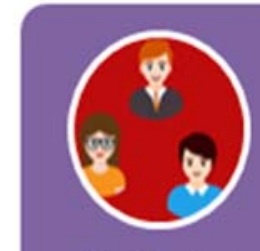

Productos

Sustitutos
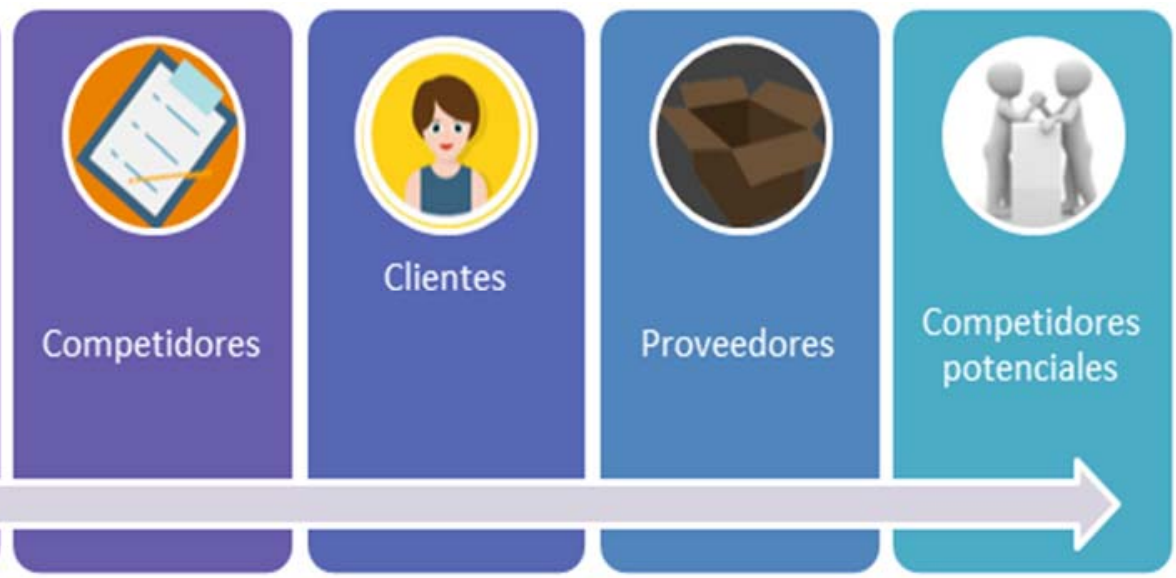

\section{Productos Sustitutos:}

Nuestro principal producto sustituto es que el cliente tenga propios contactos de cuidadores para que puedan realizar el contacto directo, pero no necesariamente es una persona que tenga la formación académica y/o experiencia en el rubro de geriatría, pueden ser técnicas enfermeras o personas de confianza que toman esta actividad de cuidar a adultos mayores por su experiencia sin necesidad de tener la educación necesaria.

\section{Competidores:}

\section{Home Care:}

En el mercado peruano tenemos como competencia directa a Home Care, una empresa que brinda servicio de enfermeras a domicilio 24 horas al día y los 365 días del año todo ello se realiza mediante su página web y su central telefónica.

Esta empresa brinda servicios de geriatría, cuidados en casa, enfermería, terapia física y procedimientos diversos, en el caso de enfermeras para cuidado solo brindan turnos de 6 y 12 horas. 


\section{Mi Enfermera}

Esta empresa al igual que Home Care brinda el servicio de enfermeras a domicilio y además ofrece venta de productos médicos por lo que estaría abarcando más al mercado de este sector.

Solo se puede obtener el servicio a través de la línea telefónica o vía WhatsApp.

En el caso de cuidado de ancianos brindan la opción de contratar el servicio por 6,8,10 y 12 horas.

\section{Clientes:}

Nosotros deseamos brindar un servicio de calidad y poder satisfacer las necesidades del mercado, por lo que nuestros cuidadores pasarán por un filtro para que el cliente al momento de tomar nuestros servicios tenga la seguridad y la diferenciación que tenemos, por lo que estarían dispuestos a pagar un precio moderadamente alto porque son un tipo de personas que valoran la asistencia de personal altamente calificado.

\section{Proveedores:}

Mediante nuestra página web tendremos un espacio de bolsa de trabajo para que los cuidadores interesados puedan dejar sus currículos y pasar los filtros de selección, así también tendremos alianzas con principales institutos de enfermería donde podremos captar nuevos talentos que deseen formar parte de nuestro staff.

\section{Competidores Potenciales:}

Nuestros competidores potenciales en el mercado son las casas de reposo ya que son instituciones que se dedican al cuidado del adulto mayor y el personal de ellos tienen un amplio conocimiento en el ámbito de geriatría por lo que si una de ellas llegase a tener una idea de negocio de brindar servicios de cuidados en forma externa, tendría una gran acogida ya que tienen un lugar físico, que sería la casa de reposo como referencia, por lo que ellos estarían ampliando su mercado si logran realizar esta implementación y se volverían competencia directa para nosotros. 


\subsubsection{Análisis FODA}

Realizaremos un análisis interno sobre las principales fortalezas y debilidades:

\section{Fortalezas:}

- Experiencia en cuidados de adultos mayores ya que cada integrante tiene personas adultas en sus hogares.

- Se cuenta con un contacto especialista en enfermería de la Universidad Privada San Juan Bautista.

- Personas en el equipo de trabajo con experiencia en administración y gestión comercial lo cual genera un gran apoyo para el desarrollo del proyecto.

- Los medios de contratar los servicios (WEB / APP) serán prácticos y muy sencillas de utilizar.

\section{Debilidades:}

- Poca experiencia en el sector de desarrollo de aplicaciones móviles.

- Propuesta nueva por lo tanto puede ser un poco complicado captar la confianza de nuestros clientes.

\section{Oportunidades:}

- Actualmente el $57 \%$ de la población se ha adaptado a solicitar un producto o servicio a través de páginas web y aplicaciones.

- Hay un 37.7\% de adultos mayores (60 años a más) en Lima Metropolitana con problemas médicos por lo que necesitan el cuidado de un profesional.

- La mayoría de familiares directos de un adulto mayor trabaja y se preocupa por el estado de salud de los usuarios.

- Hay varios profesionales en geriatría y medicina que necesitan trabajar en sus tiempos libres para obtener mayor ingreso.

- Crece el acceso a internet en personas de más de 60 años. 


\section{Amenazas:}

- La desconfianza que tiene algunas personas por contratar un servicio a través de aplicaciones y portales web.

- Existe la posibilidad de que exista postulantes que pueden falsificar la información en su hoja de vida.

- Experiencia y años en el mercado de nuestra competencia directa

Tabla ${ }^{\circ}$ 3: Matriz FODA (Fuente: Elaboración propia)

\begin{tabular}{|c|c|c|}
\hline & Fortalezas & Debilidades \\
\hline & $\begin{array}{l}\text { F1 Experiencia en cuidados de adultos mayores ya que tenemos } \\
\text { en nuestros hogares personas de ese segmentio. }\end{array}$ & $\begin{array}{l}\text { D1 Poca experiencia en el sector de desarrolo de aplicaciones } \\
\text { móviles. }\end{array}$ \\
\hline & $\begin{array}{l}\text { F2 Contamos con un contacto especiaista en enfermeria de la } \\
\text { Universidad Privada San Juan Bautista. }\end{array}$ & $\begin{array}{l}\text { D2 Somos una propuesta nueva por lo tanto puede ser un poco } \\
\text { complicado captar la confianza de nuestros clientes. }\end{array}$ \\
\hline & \begin{tabular}{|l|} 
F3 Personas en el equipo de trabajo con experiencia en \\
administración y gestion comercial lo cual genera un gran apoyo \\
para el desarrolo del proyecto.
\end{tabular} & \\
\hline & \begin{tabular}{|l}
$\begin{array}{l}\text { F4 Los medios de contratar nuestros servicios (WEB / APP) } \\
\text { seran practicas muy sencilla de utilizar. }\end{array}$ \\
\end{tabular} & \\
\hline & F5 & \\
\hline & $\mathrm{F6}$ & \\
\hline Oportunidades & Estrategia F0 & Estrategia DO \\
\hline $\begin{array}{l}01 \text { Actualmente el } 57 \% \text { de la población se ha adaptado a solictar } \\
\text { un producto o servicio a través de páginas web y apicaciones. }\end{array}$ & \multirow{2}{*}{$\begin{array}{l}\text { F01 Aprovecharemos que cada dia aumentan las personas de } \\
\text { contratar servicios por intenet ofreciendo una experiencia optima } \\
\text { en nuestra plataforma. }(F 4,01)\end{array}$} & \multirow{3}{*}{$\begin{array}{l}\text { DO1 Dar a conocer a los clientes el personal capactado para } \\
\text { todo tipo de enfermedades }(02,04)\end{array}$} \\
\hline $\begin{array}{l}02 \text { Hay un } 37.7 \% \text { de adutos mayores ( } 60 \text { años a más) en Lima } \\
\text { Metropoltana con problemas médicos por lo que necestan el } \\
\text { cuidado de un profesional. }\end{array}$ & & \\
\hline $\begin{array}{l}\text { 03 La mayoria de familiares directos de un aduto mayor trabaja } \\
\text { y se preocupa por el estado de salud de los usuarios. } \\
04 \text { Hay varios profesionales en geriatria y medicina que } \\
\text { necestan trabajar en sus tiempos libres para obtener mayor } \\
\text { ingreso. }\end{array}$ & $\begin{array}{l}\text { F0 } 2 \text { A través de nuestro contacto formaremos estrategias para } \\
\text { brindar un servicio de caildad a las personas adutas. (F2,03) }\end{array}$ & \\
\hline \multicolumn{3}{|l|}{05 Crece el acceso a internet en personas de más de 60 años. } \\
\hline Amenazas & Estrategia FA & Estrategia DA \\
\hline $\begin{array}{l}\text { A1 La desconfianza que tiene algunas personas por contratar } \\
\text { un servicio a través de apicaciones y portales web. }\end{array}$ & $\begin{array}{l}\text { FA1 El reccutamiento de personal especiafzado debe de } \\
\text { analizar detenidamente la información en la hoja de vida del } \\
\text { postulante ( } F 1, \mathrm{~A} 2)\end{array}$ & \multirow[b]{2}{*}{$\begin{array}{l}\text { DA } 1 \text { Dar a conocer nuestra propuesta y dar seguridad de que } \\
\text { es un servicio confiable }(02, \mathrm{~A} 1)\end{array}$} \\
\hline $\begin{array}{l}\text { A2 Existe la posibilidad de que exista postulantes que pueden } \\
\text { falsificar la información en su hoja de vida. } \\
\text { A3 Experiencia y años en el mercado de nuestra competencia } \\
\text { directa. }\end{array}$ & $\begin{array}{l}\text { FA } 2 \text { Dar la confianza y seguridad a los clientes de que el } \\
\text { personal es capactado y profesional para el cuidado del aduto } \\
\text { mayor }(A 1, A 3, F 4)\end{array}$ & \\
\hline
\end{tabular}

Identificación y ejecución de estrategias de acuerdo al FODA

\section{Estrategia Ofensiva}

Estrategia Interna: Estrategia de Calidad Total o mejoramiento continuo de los procesos.

Como se sabe actualmente cada vez hay más personas que realizan compras o solicitan un servicio por medio de internet, entonces lo que se busca con esta estrategia es captar 
nuevos clientes ofreciendo una experiencia satisfactoria al solicitar el servicio a través de la web o aplicación.

Lo que se plantea es mejorar nuestras plataformas de tal forma que cuando el cliente ingrese pueda solicitar el servicio de una manera práctica y sencilla.

Por otro lado, también se plantea realizar constantemente una mejora en el servicio que se ofrece, por medio de los comentarios o recomendaciones de los clientes se puede tener un punto para empezar a estudiar más el mercado y determinar nuevas necesidades para ofrecer a los clientes además de mejorar los servicios que ya se tiene en lista.

\section{Estrategia Defensiva}

\section{Estrategia Interna: Gerencia de Procesos}

Al ser una propuesta nueva lo que se busca es dar la seguridad al cliente que los colaboradores son profesionales y capacitados para el cuidado del adulto mayor, por ello al realizar el reclutamiento los postulantes tienen que pasar por un riguroso proceso en donde se pueda determinar que es apto para brindar los servicios de los cuidados.

\section{Estrategia de Ajuste}

Estrategias de Marketing

A través de la página web y aplicación se va a informar al cliente que el colaborador está capacitado para realizar el servicio de cuidado, además de mostrar la calificación y los comentarios que tiene por las anteriores experiencias sobre el cuidado de adulto mayor.

\section{Estrategia de Supervivencia}

\section{Integración Horizontal - Modalidad Fusión Horizontal y Alianza Estratégica}

Teniendo en cuenta la competencia que cada día es más creciente además que ocupa un buen lugar en la mente de sus clientes por la calidad y experiencia, lo que se busca es obtener una alianza estratégica con una institución que brinde similares servicios de geriatría para realizar una fusión que nos ayude a mejorar el negocio; esto sería beneficioso ya que se podría ampliar la capacidad de acompañantes además de brindar 
una variedad de servicios clasificándolos por especialidades con profesionales capacitados.

\subsection{Visión}

"Ser la empresa líder en soluciones tecnológicas en el cuidado del adulto mayor, reconocida por la calidad y profesionalismo de nuestro personal"

\subsection{Misión}

"Ser el aliado estratégico de las familias en el cuidado del adulto mayor, ofreciendo tranquilidad y un servicio confiable y seguro"

\subsection{Estrategia genérica:}

La estrategia que nos va a guiar para realizar las actividades y operaciones del desarrollo del proyecto Senior Care, la hemos planteado basándonos en las estrategias de Michael Porter (1980) que nos va ayudar a lograr las ventajas competitivas para diferenciarnos de la competencia, por ello hemos considerado la estrategia de enfoque.

Se ha elegido la estrategia de enfoque ya que la organización es nueva y pequeña, por lo cual sólo nos estamos dirigiendo a un segmento específico en donde se busca lograr satisfacerlos.

En el caso de SENIOR CARE nos enfocamos en los familiares que tienen a su cargo a un adulto mayor con necesidad de acompañamiento, pero no tienen tiempo disponible.

\subsection{Objetivos estratégicos}

Para el proyecto nos hemos planteado alcanzar los siguientes objetivos:

Tabla $n^{\circ}$ 4: Balanced Score Card (Fuente: Elaboración propia)

\begin{tabular}{|c|c|c|c|c|c|}
\cline { 2 - 6 } \multicolumn{1}{c|}{} & Objetivo & Indicador & Meta & Responsable & Iniciativa \\
\hline Financiero & $\begin{array}{c}\text { Aumentar } \\
\text { utilidades }\end{array}$ & Utilidad neta & $\mathbf{1 5 \% \text { cada año }}$ & $\begin{array}{c}\text { Jefe de } \\
\text { finanzas }\end{array}$ & $\begin{array}{c}\text { Control de egresos e } \\
\text { ingresos del } \\
\text { proyecto. }\end{array}$ \\
\hline
\end{tabular}




\begin{tabular}{|c|c|c|c|c|c|}
\hline & $\begin{array}{c}\text { Retorno de la } \\
\text { inversión }\end{array}$ & ROI & $25 \%$ adicional & & $\begin{array}{c}\text { Captar clientes y } \\
\text { plantear estrategias } \\
\text { para fidelizar para } \\
\text { lograr aumentar } \\
\text { nuestros ingresos y } \\
\text { recuperar en corto } \\
\text { plaza la inversión } \\
\text { realizada. }\end{array}$ \\
\hline \multirow{4}{*}{ Cliente } & $\begin{array}{c}\text { Captar en } \\
\text { nuestra base de } \\
\text { datos } 1000 \\
\text { clientes en el } \\
\text { primer año. }\end{array}$ & $\begin{array}{c}\text { \% clientes } \\
\text { nuevos }\end{array}$ & $\begin{array}{c}35 \% \text { clientes } \\
\text { nuevos }\end{array}$ & \multirow{4}{*}{$\begin{array}{c}\text { Área } \\
\text { comercial }\end{array}$} & \multirow{3}{*}{$\begin{array}{c}\text { Realizar } \\
\text { promociones sobre el } \\
\text { servicio e invertir en } \\
\text { promociones para } \\
\text { dar conocer nuestros } \\
\text { beneficios. }\end{array}$} \\
\hline & $\begin{array}{l}\text { Aprovechar las } \\
\text { alianzas } \\
\text { estratégicas para } \\
\text { incrementar } \\
\text { volumen de } \\
\text { ventas }\end{array}$ & $\begin{array}{c}\text { \% clientes } \\
\text { nuevos }\end{array}$ & $\begin{array}{c}30 \% \text { clientes } \\
\text { nuevos }\end{array}$ & & \\
\hline & $\begin{array}{c}\text { Ofrecer el } \\
\text { servicio de alta } \\
\text { calidad y así } \\
\text { poder generar } \\
\text { mayor cuota de } \\
\text { mercado }\end{array}$ & $\begin{array}{c}\text { \% clientes } \\
\text { nuevos }\end{array}$ & $\begin{array}{c}30 \% \text { clientes } \\
\text { nuevos }\end{array}$ & & \\
\hline & $\begin{array}{c}\text { Obtener } \\
\text { aprobación del } \\
\text { servicio en } 80 \%\end{array}$ & $\begin{array}{l}\text { \% clientes } \\
\text { satisfechos }\end{array}$ & $\begin{array}{c}\text { 15\% más de } \\
\text { clientes } \\
\text { fidelizados cada } \\
\text { año }\end{array}$ & & $\begin{array}{c}\text { Plantear estrategias } \\
\text { para mantener } \\
\text { satisfechos a nuestros } \\
\text { clientes sobre el } \\
\text { servicio brindado. }\end{array}$ \\
\hline \multirow[t]{2}{*}{ Proceso } & $\begin{array}{c}\text { Mejorar } \\
\text { continuamente } \\
\text { la Web y APP }\end{array}$ & $\begin{array}{l}\text { \% de clientes } \\
\text { que contratan } \\
\text { servicio por } \\
\text { web y APP }\end{array}$ & $\begin{array}{l}25 \% \text { más de } \\
\text { contratación de } \\
\text { servicios por } \\
\text { portal web y } \\
\text { APP }\end{array}$ & $\begin{array}{c}\text { Área de } \\
\text { Marketing }\end{array}$ & $\begin{array}{c}\text { Mejorar las } \\
\text { plataformas cada } 6 \\
\text { meses de tal manera } \\
\text { que sea más práctico } \\
\text { para los clientes. }\end{array}$ \\
\hline & $\begin{array}{c}\text { Gestión de } \\
\text { calidad para } \\
\text { brindar un buen } \\
\text { servicio. }\end{array}$ & $\begin{array}{c}\% \text { de clientes } \\
\text { satisfechos }\end{array}$ & $\begin{array}{c}20 \% \text { de } \\
\text { colaboradores } \\
\text { con buen } \\
\text { puntaje de }\end{array}$ & $\begin{array}{c}\text { Área de } \\
\text { calidad de } \\
\text { servicio }\end{array}$ & $\begin{array}{l}\text { Realizar un } \\
\text { seguimiento continuo } \\
\text { de los comentarios, } \\
\text { recomendaciones de } \\
\text { los clientes para } \\
\text { mejorar el servicio. }\end{array}$ \\
\hline
\end{tabular}




\begin{tabular}{|c|c|c|c|c|c|}
\hline & & & $\begin{array}{c}\text { calificación de } \\
\text { servicio }\end{array}$ & & \\
\hline \multirow[t]{2}{*}{ Aprendizaje } & $\begin{array}{l}\text { Contratación de } \\
\text { personal } \\
\text { calificado }\end{array}$ & $\begin{array}{l}\text { Número de } \\
\text { personal } \\
\text { capacitado }\end{array}$ & $\begin{array}{c}5 \text { ingresos } \\
\text { nuevos cada } 3 \\
\text { meses }\end{array}$ & \multirow[t]{2}{*}{$\begin{array}{l}\text { Área de } \\
\text { Recursos } \\
\text { Humanos }\end{array}$} & $\begin{array}{l}\text { Selección de personal } \\
\text { por medio de bolsa } \\
\text { laboral de institutos } \\
\text { de enfermería y } \\
\text { geriatría. }\end{array}$ \\
\hline & $\begin{array}{l}\text { Capacitación } \\
\text { constante de } \\
\text { personal }\end{array}$ & $\begin{array}{c}\text { Número de } \\
\text { capacitaciones }\end{array}$ & $\begin{array}{l}\text { Dos } \\
\text { capacitaciones } \\
\text { por trimestre }\end{array}$ & & $\begin{array}{l}1 \text { capacitación sobre } \\
\text { mejoras de atención } \\
\text { y } 1 \text { capacitación con } \\
\text { especialista en } \\
\text { geriatría. }\end{array}$ \\
\hline
\end{tabular}




\section{CAPITULO 4: Investigación/Validación de mercado}

\subsection{Diseño metodológico de la investigación/metodología de validación de hipótesis}

El diseño metodológico que empleamos es la investigación cuantitativa, mediante una investigación descriptiva, en este caso se utilizará el tipo de investigación que son las encuestas, con lo cual buscamos validar nuestro mercado y tratar de encontrar las mejores estrategias de marketing para nuestro proyecto de esta manera podremos llegar a una confirmación preliminar y validación de la hipótesis del negocio.

Diseño de la Investigación Cuantitativa:

\section{ENCUESTA}

PREGUNTAS FILTRO

¿En qué distrito vives?

San Borja

_ San Isidro

Surco

_ La Molina

Miraflores

__ Jesús María

_ Pueblo Libre

San Miguel

__ Magdalena

Lince 
Otros (Fin de la encuesta)

¿Cuentas con un familiar adulto mayor en casa?

Sí ___ (Continuar con la encuesta) No_ (Fin de la encuesta)

¿Eres responsable del cuidado del adulto mayor en casa?

Sí ___ (Continuar con la encuesta) No_ (Fin de la encuesta)

\section{PREGUNTAS:}

Objetivo: Conocer los momentos más críticos durante el cuidado del adulto mayor

1. ¿Cuáles son las dificultades que tienes durante el cuidado del adulto mayor?

A. Llevarlo al médico

B. Supervisar su alimentación

C. Suministro de medicamentos

D. Aseo personal

E. Acompañamiento durante sus horas libres

F. Otros (especificar)

G. __ Ninguna (Fin de la encuesta)

2. ¿Con qué frecuencia sueles tener estas dificultades?
A. _ Diario
B. Semanal
C. __ Quincenal
D. __ Mensual
E. __ Cada 3 meses 
F. Cada 6 meses

G. __ Mayor a un año

H. Otros

Objetivo: Identificar la cantidad de horas dedicadas al cuidado del adulto mayor por día.

3. De las veces que presentan las dificultades, ¿Cuántas horas en promedio dedicas a esos cuidados?
A. _ De 2 a 4 horas
B. _ De 4 a 6 horas
C. _ De 6 a 8 horas
D. __ De 8 horas a más

4. ¿En qué rango del día es tu mayor necesidad?
A. __ Todo el día
B. __ Mañana
C. _ Tarde
D. _ Noche
E. __ Madrugada

Objetivo: Conocer las características que consideran importantes en el servicio y el acompañante.

5. En una escala del 1 al 5 (donde 5 = máximo nivel de importancia y 1 = mínimo nivel de importancia) ¿Cómo calificarías a cada uno de los siguientes aspectos al momento de contratar un servicio?
A. $\longrightarrow$ Precio
B. Trato amable 

C. __ Eficiencia
D. __ Experiencia
E. Cercanía a mi casa
F. _ Honestidad
G. __ Discreción
H. _ Otros (especificar)

6. En una escala del 1 al 5 (donde $5=$ máximo nivel de importancia y 1 = mínimo nivel de importancia) ¿Qué características deben tener los acompañantes para que pueda contratar el servicio?
A. Edad
B. Experiencia
C. Formación académica
D. Apariencia física
E. Condición física
F. Otros (especificar)

\section{Objetivo: Conocer el interés en contratar un servicio vía internet}

7. ¿Estaría interesado usted en contratar por una plataforma virtual servicios de acompañamiento al adulto mayor donde podrá ver los perfiles de ellos además podrá leer testimonios de otros clientes y revisar valoraciones de los cuidadores?

_ Si (Continúa con la siguiente pregunta)

_ No (Fin de la encuesta)

\section{Objetivo: Determinar el monto que estarían dispuestos a pagar por hora.}

8. ¿Cuánto has pagado o estarías dispuesto a pagar por un servicio de acompañamiento del adulto mayor? (Referencia: Servicio por hora S/. ) 

A. De s/ 20 a s/ 30
B. De s/ 30 a s/ 40
C. De s/ 40 a s/ 50
D. DE s/ 50 a más (especificar)

Objetivo: Conocer la preferencia en el método de pago.

9. ¿A través de qué medio preferiría realizar el pago?
A. Efectivo
B. $\quad$ POS
C. Transferencia bancaria
D. _ Otros (especificar)

Objetivo: Conocer las necesidades básicas para el servicio de acompañamiento.

10. ¿Qué servicios adicionales usted pediría?

\subsection{Resultados de la investigación}

Para realizar el proyecto empresarial se aplicó la encuesta a 115 personas pertenecientes a la clase A y B, de las cuales sólo 107 pasaron nuestras preguntas filtro y obtuvimos los siguientes resultados:

Objetivo 1: Conocer los momentos más críticos durante el cuidado del adulto mayor

1. ¿Cuáles son las dificultades que tienes durante el cuidado del adulto mayor? 
Figura $n^{\circ}$ 4: Resultado respuesta 1 (Fuente: Elaboración propia)

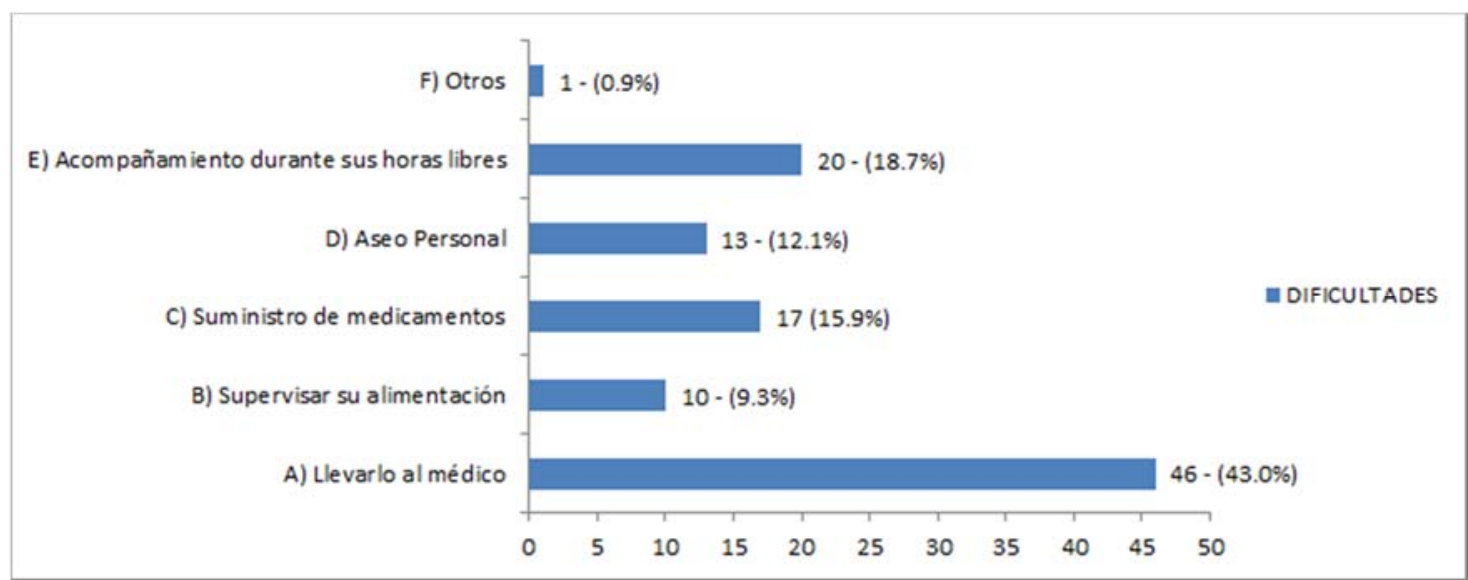

De las personas encuestadas, el $43.0 \%$ indicaron que su mayor necesidad es llevar al adulto mayor al médico, seguido de acompañamiento durante de horas libre (18.7\%) y suministros de medicamentos $(15.9 \%)$

2. ¿Con qué frecuencia sueles tener estas dificultades?

Figura $\mathrm{n}^{\circ}$ 5: Resultado respuesta 2 (Fuente: Elaboración propia)

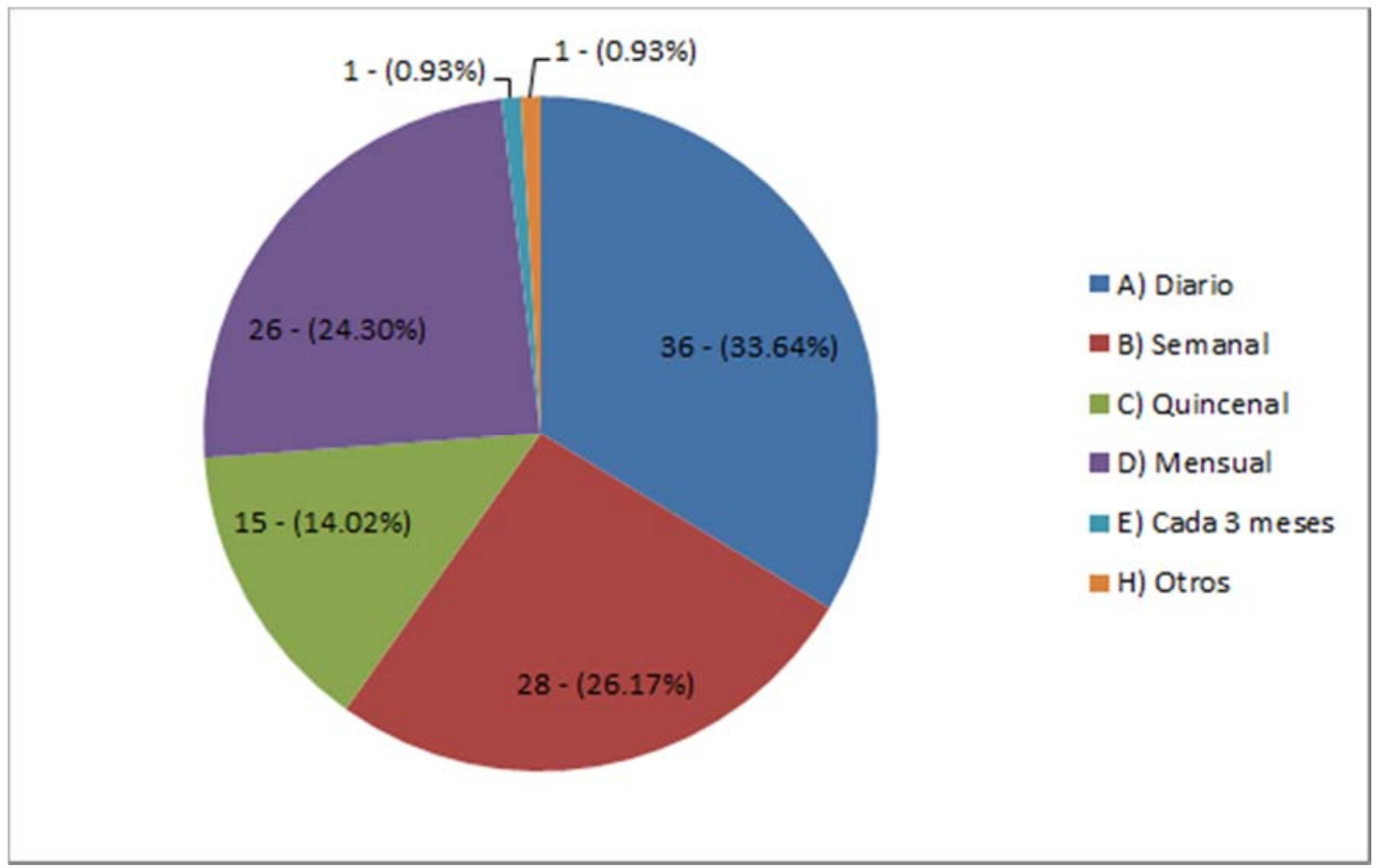

Se ha determinado que la frecuencia en que presentan las necesidades mencionadas anteriormente es diariamente (33.64\%), seguido de semanal (26.17\%) y mensualmente $(24.30 \%)$. 
Objetivo 2: Identificar la cantidad de horas dedicadas al cuidado del adulto mayor por día.

3. De las veces que presentan las dificultades, ¿Cuántas horas en promedio dedicas a esos cuidados?

Figura $n^{\circ}$ 6: Resultado respuesta 3 (Fuente: Elaboración propia)

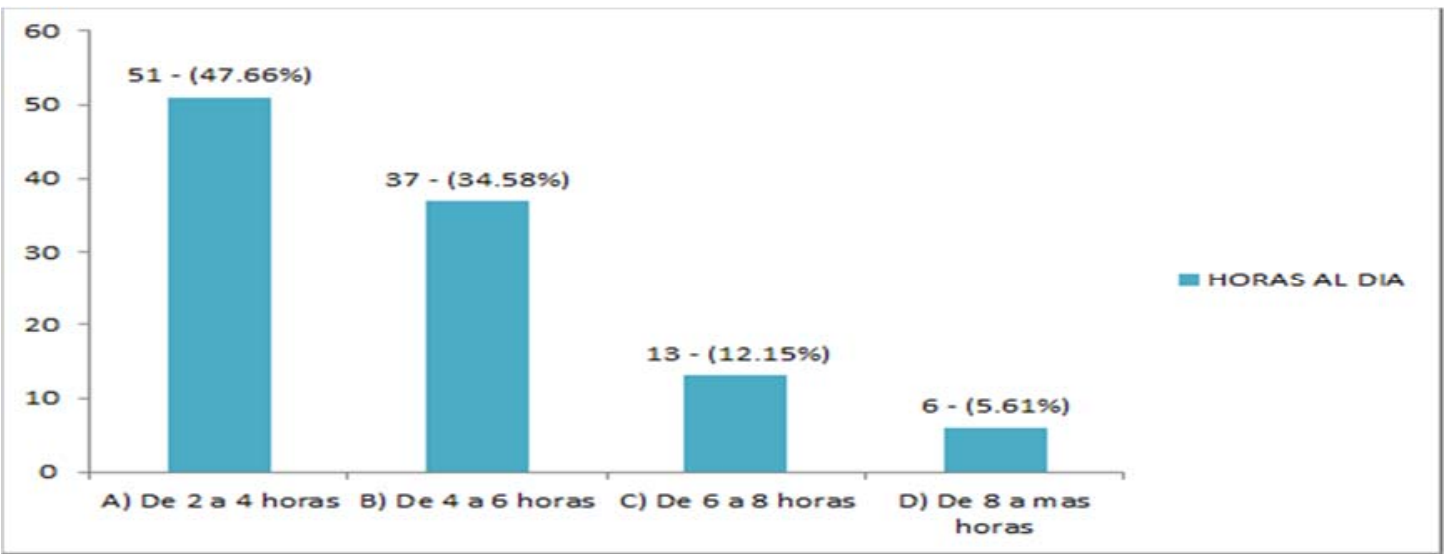

De las encuestas realizadas, se tiene como resultado que en promedio las personas presentan las dificultades de 2 a 4 horas (47.66\%), seguida de 4 a 6 horas (34.58\%), son las frecuencias mayores durante el día.

4. ¿En qué rango del día es tu mayor necesidad?

Figura $\mathrm{n}^{\circ}$ 7: Resultado respuesta 4 (Fuente: Elaboración propia)

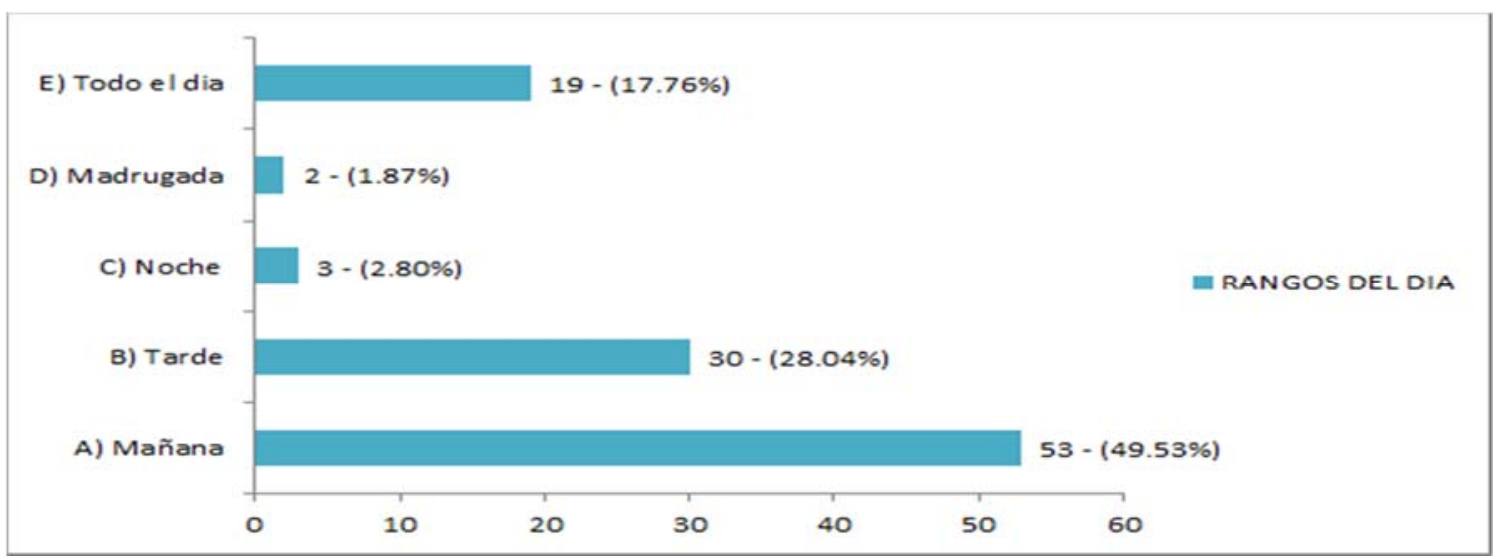

El $49.53 \%$ de los encuestados manifestó que su mayor necesidad lo presentan en la mañana. 
El 28.04\% de los encuestados indicaron que presentan mayor necesidad durante la tarde, seguido del $17.76 \%$ que manifestaron que presentan su necesidad de cuidado y/o acompañamiento durante todo el día.

Objetivo 3: Conocer las características que consideran importantes en el servicio y el acompañante.

5. En una escala del 1 al 5 (donde $5=$ máximo nivel de importancia y $1=$ mínimo nivel de importancia) ¿Cómo calificarías a cada uno de los siguientes aspectos al momento de contratar un servicio?

Figura $\mathrm{n}^{\circ}$ 8: Resultado respuesta 5 (Fuente: Elaboración propia)

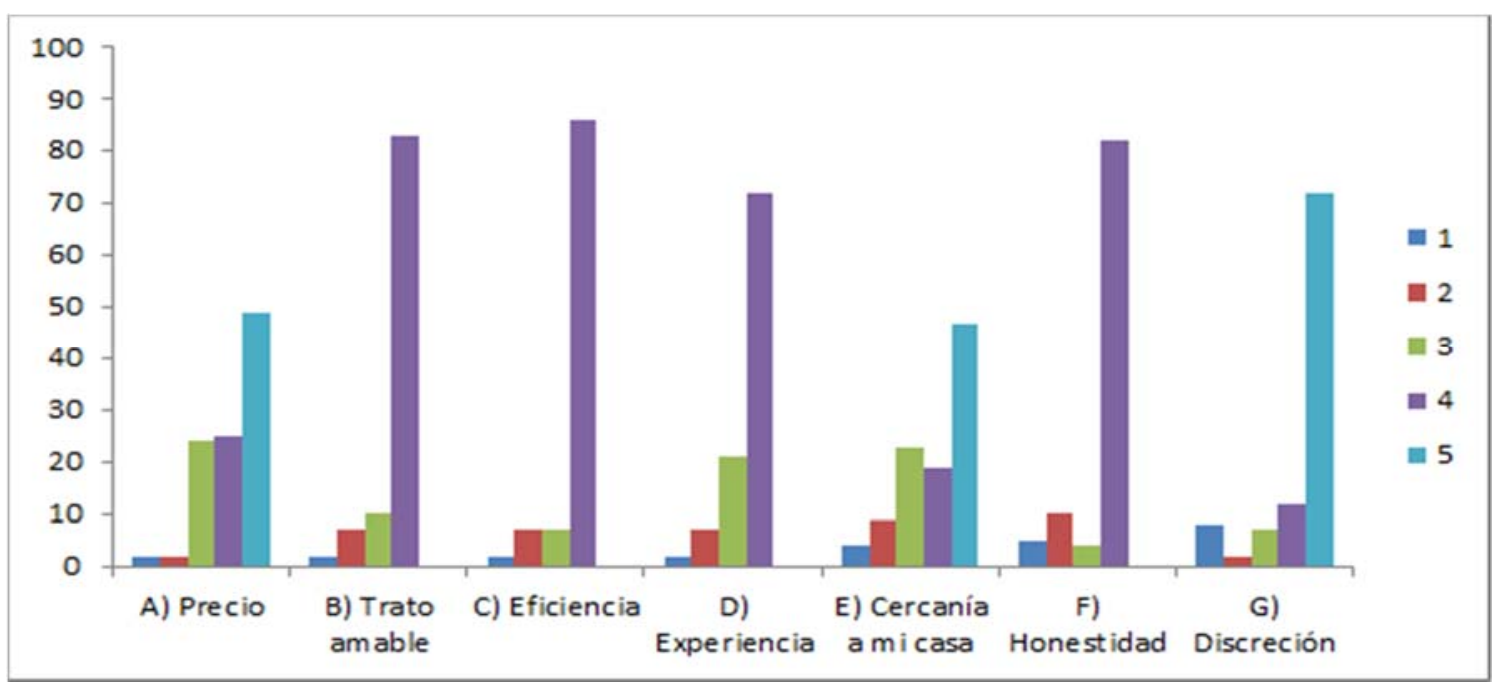

La mayoría de los encuestados valora más el trato amable, eficiencia y honestidad al momento de contratar el servicio.

Por otro lado, también tiene mayor valoración la discreción el precio y la cercanía a sus domicilios.

6. En una escala del 1 al 5 (donde $5=$ máximo nivel de importancia y $1=$ mínimo nivel de importancia) ¿Qué características deben tener los acompañantes para que pueda contratar el servicio? 
Figura $n^{\circ}$ 9: Resultado respuesta 6 (Fuente: Elaboración propia)

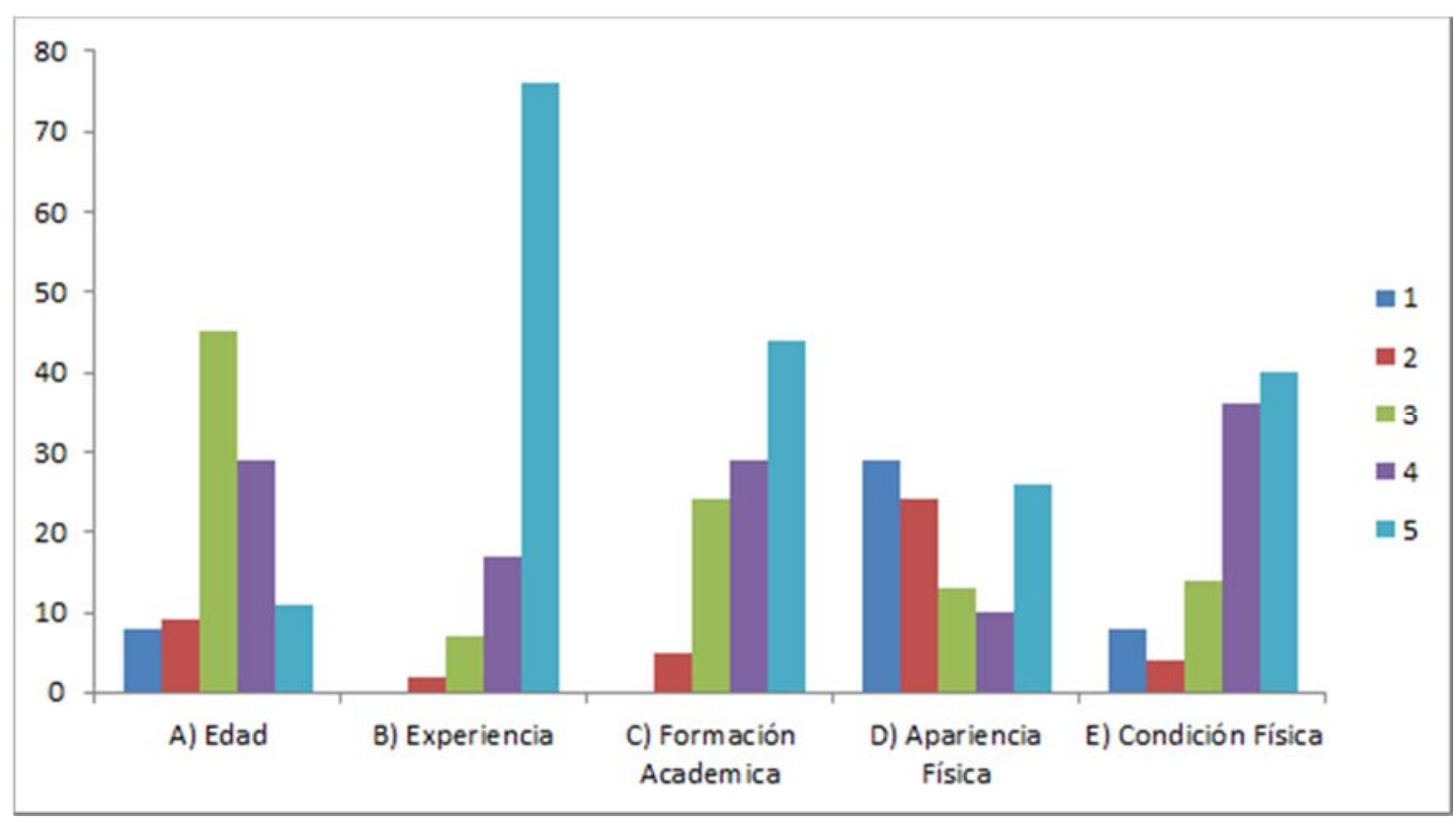

La mayoría de los encuestados manifestaron que las características que tienen mayor importancia de los acompañantes es la experiencia, formación académica y la condición física.

Objetivo 4: Conocer el interés en contratar un servicio vía internet

7. ¿Estaría interesado usted en contratar por una plataforma virtual servicios de acompañamiento al adulto mayor donde podrá ver los perfiles de ellos además podrá leer testimonios de otros clientes y revisar valoraciones de los cuidadores?

_ Si (Continúa con la siguiente pregunta)

_ No (Fin de la encuesta)

Figura $n^{\circ}$ 10: Resultado respuesta 7 (Fuente: Elaboración propia)

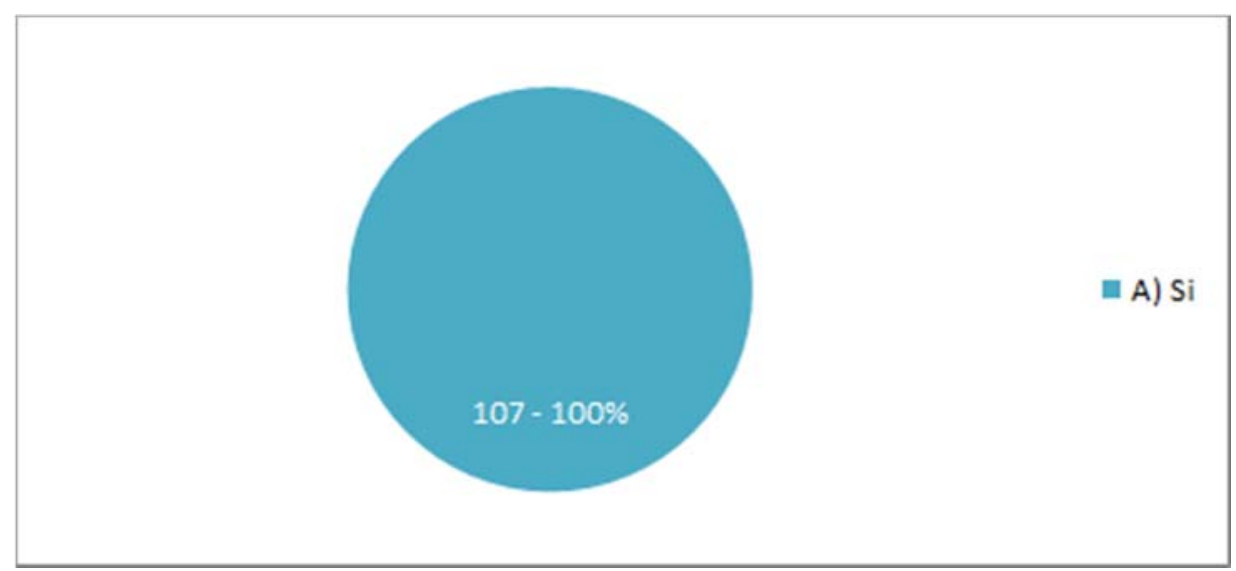


El $100 \%$ de los encuestados indicaron que estarían dispuestos a contratar el servicio de acompañamiento al adulto mayor desde una aplicación y plataforma web.

Objetivo 5: Determinar el monto que estarían dispuestos a pagar por hora.

8. ¿Cuánto has pagado o estarías dispuesto a pagar por un servicio de acompañamiento del adulto mayor? (Referencia: Servicio por hora S/.)

Figura $\mathrm{n}^{\circ}$ 11: Resultado respuesta 8 (Fuente: Elaboración propia)

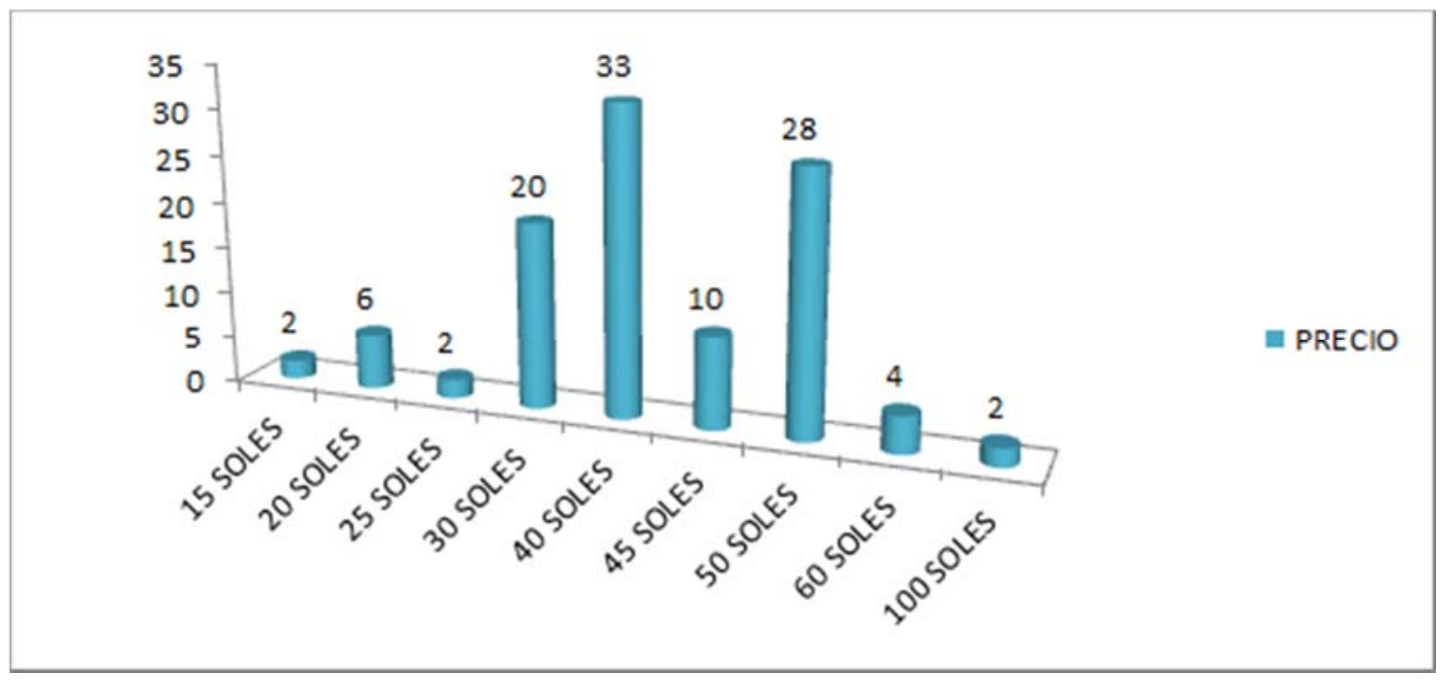

El $30.84 \%$ de los encuestados manifestaron que estarían dispuestos a pagar 40 soles por hora por un servicio de acompañamiento del adulto mayor, seguido del $26.17 \%$ que manifestaron que estarían dispuestos a pagar 50 soles por hora.

Finalmente, el $28.69 \%$ indicaron que pagarían por el servicio 30 soles por hora.

Objetivo 6: Conocer la preferencia en el método de pago.

9. ¿A través de qué medio preferiría realizar el pago?

E. _ Efectivo

F. _ POS

G. __ Transferencia bancaria

H. Otros (especificar) 
Figura $n^{\circ}$ 12: Resultado respuesta 9 (Fuente: Elaboración propia)

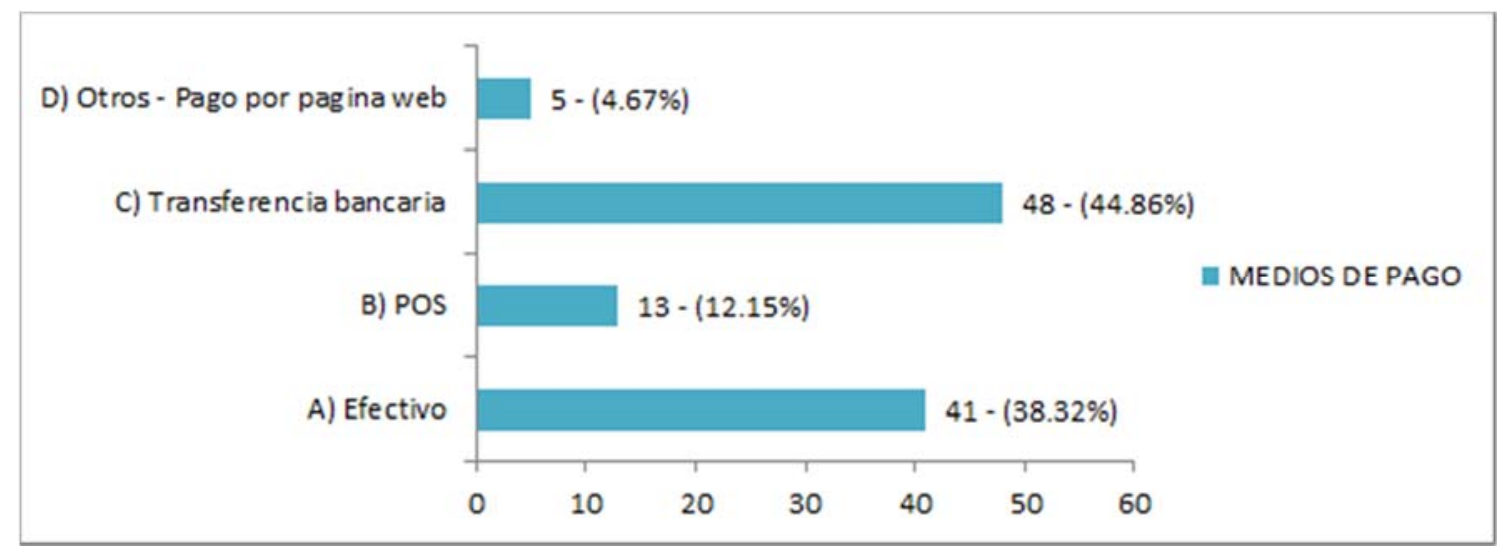

El 44.86\% de los encuestaron indicaron que prefieren cancelar el servicio a través de una transferencia bancaria ya que es un medio de pago más seguro.

Por otro lado, el $38.32 \%$ de los encuestados indicaron que prefieren cancelar el servicio en efectivo porque es más fácil.

Objetivo 7: Conocer las necesidades básicas para el servicio de acompañamiento.

10. ¿Qué servicios adicionales usted pediría?

Figura $n^{\circ} 13$ : Resultado respuesta 10 (Fuente: Elaboración propia)

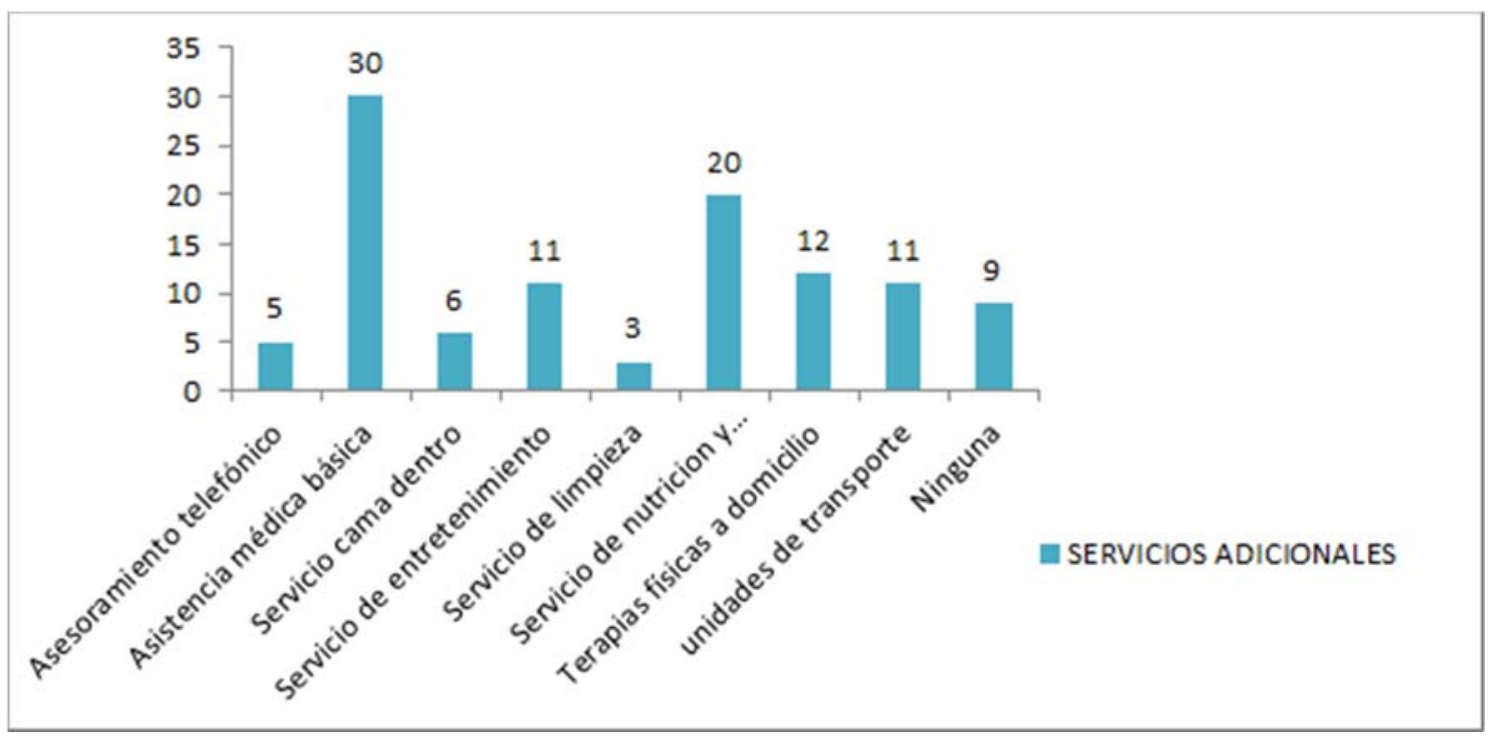

El 28.04\% de los encuestados de esta pregunta abierta nos manifestaron que les gustaría que también brindemos un servicio de asistencia médica básica ya que les puede ayudar en cualquier emergencia. 
Por otro lado, el $18.69 \%$ de los encuestados también manifestaron que sería interesante brindar el servicio de nutrición y preparación de alimentos ya que muchas personas no tienen tiempo para cocinar las dietas especiales y utilizar los ingredientes adecuados que les indican los médicos.

\subsection{Informe final: elaboración de tendencias, patrones $y$ conclusiones}

Terminada la elaboración de datos e información recibida de las encuestas, la mayoría de las personas encuestas alguna vez durante su día de la semana, ha buscado un servicio de acompañamiento para el cuidado de un adulto mayor en casa.

Se conoce que las personas con un adulto mayor en casa, consideran un factor positivo contar con el apoyo de una persona por horas a través del servicio de una plataforma virtual, donde podrá encontrar el staff de enfermeras profesionales según sus necesidades.

En la etapa de la validación se ha podido identificar que uno de los principales motivos que las personas que tienen a su cargo un adulto mayor están pasando momentos de apuros o contratiempos cuando se les presenta un inconveniente de dejar al familiar solo en casa.

Finalmente, los resultados de la landing page, podemos apreciar que existe un interés por en el servicio ofrecido SENIOR CARE (acompañamiento de un adulto mayor en casa), esto significa que podemos contar con un público objetivo, y realizar las proyecciones de expansión de nuestros servicios a otros puntos donde se requiera el servicio, tales como albergues de hogar, hospitales, y proporcionar los mismos servicios para los nuevos clientes futuros. 
Figura $n^{\circ} 14:$ Tendencias (Fuente: Diario El Peruano)

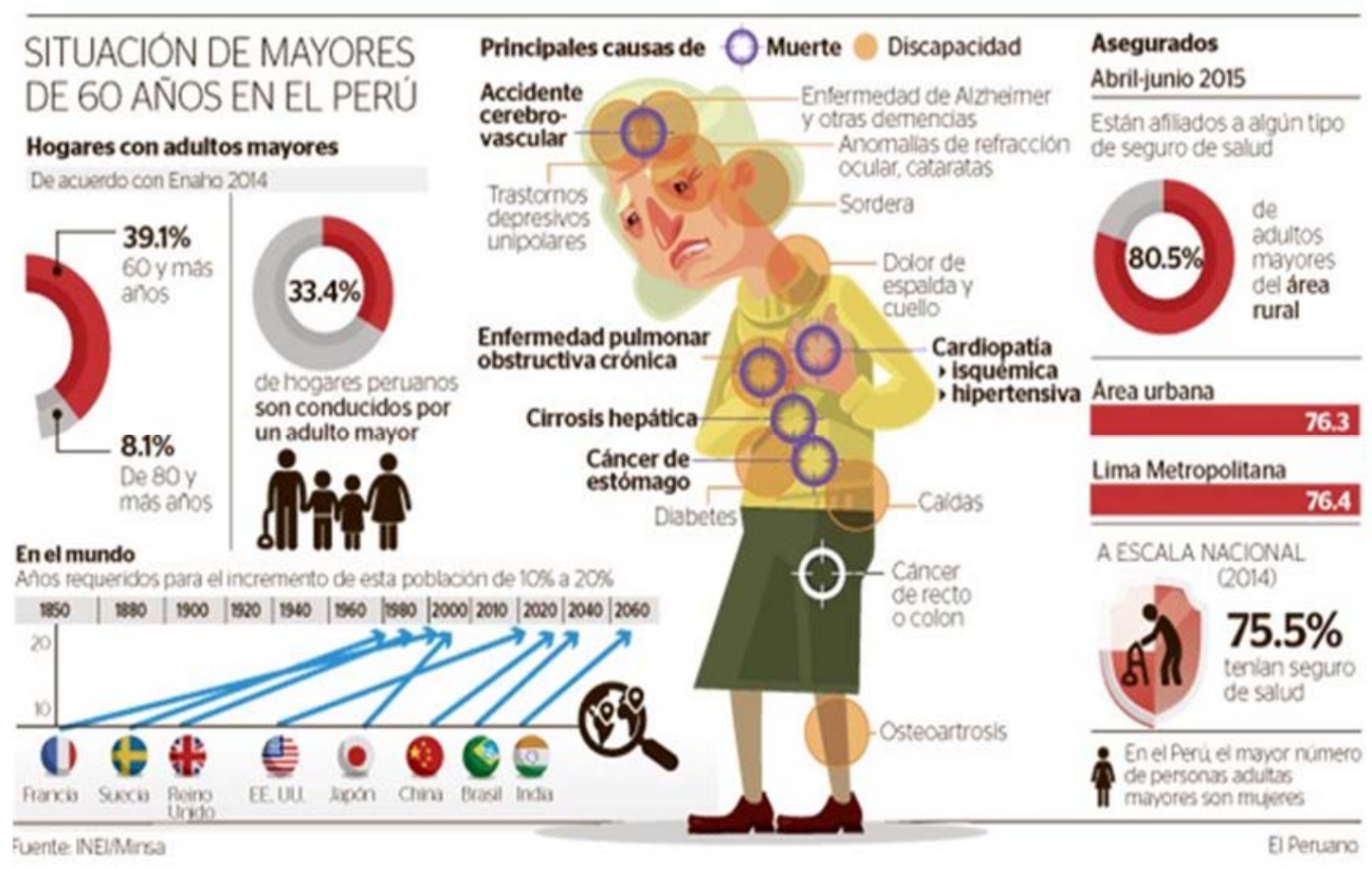

La tendencia de crecimiento nos indica que el $25 \%$ de la población actual será adulta mayor para el año 2050, es por ello que este negocio de acompañamiento estará en crecimiento durante los próximos años. (EL PERUANO , 2017)

La Municipalidad de Lima cuenta con el programa Centro Integral de Atención al Adulto Mayor - CIAM dirigido a los adultos mayores dentro de Lima Metropolitana con ello busca promover actividades que permitan un envejecimiento activo y saludable. (MUNICIPALIDAD DE LIMA, s.f.)

Patrones:

El patrón de nuestros clientes potenciales son personas que están familiarizadas con el uso de tecnología para adquirir servicios y/o productos por internet.

Son personas que trabajan y no cuentan con el tiempo suficiente para brindar el cuidado necesario al adulto mayor. Al tener un estilo de vida moderno estarían interesados en poder adquirir un servicio de cuidado a través de una plataforma virtual, ya que les resultaría una forma rápida de satisfacer su necesidad.

Conclusiones: 
- Según el resultado de nuestras encuestas, el 100\% estaría interesado en utilizar nuestro servicio a través de una plataforma virtual.

- Nuestros clientes potenciales tienen un estilo de vida moderno por lo que están dispuestos a usar nuestros servicios por ser una solución inmediata a sus necesidades.

- La tasa de crecimiento del adulto mayor en el Perú está en aumento por lo que se tendrá un amplio mercado en los próximos años según lo proyectado por el INEI. 


\section{CAPITULO 5: PLAN DE MARKETING}

\subsection{Planteamiento de objetivos de marketing}

Nuestra estrategia de marketing será lograr el posicionamiento de nuestro servicio al público objetivo, estar en "la mente y el corazón del cliente", cuando haya la oportunidad de buscar la necesidad del servicio que ofrecemos ser una alternativa única a elegir.

Corto Plazo:

- Atender por lo menos el 15\% del total de adultos mayores en la Zona 6 de los distritos de San Miguel, Jesús María, Magdalena y Pueblo Libre, en el primer año de operaciones.

- Lograr el reconocimiento de la red de servicios de cuidado del adulto mayor en nuestros principales distritos (San Miguel, Jesús María, Magdalena y Pueblo Libre) con personal profesional.

- Lograr un indicador mayor al 90\% de satisfacción al cliente mediante un servicio de calidad y una atención personalizada.

- Captar el 10\% de personal técnico-calificado en el primer trimestre del primer año para brindar un staff de profesionales al servicio.

\section{Mediano Plazo:}

- Incrementar las ventas no menores a un $15 \%$ anual.

- En un plazo no menor a dos años lograr alianzas estratégicas con hospitales y clínicas las cuales puedan recomendar nuestros servicios.

- Expandir nuestra publicidad a través de medios televisivos y radiales con la finalidad de captar mayores clientes.

- Obtener un crecimiento de nuestro mercado en un $15 \%$ anual. 
- Ampliar nuestra línea de negocio con servicios más especializados en geriatría y servicios clínicos en un plazo no mayor a 5 años.

- Expandir nuestros servicios de cuidados al adulto mayor en provincias en un plazo no mayor a 5 años.

- Atender por lo menos el 60\% de los mercados del adulto mayor en la zona de Lima Metropolitana y Provincias en un plazo no mayor a 6 años.

\subsection{Estrategias de marketing:}

\subsubsection{Segmentación}

Nuestro público objetivo son los familiares directos del adulto mayor, que se encuentren trabajando, tengan poder adquisitivo y pertenezcan al segmento A y B, y por factor tiempo no tengan la disponibilidad de poder atender y/o cuidar adulto mayor por lo que esté interesado en un servicio de cuidado y acompañamiento.

\subsubsection{Características demográficas:}

Sexo: Hombres y mujeres

Edad: Mayores de 60 años

NSE: A y B

\subsubsection{Características geográficas:}

Abarcaremos sectores de nivel socioeconómico A y B, por lo cual nos enfocaremos en las zonas 6 y 7 de Lima Metropolitano, de acuerdo a imagen, ya que tienen un poder adquisitivo mayor. 
Figura $\mathrm{n}^{\circ}$ 15: Distritos Lima Metropolitana por zonas (Fuente: APEIM 2016: Data

ENAHO 2015)

- Zona 1: Ventanilla, Puente Piedra, Comas, Carabayllo.

- Zona 2: Independencia, Los Olivos, San Martín de Porras.

- Zona 3: San Juan de Lurigancho.

- Zona 4: Cercado, Rimac, Breña, La Victoria.

- Zona 5: Ate, Chaclacayo, Lurigancho, Santa Anita, San Luis, El Agustino.

- Zona 6: Jesús María, Lince, Pueblo Libre, Magdalena, San Miguel.

- Zona 7: Miraflores, San Isidro, San Borja, Surco, La Molina.

- Zona 8: Surquillo, Barranco, Chorrillos, San Juan de Miraflores.

- Zona 9: Villa El Salvador, Villa maría del Triunfo, Lurín, Pachacamac.

- Zona 10: Callao, Bellavista, La Perla, La Punta y Carmen de la Legua.

\subsubsection{Características psicográficas:}

Son personas que cuentan con un trabajo que les consume gran parte de su tiempo. Sin embargo, a pesar de ello sienten preocupación por la salud y cuidado del adulto mayor a cargo.

Valoran la calidad, servicio y eficiencia sobre el precio a pagar, con tal de poder contar con un servicio de calidad y sentirse tranquilo al saber que su familiar se encontrará seguro y con los cuidados necesarios.

\subsubsection{Posicionamiento}

SENIOR CARE será brindado a través de una página web y/o aplicativo que podrá ser descargado en cualquier dispositivo electrónico a través de Google Play y app store, mediante el cual nuestros clientes podrán acceder de manera rápida y fácil a profesionales especializados en brindar servicio de cuidado de salud a adultos mayores y también un acompañamiento especializado.

El servicio incluirá diversos paquetes adecuados por horas, días, semanas e inclusive meses, con la opción de acceder a descuentos especiales en caso de programación anticipada mensual que incluye un mínimo de horas. 
Asimismo, el cliente podrá elegir al personal de su agrado, toda vez que la aplicación mostrará información relevante de cada especialista, como por ejemplo estudios, experiencia, recomendaciones, etc.

\subsection{Mercado objetivo:}

\subsubsection{Tamaño de mercado}

Para determinar el tamaño de mercado nos hemos enfocado en la población de Lima Metropolitana de las zonas 6 y 7 del nivel socioeconómico A y B.

En tal sentido extrajimos los reportes por APEIM del año 2017 para calcular el mercado potencial de personas adultas mayores.

Tabla $\mathrm{n}^{\circ}$ 5: Total de población en Lima Metropolitana (Fuente: Elaboración propia)

\begin{tabular}{|c|c|c|c|c|}
\hline Total de población en Perú Urbano & & $24,672,681$ & & \\
\hline NSE & DISTRIBUCION & $\begin{array}{l}\text { TOTAL DE } \\
\text { POBLACION }\end{array}$ & $\begin{array}{l}\text { FAMILIAS QUE TIENEN } \\
\text { ADULTO MAYOR }\end{array}$ & TOTAL DE POBLACION \\
\hline A & $2.40 \%$ & 592,144 & $37.10 \%$ & 219,686 \\
\hline B & $16.30 \%$ & $4,021,647$ & $37.10 \%$ & $1,492,031$ \\
\hline & & & & $1,711,717$ \\
\hline
\end{tabular}

Figura ${ }^{\circ}$ 16: Distribución de personas según NSE 2017 (Fuente: APEIM 2017)

\section{Apeim}

DISTRIBUCIÓN DE PERSONAS SEGÚN NSE 2017 - PERÚ URBANO

\begin{tabular}{|c|c|c|c|c|c|c|}
\hline \multirow{3}{*}{ NSE A } & \multicolumn{2}{|c|}{ Nº PERSONAS 24'672,681* } & \multirow{3}{*}{$\begin{array}{c}\text { NSE } \\
\text { A }\end{array}$} & \multirow{2}{*}{$\begin{array}{c}\text { Estrato } \\
\text { A1 } \\
\end{array}$} & \multicolumn{2}{|c|}{ Porcentaje } \\
\hline & \multirow{2}{*}{2.6} & & & & 0.4 & \multirow{2}{*}{2.6} \\
\hline & & & & A2 & 2.2 & \\
\hline \multirow{2}{*}{ NSE B } & \multirow{2}{*}{16.3} & \multirow{2}{*}{$-52.9 \%$} & \multirow{2}{*}{ B } & B1 & 5.7 & \multirow{2}{*}{16.3} \\
\hline & & & & B2 & 10.5 & \\
\hline \multirow{2}{*}{ NSE C } & \multirow{2}{*}{34.0} & & \multirow{2}{*}{ C } & $\mathrm{C} 1$ & 20.9 & \multirow{2}{*}{34.0} \\
\hline & & & & $\mathrm{C} 2$ & 13.2 & \\
\hline NSE D & 28.9 & & D & $\mathrm{D}$ & 28.9 & 28.9 \\
\hline NSE E & 18.2 & & $\mathbf{E}$ & $E$ & 18.2 & 18.2 \\
\hline
\end{tabular}

APEIM 2017 
Tabla $n^{\circ}$ 6: Distribución de niveles por zonas APEIM 2017 de Lima Metropolitana (Fuente: APEIM 2017)

\section{Apeim}

DISTRIBUCIÓN DE NIVELES POR ZONA APEIM 2017 - LIMA METROPOLITANA

PERSONAS - (\%) HORIZONTALES

\begin{tabular}{|c|c|c|c|c|c|c|}
\hline \multirow{2}{*}{ Zona } & \multirow[b]{2}{*}{ TOTAL } & \multicolumn{5}{|c|}{ Niveles Socioeconómicos } \\
\hline & & NSE A & NSE B & NSE C & NSE D & NSE E \\
\hline Total & 100 & 4.4 & 24.5 & 42.2 & 23.0 & 5.9 \\
\hline Zona 1 (Puente Piedra, Comas, Carabayllo) & 100 & 0.0 & 13.6 & 46.4 & 30.7 & 9.3 \\
\hline Zona 2 (Independencia, Los Olivos, San Martin de Porras) & 100 & 2.5 & 28.3 & 49.8 & 18.9 & 0.5 \\
\hline Zona 3 (San Juan de Lurigancho) & 100 & 1.2 & 16.1 & 43.5 & 31.5 & 7.7 \\
\hline Zona 4 (Cercado, Rimac, Breña, La Victoria) & 100 & 2.8 & 31.0 & 43.6 & 20.1 & 2.5 \\
\hline Zona 5 (Ate, Chaclacayo, Lurigancho, Santa Anita, San Luis, El & 100 & 1.0 & 17.0 & 47.3 & 27.3 & 7.4 \\
\hline Zona 6 (Jesús Maria, Lince, Pueblo Libre, Magdalena, San Miguel) & 100 & 14.9 & 59.3 & 19.8 & 5.9 & 0.1 \\
\hline Zona 7 (Miraflores, San Isidro, San Borja, Surco, La Molina) & 100 & 34.9 & 46.0 & 11.4 & 6.2 & 1.5 \\
\hline Zona 8)(Surquilo, Barranco, Chomilos, San Juan de Miratiores) & 100 & 2.7 & 31.3 & 42.3 & 19.1 & 4.6 \\
\hline Zona 9 (Villa El Salvador, Villa Maria del Triunfo, Lurín, Pachacamác) & 100 & 0.0 & 10.4 & 48.4 & 30.4 & 10.8 \\
\hline $\begin{array}{l}\text { Zona } 10 \text { (Callao, Bellavista, La Perla, La Punta, Carmen de la Legua, } \\
\text { Ventanilla) }\end{array}$ & 100 & 1.6 & 21.5 & 45.6 & 22.0 & 9.3 \\
\hline Otros & 100 & 0.0 & 10.3 & 32.3 & 37.9 & 19.5 \\
\hline
\end{tabular}

APEIM 2017: Data ENAHO 2016

Tabla n 7: Perfil de personas según NSE 2017 de Lima Metropolitana (Fuente: APEIM 2017)

\section{Apeim \\ PERFIL DE PERSONAS SEGÚN NSE 2017 - LIMA METROPOLITANA}

\begin{tabular}{|c|c|c|c|c|c|c|c|c|c|}
\hline & \multicolumn{8}{|c|}{ Lima Metropolitana } \\
\hline & & Total & NSE A & NSE B & NSE C & NSE C1 & NSE C2 & NSE D & NSEE \\
\hline \multirow{2}{*}{ Sexo } & Hombre & $48.4 \%$ & $49.6 \%$ & $46.3 \%$ & $48.8 \%$ & $48.1 \%$ & $50.0 \%$ & $48.7 \%$ & $53.0 \%$ \\
\hline & Mujer & $51.6 \%$ & $50.4 \%$ & $53.7 \%$ & $51.2 \%$ & $51.9 \%$ & $50.0 \%$ & $51.3 \%$ & $47.0 \%$ \\
\hline \multirow{8}{*}{$\begin{array}{l}\text { QQúe edad tiene en año } \\
\text { cumplidos? (En anos) } \\
\text { (agrupado) }\end{array}$} & $<=12$ & $18.7 \%$ & $14.2 \%$ & $14.3 \%$ & $18.8 \%$ & $16.5 \%$ & $22.8 \%$ & $22.9 \%$ & $25.3 \%$ \\
\hline & $13 \cdot 17$ & $7.3 \%$ & $5.6 \%$ & $7.0 \%$ & $6.9 \%$ & $6.8 \%$ & $7.1 \%$ & $8.1 \%$ & 9.2 \\
\hline & $18 \cdot 25$ & $13.7 \%$ & $9.2 \%$ & $13.7 \%$ & $13.7 \%$ & $13.8 \%$ & $13.6 \%$ & $13.7 \%$ & 16.3 \\
\hline & $26 \cdot 30$ & $7.7 \%$ & $6.7 \%$ & $7.5 \%$ & $7.8 \%$ & $7.8 \%$ & $7.9 \%$ & $7.7 \%$ & \\
\hline & $31 \cdot 35$ & $7.1 \%$ & $8.1 \%$ & $6.9 \%$ & $6.9 \%$ & $6.6 \%$ & $7.3 \%$ & $7.3 \%$ & 76 \\
\hline & $36 \cdot 45$ & $14.1 \%$ & $16.3 \%$ & $12.8 \%$ & $14.4 \%$ & $14.5 \%$ & $14.1 \%$ & $14.2 \%$ & 15.5 \\
\hline & $46 \cdot 55$ & $12.0 \%$ & $13.4 \%$ & $14.4 \%$ & $11.7 \%$ & $12.0 \%$ & $11.3 \%$ & $10.7 \%$ & 7.5 \\
\hline & $56+$ & $19.4 \%$ & $26.5 \%$ & $23.4 \%$ & $19.8 \%$ & $22.0 \%$ & $15.9 \%$ & $15.4 \%$ & $10.3 \%$ \\
\hline \multirow{6}{*}{$\begin{array}{l}\text { Coual es su estado civilo } 0 \\
\text { conyugar? (De } 12 \text { antos a } \\
\text { más) }\end{array}$} & Conviviente & $18.6 \%$ & & 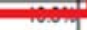 & $19.5 \%$ & $16.2 \%$ & $25.8 \%$ & $26.4 \%$ & $29.1 \%$ \\
\hline & Casado (a) & $28.2 \%$ & $49.5 \%$ & $38.2 \%$ & $27.6 \%$ & $30.4 \%$ & $22.3 \%$ & $16.7 \%$ & 13.6 \\
\hline & Viudo (a) & $4.7 \%$ & $4.7 \%$ & $4.6 \%$ & $4.6 \%$ & $4.6 \%$ & $4.5 \%$ & $5.4 \%$ & \\
\hline & Divorciado (a) & $1.0 \%$ & $2.1 \%$ & $1.9 \%$ & $0.7 \%$ & $0.6 \%$ & $0.9 \%$ & $0.4 \%$ & \\
\hline & Separado (a) & $9.3 \%$ & $4.0 \%$ & $6.0 \%$ & $9.5 \%$ & $9.1 \%$ & $10.3 \%$ & $12.7 \%$ & 13.6 \\
\hline & Soltero (a) & $38.2 \%$ & $34.8 \%$ & $38.5 \%$ & $38.1 \%$ & $39.1 \%$ & $36.2 \%$ & $38.4 \%$ & $40.3 \%$ \\
\hline \multirow{9}{*}{$\begin{array}{l}\text { Afliliación al sistema de } \\
\text { salud (Respuesta Mulliple) }\end{array}$} & ESSALUD (antes IPSS) & $40.0 \%$ & $58.4 \%$ & $57.4 \%$ & $41.5 \%$ & $44.6 \%$ & $35.7 \%$ & $22.2 \%$ & $12.6 \%$ \\
\hline & Seguro Privado de Salud & $4.7 \%$ & $36.5 \%$ & $9.3 \%$ & $1.6 \%$ & $2.0 \%$ & $0.9 \%$ & $0.3 \%$ & \\
\hline & Entidad Prestadora de Salud & $3.6 \%$ & $24.6 \%$ & $7.5 \%$ & $1.5 \%$ & $1.6 \%$ & $1.3 \%$ & $0.1 \%$ & \\
\hline & Seguro FFAA - PNP & $3.9 \%$ & $6.9 \%$ & $9.3 \%$ & $2.8 \%$ & $3.6 \%$ & $1.2 \%$ & $0.7 \%$ & \\
\hline & Seguro Integral de Salud & $26.3 \%$ & $0.9 \%$ & $7.5 \%$ & $24.8 \%$ & $21.8 \%$ & $30.5 \%$ & $46.0 \%$ & 57.4 \\
\hline & Seguro Universitario & $0.8 \%$ & $0.9 \%$ & $1.4 \%$ & $0.7 \%$ & $1.0 \%$ & $0.1 \%$ & $0.4 \%$ & \\
\hline & Seguro Escolar Privado & $0.1 \%$ & $0.4 \%$ & $0.3 \%$ & $0.1 \%$ & $0.1 \%$ & $0.0 \%$ & $0.0 \%$ & 0.2 \\
\hline & Otro & $0.2 \%$ & $0.5 \%$ & $0.4 \%$ & $0.1 \%$ & $0.1 \%$ & $0.1 \%$ & $0.2 \%$ & \\
\hline & No afiliado & $25.5 \%$ & $7.8 \%$ & $17.6 \%$ & $28.7 \%$ & $27.2 \%$ & $31.4 \%$ & $30.7 \%$ & $28.9 \%$ \\
\hline \multirow{4}{*}{$\begin{array}{l}\text { Situación laboral (De } 14 \\
\text { años a más) }\end{array}$} & Independiente 1/ & $17.0 \%$ & $6.8 \%$ & $10.1 \%$ & $18.3 \%$ & $17.7 \%$ & $19.4 \%$ & $21.8 \%$ & $21.3 \%$ \\
\hline & Dependiente 2 & $42.0 \%$ & $55.4 \%$ & $43.5 \%$ & $41.5 \%$ & $41.8 \%$ & $41.0 \%$ & $39.6 \%$ & 41.3\% \\
\hline & No TrabajaNo remunerado $3 /$ & $37.7 \%$ & $33.9 \%$ & $42.6 \%$ & $36.9 \%$ & $37.1 \%$ & $36.6 \%$ & $35.7 \%$ & $35.0 \%$ \\
\hline & Dueno PYME 4/ & $3.3 \%$ & $3.9 \%$ & $3.8 \%$ & $3.3 \%$ & $3.4 \%$ & $3.0 \%$ & $2.9 \%$ & 2.4 \\
\hline
\end{tabular}




\subsubsection{Tamaño de mercado disponible}

De acuerdo al análisis realizado y mediante el landing page se obtuvo un Ratio de Conversión del $39.70 \%$ lo cual nos ayudará a determinar el tamaño del mercado disponible.

Tabla $n^{\circ}$ 8: Tamaño de Mercado disponible (Fuente: Elaboración propia)

\begin{tabular}{|l|r|}
\hline Tamaño del Mercado & $1,711,717$ \\
\hline Tasa de Conversión (39.70\%) & 679,551 \\
\hline
\end{tabular}

\subsubsection{Tamaño de mercado operativo (target)}

El cálculo del tamaño del mercado se ha utilizado el total de la población en Perú Urbano que es un total de 24'672,681 según información publicada de APEIM del año 2017, desde ahí empezamos a determinar los filtros del NSE A y B que corresponde al $2.40 \%$ y $16.30 \%$ respectivamente, seguido del porcentaje de las familias que cuentan con un adulto mayor (37.10\%), para continuar con la investigación realizada en Landing page el cual obtuvimos la tasa de conversión de 39,70\% y la intención de contratar el servicio $40.77 \%$. Por lo tanto se puede concluir que nuestro público objetivo es de 277,053 personas en el Perú urbano.

Tabla $n^{\circ}$ 9: Total de población en Perú Urbano (Fuente: Elaboración propia)

\begin{tabular}{|l|r|}
\hline Total de población en Perú Urbano & $\mathbf{2 4 , 6 7 2 , 6 8 1}$ \\
\hline
\end{tabular}

\begin{tabular}{|c|c|c|c|c|c|c|}
\hline NSE & DISTRIBUCION & $\begin{array}{l}\text { TOTAL DE } \\
\text { POBLACION }\end{array}$ & $\begin{array}{l}\text { FAMILIAS QUE } \\
\text { TIENEN ADULTO } \\
\text { MAYOR }\end{array}$ & $\begin{array}{l}\text { TOTAL DE } \\
\text { POBLACION }\end{array}$ & $\begin{array}{c}\text { TASA DE CONVERSIÓN } \\
(39.70 \%)\end{array}$ & $\begin{array}{c}\text { INTENCIÓN DE } \\
\text { CONTRATAR } \\
\text { (40.77\%) }\end{array}$ \\
\hline A & $2.40 \%$ & 592,144 & $37.10 \%$ & 219,686 & 87,215 & 35,558 \\
\hline B & $16.30 \%$ & $4,021,647$ & $37.10 \%$ & $1,492,031$ & 592,336 & 241,496 \\
\hline & & & & & & 277,053 \\
\hline
\end{tabular}

\subsubsection{Potencial de crecimiento del mercado}

De acuerdo a las proyecciones del INEI, la población adulta mayor alcanzará una cifra de 6,5 millones para el 2050 lo cual es una oportunidad para el desarrollo del proyecto.

Por otro lado, según la información publicada por el INEI el envejecimiento de la población peruana adulto mayor aumenta en una proporción de $5.7 \%$ en el año 1950 a $10.1 \%$ en el año 2017. 
Figura $\mathrm{n}^{\circ}$ 17: Evolución de la población por rango de edad (Fuente: INEI)

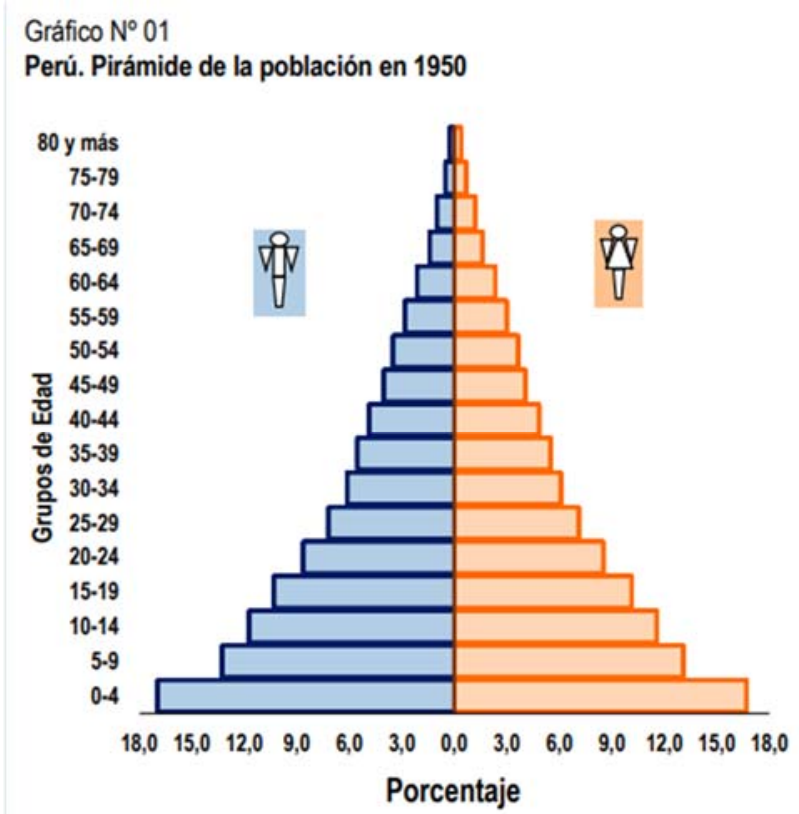

Gráfico $N^{\circ} 02$
Perú. Pirámide de la población en 2017

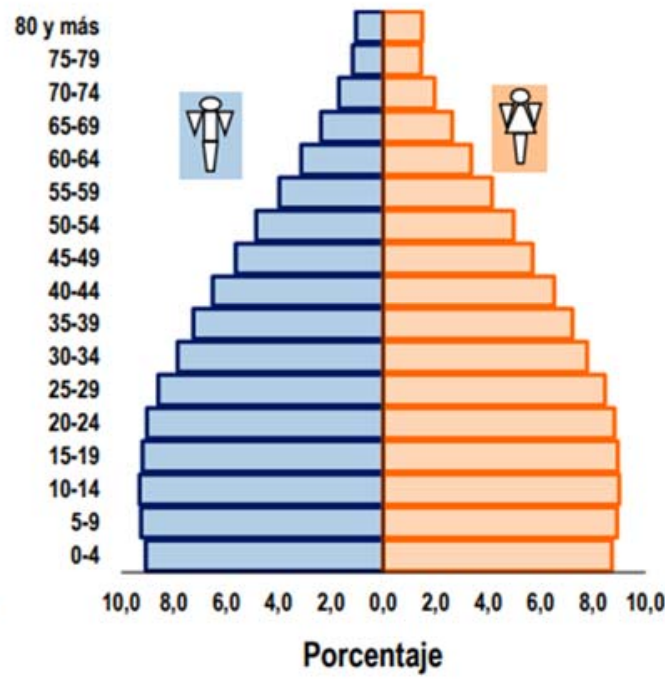

Fuente: Instituto Nacional de Estadistica e Informática.

Además, tenemos en cuenta las siguientes proyecciones de crecimiento de la población de adulto mayor.

Tabla $\mathrm{n}^{\circ}$ 10: Estimaciones y proyecciones de la población total por años calendario, según edad, 1950 - 2020 (Fuente: INEI)

\begin{tabular}{|c|c|c|c|c|c|c|c|c|c|c|c|}
\hline Edad & 1950 & 1960 & 1970 & 1980 & 1990 & 2000 & 2010 & 2015 & 2016 & 2017 & 2020 \\
\hline Total & 7632460 & 9930965 & 13192677 & 17324179 & 21764515 & 25983588 & 29461933 & 31151643 & 31488625 & 31826018 & 32824358 \\
\hline $0-14$ & 3172496 & 4301801 & 5805842 & 7263006 & 8336944 & 8866146 & 8823329 & 8698780 & 8668393 & 8636152 & 8529026 \\
\hline $15-29$ & 1977024 & 2544759 & 3383180 & 4774371 & 6239602 & 7421162 & 8116836 & 8377262 & 8412127 & 8440802 & 8499878 \\
\hline $30-59$ & 2049735 & 2524170 & 3272721 & 4324463 & 5869376 & 7841744 & 9988280 & 11064551 & 11289493 & 11519188 & 12202400 \\
\hline 60 y más & 433205 & 560235 & 730934 & 962339 & 1318593 & 1854536 & 2533488 & 3011050 & 3118612 & 3229876 & 3593054 \\
\hline $60-64$ & 169493 & 219059 & 274096 & 336490 & 462193 & 618681 & 804729 & 967702 & 1000958 & 1034068 & 1140825 \\
\hline $65-69$ & 113783 & 159641 & 199967 & 267849 & 343403 & 487034 & 623443 & 736059 & 764379 & 794999 & 892389 \\
\hline $70-74$ & 81232 & 102462 & 140614 & 189087 & 242429 & 344733 & 480926 & 545659 & 563472 & 582918 & 650782 \\
\hline $75-79$ & 43840 & 50873 & 77658 & 107012 & 160581 & 221599 & 336472 & 394230 & 405372 & 416026 & 452993 \\
\hline 80 y más & 24857 & 28200 & 38599 & 61901 & 109987 & 182489 & 287918 & 367400 & 384431 & 401865 & 456065 \\
\hline
\end{tabular}

Fuente: Instituto Nacional de Estadistica o Informática.

Teniendo en cuenta la información anterior y además el crecimiento de los usuarios que actualmente contratan servicios a través de aplicaciones y plataformas web se puede 
concluir que el proyecto tiene una gran oportunidad de poder crecer en el mercado y lograr posicionarse en la mente de los clientes por su calidad de servicio.

\subsection{Desarrollo y estrategia del marketing mix}

\subsubsection{Estrategia de producto/servicio}

Nuestra estrategia es poder cubrir la necesidad de adquirir un servicio de cuidado de adulto mayor a través de una plataforma virtual que podrá ser adquirido a través de Play Store y App Store.

En la actualidad es poco común este tipo de servicio y buscamos llegar a nuestro público objetivo a través de nuestros planes de contratación con flexibilidad de horarios según sea el requerimiento o necesidad.

Figura $n^{\circ}$ 18: Ciclo de vida del servicio (Fuente: Elaboración propia)

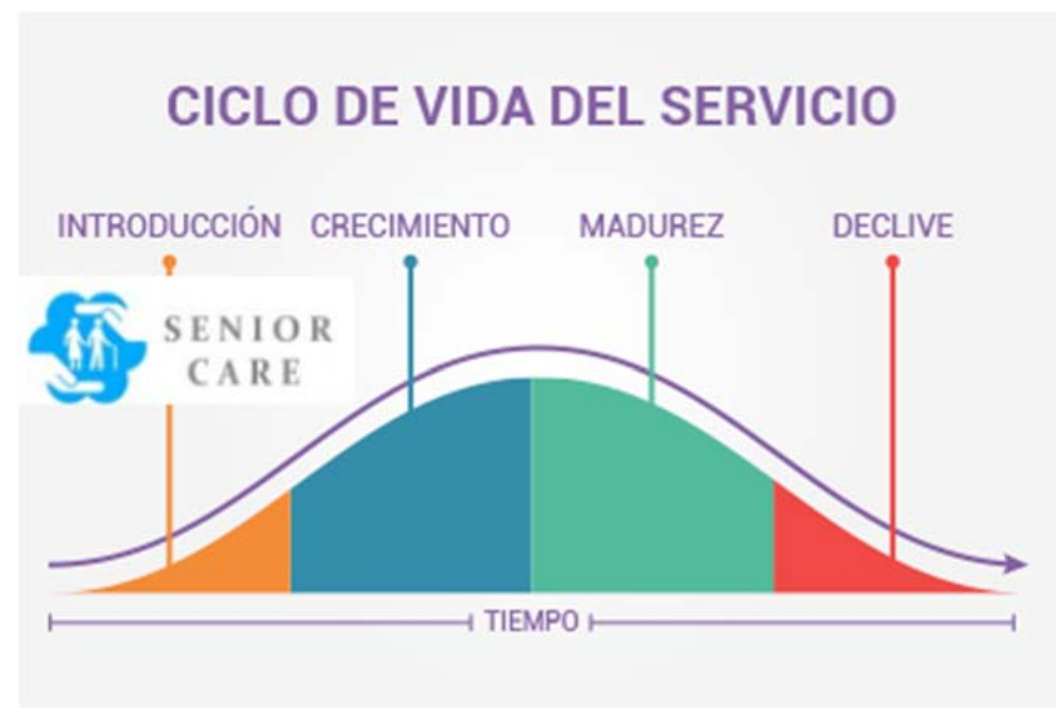

En la actualidad nos encontramos en la etapa de introducción ya que estamos lanzando una nueva plataforma virtual novedosa, pero buscamos pasar rápida esta etapa para poder estar en la de crecimiento y poder desarrollar más nuestro servicio y ampliar nuestro mercado fuera de Lima Metropolitana en un plazo no mayor a 6 años.

Los beneficios claves que brindaremos a nuestros clientes será los siguientes:

- Atención personalizada al adulto mayor.

- Personal con conocimientos y amplios conocimientos en el rubro. 
- Disponibilidad de cuidadores las 24 horas del día por medio de horario flexibles.

- Facilidades de métodos de pago, brindaremos opción de pago en efectivo y por medio de tarjetas de crédito o débito, Visa, Amex, Diners, Mastercard, etc.

- Ofreceremos seguridad con los cuidadores, ya que son seleccionados a través de rigurosos filtros.

- Comunicación estrecha con el cuidador, quien durante el tiempo del cuidado podrá reportar cualquier incidencia o actualización de las actividades a realizar.

\subsubsection{Diseño de producto/servicio}

Actividades claves:

Las actividades claves más importantes que tenemos es desarrollar la aplicación con contenido actualizado, así como también la promoción vía redes sociales ya que es el medio más utilizado para la interacción y actualmente la fuente más importante para captar nuevos clientes.

Por otro lado, otra actividad clave que tenemos es tener a nuestros cuidadores fidelizados con nosotros ya que tenemos conocimiento del riesgo que tenemos al brindar contacto directo al familiar con el cuidador, este puede trabajar en forma particular con ellos y desligarse de Senior Care, por lo que buscamos que nuestros cuidadores tengan capacitaciones constantes y sentirse a gusto con los horarios y contactos de trabajos que podemos conseguirles a través del tiempo.

\section{Alianzas claves:}

Nuestras Alianza Claves es tener personas totalmente capacitadas y con experiencia amplia en geriatría, quienes captaremos a través de nuestra bolsa de trabajo que tendremos en nuestra página web así también tendremos alianzas con institutos de enfermería donde podremos captar nuevos talentos aprovechando que son personas recién egresadas y cuentan con experiencia en hospitales por las prácticas constantes que realizan durante el periodo de estudios.

Relación con los clientes:

Buscamos brindar una atención personalizada por lo que cada paciente contará con historial en línea donde el cuidador podrá subir actualizaciones en tiempo real de las 
actividades o sucesos ocurridos durante el tiempo de permanencia del cuidado del adulto mayor, esto ayudará primero a que el familiar pueda tener conocimiento de todo lo sucedido dentro del servicio de cuidado y así también si en una futura oportunidad vuelven a solicitar nuestros servicios, el cuidador a cargo podrá utilizar esta herramienta para tener conocimiento de la historia del adulto mayor a cargo.

Canales:

Nuestros canales serán las redes sociales donde captaremos a nuestros potenciales clientes, la página web será también herramienta fundamental ya que por ahí podrán conocer sobre nuestros servicios y también las personas interesadas en formar parte del staff de cuidadores podrán brindar sus datos y para que puedan pasar el proceso de selección y, por último, la aplicación donde podrán solicitar nuestros servicios podrá ser descargada por Google Play y App Store.

Diseño de la App:

Buscamos tener una aplicación totalmente amigable donde el cliente pueda utilizarla con total facilidad, por medio de ella brindaremos un pequeño perfil del cuidador disponible y también una vez utilizado el servicio podrá calificar y colocar una pequeña reseña sobre el servicio, esto servirá para que futuros clientes puedan leer las experiencias y referencias sobre la atención brindada. 
Figura $\mathrm{n}^{\circ}$ 19: Vista de App (Fuente: Elaboración propia)

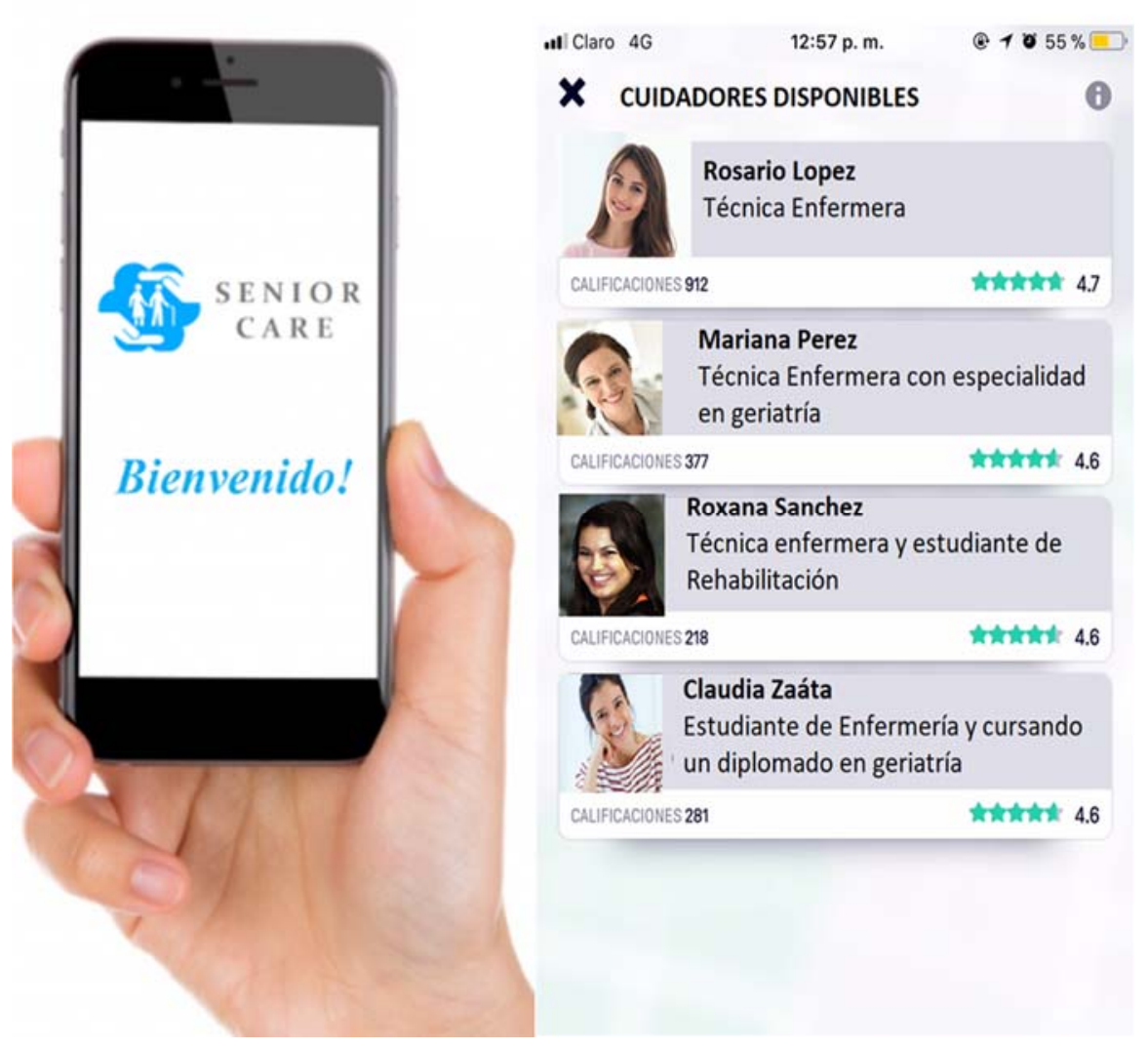

Página Web/Redes Sociales:

Nuestra página al igual que la app será totalmente amigable donde encontrará los accesos directos a los intereses puntuales del cliente, por medio de nuestra página el cliente podrá conocer acerca de nosotros, nuestro enfoque de negocio, visión, misión. También podrán ver los servicios que ofrecemos y detalles de ello, tendremos la sección donde nos podrán contactar y/o dejar sus datos personales para que un asesor los contacte, finalmente tendremos la opción de poder reclutar a cuidadores interesados en pertenecer al Staff de cuidadores de Senior Care. 
Figura $n^{\circ} 20$ : Página Web/ Redes Sociales (Fuente: Elaboración propia)
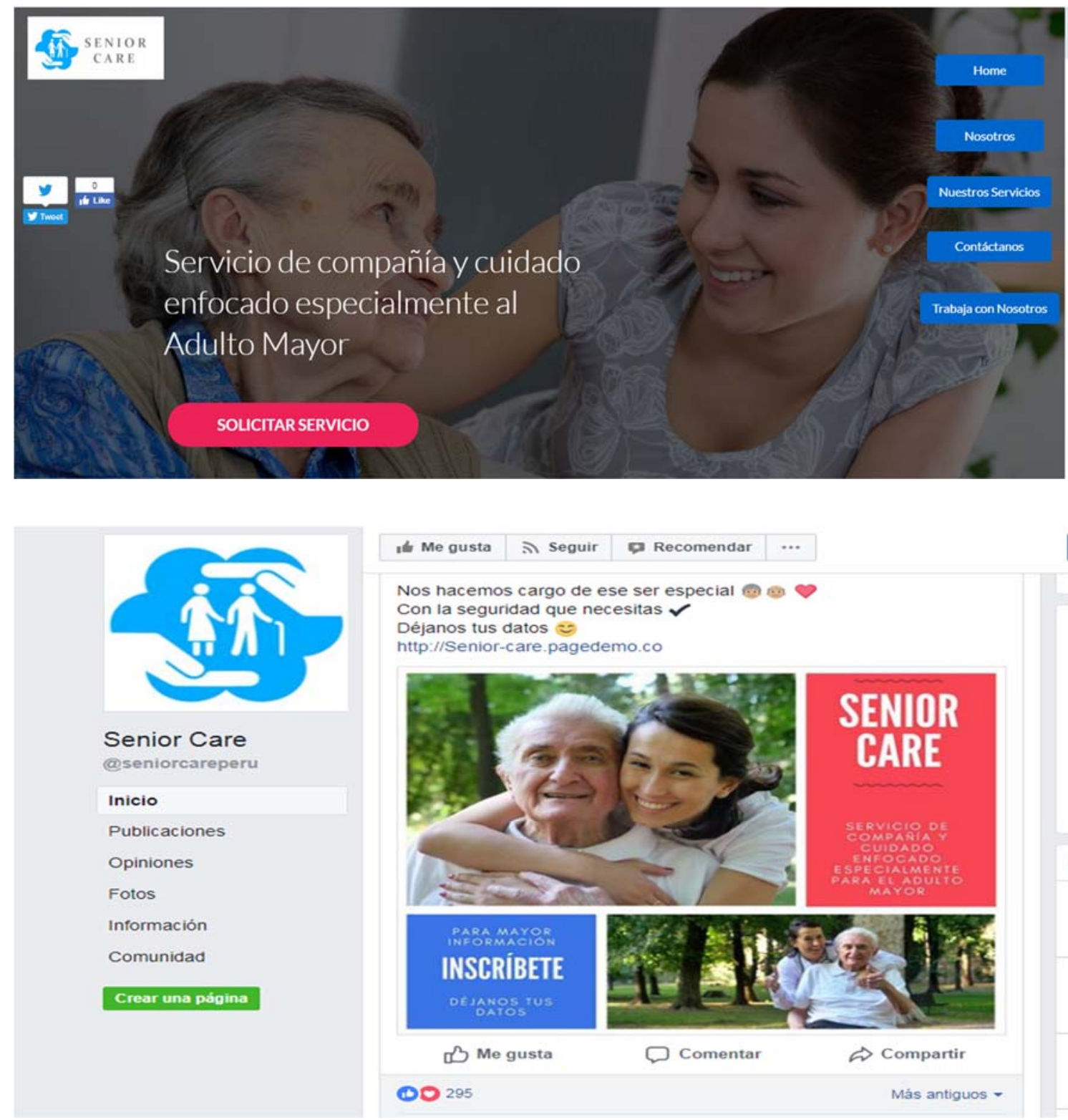

\subsubsection{Estrategia de precios (Análisis de costos, precios de mercado)}

Para la estrategia de precio hemos considerado diversas variables como los precios del mercado y los resultados de la encuesta realizada. Además, el negocio cuenta con un valor agregado que no se encuentra en las otras empresas del rubro.

El cliente valora la calidad del servicio y la eficiencia sobre el precio a pagar. Para esto contaremos con los mejores profesionales en el cuidado del adulto mayor.

Los precios promedios a pagar serán: 
Tabla $n^{\circ}$ 11: Tarifario de servicios (Fuente: Elaboración propia)

TARIFA DE SERVICIOS

\begin{tabular}{|l|lr|}
\hline \multicolumn{1}{|c|}{ Horas } & \multicolumn{2}{c|}{ Valor } \\
\hline 3 horas & S/ & 45.00 \\
\hline 6 horas & S/ & 80.00 \\
\hline 12 horas & S/ & 150.00 \\
\hline
\end{tabular}

\subsubsection{Estrategia comunicacional}

La estrategia de comunicación será dirigida principalmente a los familiares de los adultos mayores, ya que serán ellos los que tomarán la decisión sobre la toma del servicio.

Utilizaremos los siguientes canales de comunicación:

Publicidad:

A través de redes sociales como Facebook, YouTube y también se utilizará Google AdWords para ser la primera opción de búsqueda ante palabras claves como cuidado del adulto mayor.

Participación en eventos:

Debemos estar presentes en los principales eventos relacionados a la salud y medicina, dando a conocernos.

Telemarketing:

Nos comunicaremos con aquellos clientes potenciales que dejaron su información en la etapa inicial de la validación.

Marketing directo:

Utilizaremos el e-mailing ya que nos permitirá enviar información solo al segmento que necesitamos.

Marketing digital: 
Se utilizarán redes sociales como Facebook y YouTube, en este último grabaremos videos de 15 segundos donde figuras públicas reconocidas y de buena credibilidad brindarán un breve testimonio y recomendación sobre nuestros servicios, ya que se les ofrecerá utilizarlo a cambio que ellos puedan brindar este pequeño testimonio a nuestro público objetivo, así como también usaremos Adwords para búsquedas en Google para dar a conocer no solo nuestro servicio sino también información importante relacionada al tema.

Storytelling:

Utilizando esta herramienta podemos crear una conexión más profunda con nuestros potenciales clientes.

\subsubsection{Estrategia de distribución}

SENIOR CARE empleará una estrategia B2C ya que nuestra comunicación será directa al consumidor final.

Se ofrecerá nuestros servicios a través de nuestra plataforma virtual, y el cliente podrá seleccionar al cuidador, las horas que requiere y solicitará el servicio de manera directa sin necesidad de algún intermediario.

Estaremos presentes en redes sociales, página web y a través de nuestra central telefónica para atender cualquier consulta y/o reclamo

Figura $n^{\circ} 21$ : Plataforma virtual (Fuente: Elaboración propia)

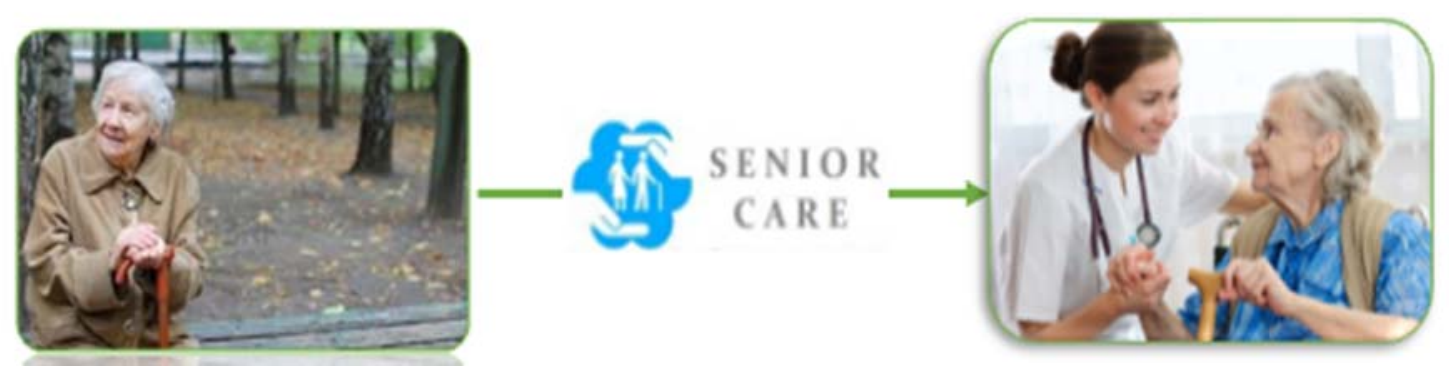

\subsection{Plan de ventas y proyección de la demanda}

Las proyecciones de las ventas estarán basadas en servicio atención al cliente, siendo la clave de éxito para la empresa, son a través de nuestros clientes que se desarrollará el servicio de alta calidad y satisfacción como forma de vivir una vida nueva y feliz. Para 
ofrecer a nuestros clientes y genera nuevos clientes tomará en cuenta las proyecciones de ventas.

El servicio brindado será a cargo de una comisión del 30\%, del precio sin IGV, siendo para proyectar la demanda de S/. 215 Soles promedio, que incluye el 30\% de margen bruto.

Tabla $n^{\circ}$ 12: Precio venta y comisión por servicio (Fuente: Elaboración propia)

\begin{tabular}{|l|lr|lr|ll|}
\cline { 2 - 7 } \multicolumn{1}{c|}{} & \multicolumn{2}{c|}{ Precio venta } & \multicolumn{2}{|l|}{ Precio sin IGV } & \multicolumn{2}{l|}{ Comisión $\mathbf{3 0 \%}$} \\
\hline 3 horas & S/ & 45 & S/ & 36.90 & S/ & 11.07 \\
\hline 6 horas & S/ & 80 & S/ & 65.60 & S/ & 19.68 \\
\hline 12 horas & S/ & 150 & S/ & 123.00 & S/ & 36.90 \\
\hline
\end{tabular}

Teniendo como base un público objetivo de 222,647, para tomar como data a fin de proyectar la demanda para los próximos 5 años, con un porcentaje de market share de crecimiento de publicidad de $10 \%, 12 \%, 13 \%, 14 \%$ y $15 \%$ que nos permita alcanzar un público objetivo mayor al inicialmente propuesto.

Asimismo, dentro de los objetivos de marketing se ha planteado lograr un crecimiento del 15\% para el primer año e ir incrementándose paulatinamente durante los próximos 5 años a lo largo del horizonte del proyecto

Tabla n 13: Proyección de la demanda (Fuente: Elaboración propia)

\begin{tabular}{|c|r|r|r|r|r|}
\cline { 2 - 6 } \multicolumn{1}{c|}{} & \multicolumn{1}{c|}{ Año 1 } & \multicolumn{1}{c|}{ Año 2 } & \multicolumn{1}{c|}{ Año 3 } & \multicolumn{1}{c|}{ Año 4 } & \multicolumn{1}{c|}{ Año 5 } \\
\hline Mercado objetivo & 277,053 & 277,053 & 277,053 & 277,053 & 277,053 \\
\hline Market share & $10 \%$ & $12 \%$ & $13 \%$ & $14 \%$ & $15 \%$ \\
\hline Venta esperada & 27,705 & 33,246 & 36,017 & 38,787 & 41,558 \\
\hline Crecimiento anual & $15 \%$ & $15 \%$ & $20 \%$ & $30 \%$ & $40 \%$ \\
\hline
\end{tabular}

A continuación, se presenta la proyección de las ventas de los próximos 5 años, con sus respectivos ingresos según la estacionalidad del servicio dedicado al adulto mayor, donde se puede apreciar el incremento de la población de esa edad. 
Tabla $n^{\circ}$ 14: Proyección de la demanda y la demanda esperada para los próximos 5 años (Fuente: Elaboración propia)

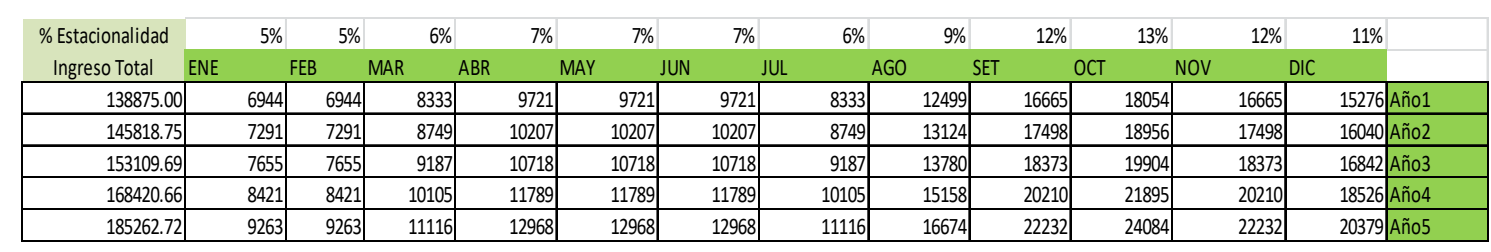

\begin{tabular}{|c|c|c|c|c|c|}
\hline \multicolumn{6}{|c|}{ Crecimiento } \\
\hline TIPO & 2018 & 2019 & 2020 & 2021 & 2022 \\
\hline Ventas Promedio horas & S/. $138,875.00$ & S/. $152,762.50$ & S/. $171,094.00$ & S/. $196,758.10$ & S/. 236,109.72 \\
\hline TOTALES & S/. $138,875.00$ & S/. 152,762.50| & S/. $171,094.00$ & S/. $196,758.10$ & S/. 236,109.72 \\
\hline$\%$ de Crecimiento & & $10.00 \%$ & $12.00 \%$ & $15.00 \%$ & $20.00 \%$ \\
\hline
\end{tabular}

\subsection{Presupuesto de marketing}

El presupuesto de Marketing obtenido para el primer año es de S/ 91,670, ya que al ser una plataforma virtual donde nuestros principales clientes potenciales serán captados por redes sociales, necesitaremos tener un Community Manager que mantenga nuestro Facebook 100\% activo mediante actualizaciones de nuestros servicios, testimonios, asimismo requerimos utilizar la publicidad que brinda Facebook con una inversión mensual es S/ 1,750.00, y colocar publicidad en YouTube donde tendremos videos de 15 segundos de figuras públicas brindando un breve testimonio sobre nuestro servicio, se presupuesta los 3 primeros meses S/ 4950.00 ya que por introducción presupuestamos invertir 50 USD por día, luego de los 3 meses nuestro presupuesto final será 20USD diarios que será una inversión de S/ 1980.00, también para poder ser ubicados en primera instancia a través de Google invertiremos S/ 2000.00 mensuales para ser la primera opción de búsqueda ante palabras claves como cuidado de adulto mayor o servicio a domicilio de cuidado al adulto mayor. También planeamos invertir en material pop cada 6 meses, esto será pieza importante para nuestro marketing boca a boca. Se proyecta que los 2 primeros años tendrán una suma importante de inversión por empezar a introducirnos en el mercado y los siguientes 3 años se disminuirá esta inversión en un $30 \%$.

Con toda esta inversión planeamos sacar provecho al máximo en poder captar y fidelizar a nuestros clientes potenciales dentro de Lima Metropolitana ya que estamos enfocados a un sector específico de Nivel Socioeconómico A y B. 
Tabla $n^{\circ}$ 15: Presupuesto (Fuente: Elaboración propia)

\begin{tabular}{|c|c|c|c|c|c|c|c|c|c|c|c|c|c|c|c|c|c|c|c|c|c|c|c|c|c|c|}
\hline & \multicolumn{2}{|c|}{ Mes 1} & \multicolumn{2}{|c|}{ Mes 2} & \multicolumn{2}{|c|}{ Mes 3} & \multicolumn{2}{|c|}{ Mes 4} & \multicolumn{2}{|c|}{ Mes 5} & \multicolumn{2}{|c|}{ Mes 6} & \multicolumn{2}{|c|}{ Mes 7} & \multicolumn{2}{|c|}{ Mes 8} & \multicolumn{2}{|c|}{ Mes 9} & \multicolumn{2}{|c|}{ Mes 10} & \multicolumn{2}{|c|}{ Mes 11} & \multicolumn{2}{|c|}{ Mes 12} & & \\
\hline \multicolumn{25}{|l|}{ REDES SOCIALES } & & \\
\hline Community Manager & S/ & 750 & S/ & 750 & S/ & 750 & S/ & 750 & S/ & 750 & S/ & 750 & S/ & 750 & S/ & 750 & S/ & 750 & S/ & 750 & S/ & 750 & S/ & 750 & & \\
\hline Publicidad en Redes Sociales & S/ & 1,750 & S/ & 1,750 & S/ & 1,750 & S/ & 1,750 & S/ & 1,750 & S/ & 1,750 & S/ & 1,750 & S/ & 1,750 & S/ & 1,750 & S/ & 1,750 & S/ & 1,750 & S/ & 1,750 & & \\
\hline Adowords & S/ & 2,000 & S/ & 2,000 & S/ & 2,000 & S/ & 2,000 & S/ & 2,000 & $\mathrm{~S} /$ & 2,000 & S/ & 2,000 & S/ & 2,000 & S/ & 2,000 & S/ & 2,000 & S/ & 2,000 & s/ & 2,000 & & \\
\hline Publicidad en Youtube & S/ & 4,950 & S/ & 4,950 & S/ & 4,950 & S/ & 1,980 & S/ & 1,980 & S/ & 1,980 & S/ & 1,980 & S/ & 1,980 & S/ & 1,980 & S/ & 1,980 & S/ & 1,980 & s/ & 1,980 & & \\
\hline \multicolumn{25}{|l|}{ CANAL TRADICIONAL } & & \\
\hline \multirow[t]{6}{*}{ Material POP } & S/ & 2,500 & S/ & - & S/ & - & S/ & - & S/ & - & S/ & - & S/ & 2,500 & S/ & - & S/ & - & S/ & - & S/ & - & S/ & - & & \\
\hline & S/ & 11,950 & S/ & 9,450 & S/ & 9,450 & S/ & 6,480 & S/ & 6,480 & S/ & 6,480 & S/ & 8,980 & S/ & 6,480 & S/ & 6,480 & $\mathrm{~S} /$ & 6,480 & S/ & 6,480 & s/ & 6,480 & S/ & 91,670 \\
\hline & S/ & 11,950 & S/ & 9,450 & S/ & 9,450 & $\mathrm{~S} /$ & 6,480 & $\mathrm{~S} /$ & 6,480 & S/ & 6,480 & S/ & 8,980 & S/ & 6,480 & S/ & 6,480 & S/ & 6,480 & S/ & 6,480 & s/ & 6,480 & s/ & 91,670 \\
\hline & S/ & 8,365 & S/ & 6,615 & S/ & 6,615 & S/ & 4,536 & S/ & 4,536 & S/ & 4,536 & S/ & 6,286 & S/ & 4,536 & S/ & 4,536 & S/ & 4,536 & S/ & 4,536 & S/ & 4,536 & s/ & 64,169 \\
\hline & S/ & 8,365 & S/ & 6,615 & S/ & 6,615 & S/ & 4,536 & S/ & 4,536 & S/ & 4,536 & S/ & 6,286 & S/ & 4,536 & S/ & 4,536 & S/ & 4,536 & S/ & 4,536 & S/ & 4,536 & s/ & 64,169 \\
\hline & S/ & 8,365 & S/ & 6,615 & S/ & 6,615 & S/ & 4,536 & $S /$ & 4,536 & s/ & 4,536 & S/ & 6,286 & S/ & 4,536 & S/ & 4,536 & S/ & 4,536 & S/ & 4,536 & s/ & 4,536 & $\mathrm{~s} /$ & 64,169 \\
\hline
\end{tabular}

Figura $n^{\circ} 22$ : Interacciones (Fuente: Facebook Senior Care)

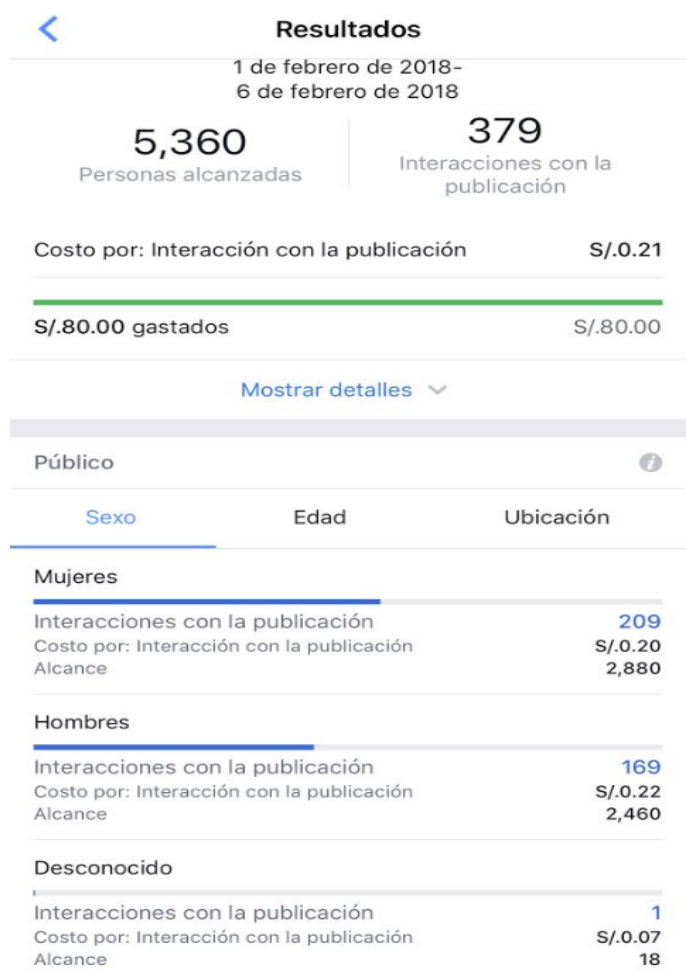

Según la validación realizada a través de la publicidad en el Facebook de Senior Care por una suma de S/ 80 se tuvo un alcance por 5360 personas, de las cuales sólo 379 personas interactuaron con la publicidad y alrededor de 70 personas nos dejaron sus datos.

\begin{tabular}{|c|cc|}
\hline Costo por interacción & S/ & 0.21 \\
\hline Nuestro Real costo por interacción & S/ & 1.14 \\
\hline $\begin{array}{c}\text { Público netamente que se alcanzará por una } \\
\text { inversión de S/ 1750 mensual }\end{array}$ & \\
\hline
\end{tabular}

Figura $n^{\circ} 22$ : Embudo (Fuente: Elaboración propia) 


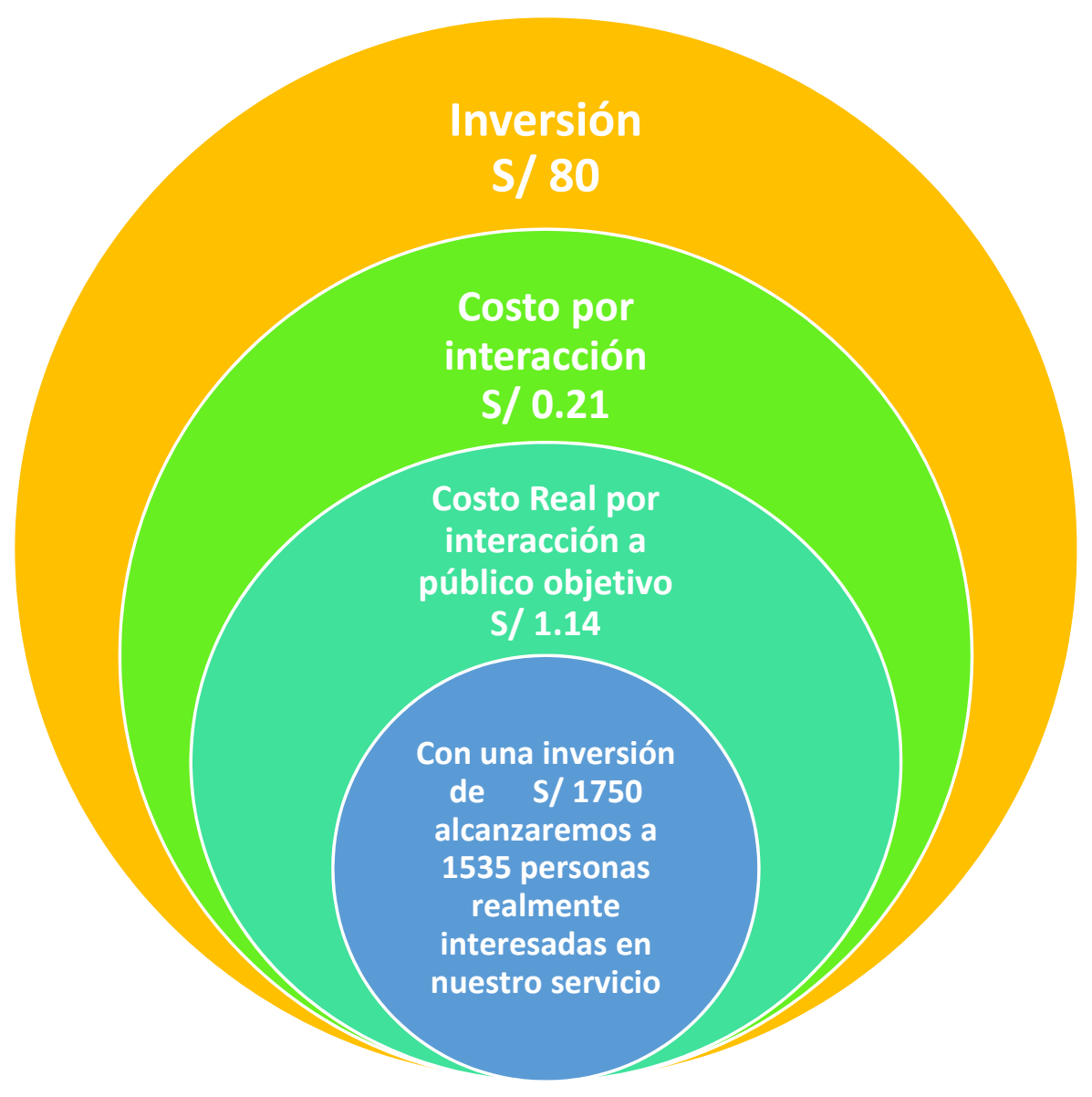




\section{CAPITULO 6: PLAN DE OPERACIONES}

\subsection{Políticas Operacionales}

La empresa SENIOR CARE, es una empresa del rubro del cuidado del adulto mayor, y se siente comprometida con el cliente a brindar un servicio seguro, confiable, que permita al cliente generar empatía de acuerdo a su ritmo de vida, respecto al acompañamiento del adulto mayor por un profesional de salud. SENIOR CARE, presenta una propuesta de valor:

- Servicio exclusivo de atención personalizada al adulto mayor, por profesionales especializados en el rubro.

- Disponibilidad de cuidadores las 24 horas del día, por medio de horario flexibles.

- Ofreceremos seguridad con los cuidadores, ya que son seleccionados a través de rigurosos filtros.

\section{SENIOR CARE, presenta las características del servicio:}

- El servicio de acompañamiento de adulto mayor tiene una duración de acuerdo a la solicitud del cliente que puede ser 3 horas, 6 horas y hasta 12 horas.

- El personal se presentará al hogar del cliente, con su respectiva identificación de la empresa SENIOR CARE, a fin de atender los requerimientos del cliente según el tipo de personal solicitado.

- Los servicios que brindaremos serán: control en medicación; nuestros acompañantes realizarán un seguimiento en la correcta toma de medicinas, comidas según dieta, mantener al adulto mayor con actividad, higiene y aseo personal, ayuda para vestirse y en la higiene íntima.

- Se les brindará las facilidades de métodos de pago, brindaremos opción de pago en efectivo y por medio de tarjetas de crédito o débito, Visa, Amex, Diners, Mastercard, etc. 
- Para llevar un mejor control de los servicios, se hará una notificación de recordatorio al cliente para que se encuentre al tanto antes de iniciar el servicio, y estar preparados para la llegada del personal especializado en adulto mayor.

- Nuestro personal profesional, contará con un procedimiento para efectuar el servicio al adulto mayor, antes, durante y después de realizar el servicio.

- La enfermera inicia el servicio del cuidado de adulto a través de la utilización de nuestra App.

- La enfermera se identifica cuando realiza el servicio a domicilio y nuestra empresa SENIOR CARE, estará monitoreando el servicio por medio del App, a fin de evitar cualquier riesgo a la salud e integridad de nuestros profesionales.

- La enfermera se entrevista con el cliente y luego es presentada al adulto mayor, quien le brinda una breve explicación de los servicios a recibir.

- La enfermera, es quien toma la iniciativa a fin de crear la empatía con el usuario y llevar a cabo su trabajo con tranquilidad, durante el tiempo que fue contratada.

- Finalmente, culminado el servicio elegido, la enfermera pasará a retirarse dando a entender al usuario, gentilmente que el servicio ha concluido y que lo volverá a ver pronto según el requerimiento que le haga el cliente. El trabajo se cierra a través del App, asimismo enviará un mensaje al cliente a fin de solicitarle una calificación del servicio brindado.

\section{Posibles problemas a ocurrir durante el servicio}

No encontrar al usuario o cliente en la dirección indicada, por lo tanto, se deberá notificar al cliente previamente antes de iniciar el servicio a su familiar adulto mayor, a través de un mensaje o llamada telefónica de respuesta con la confirmación del servicio a brindar, antes de efectuarse el servicio al domicilio.

\section{Capital Humano}

La finalidad de la empresa SENIOR CARE, es brindar la satisfacción y redituar a nuestros futuros clientes potenciales, por medio de nuestro servicio oportuno y eficaz, creando nuevas expectativas a nuestros clientes. Por ello, SENIOR CARE, se encuentra en la continua capacitación de nuestro staff de profesionales de la salud del adulto mayor. Para 
llevar acabo, el servicio nuestro personal clave de los enfermeros en diferentes especialidades de geriatría y rehabilitación, contaran con un ingreso compartido del $75 \%$ por servicio para las enfermeras y el 30\%, quedará a cargo de la empresa SENIOR CARE, quien se encargará de buscar los contactos de los clientes.

\section{Tecnología}

Nuestro servicio se encuentra plasmado en la interacción del App, siendo una herramienta clave para el cliente, nos permite conocer las características de sus necesidades y la frecuencia del servicio a solicitar. Su percepción del servicio. La app, permitirá ofrecer al cliente todos los beneficios de nuestro servicio.

\section{Precio}

Los precios son variables y se encuentran sujetos a la disponibilidad de nuestros clientes, según la cantidad de horas solicitadas. Los mismos, que se pueden ofrecer un descuento si es un cliente continúo de acuerdo a las políticas internas de la empresa.

\subsubsection{Calidad}

La empresa SENIOR CARE, se encuentra conformada por profesionales de la salud, quienes brindarán un servicio de atención inmediata según el requerimiento del cliente en forma segura y eficaz. Por ello, se elabora las siguientes políticas internas de calidad a nuestros clientes, para garantizar la excelencia del servicio.

\section{Calidad del servicio}

- Los servicios solicitados de nuestros clientes serán atendidos a través del App o página web de la empresa, para generar la confiabilidad, transparencia y seguridad del servicio, cualquier otra modalidad no se encuentra permitido. Primero se deberá crear una cuenta de usuario, ingresando sus datos, correo, teléfono, con la cuenta creada podrá solicitar información o servicios que necesite, y ahí podremos contactarnos directamente con el cliente.

- Nuestro staff de enfermeros, se encuentra capacitados con los procedimientos del servicio, antes, durante y después, para cumplir con los protocolos establecidos internamente. Nuestros procedimientos, son de conocimiento de todos los empleados de la empresa desde los directivos hasta el último personal, a fin de cumplirlos a cabalidad, que nos permita garantizar la satisfacción de las necesidades de nuestros clientes. 
- El uso de los celulares no se encuentra permitido durante la realización del servicio a domicilio del cuidado del adulto mayor, salvo surja una urgencia, consultar con el usuario y/o cliente previamente, a fin de evitar distracciones.

\subsubsection{Procesos}

En la empresa SENIOR CARE, los procesos operacionales son el corazón del negocio, por lo tanto, cada proceso nos llevará al éxito dentro de la organización, asimismo, se ha definido las políticas que permiten crear mejoras continuas día tras día en la forma de brindar el servicio a nuestros usuarios, que nos permitan lograr la satisfacción del cliente. Para ellos, se ha elaborado e implementado, el proceso de atención al cliente, donde nos facilitará la eficiencia y eficacia de nuestros enfermeros, generando una empresa confiable y rentable en el tiempo.

\section{Proceso Estratégico:}

- Para los usuarios: el adulto mayor será atendido por las enfermeras técnicas especialistas en geriatría, durante las horas solicitadas por sus familiares (clientes), la asistencia del usuario será interconectarse con la enfermera a fin de brindar un servicio adecuado y poder ayudarlo en lo que se requiere en cuento a su estado físico o mental del adulto mayor.

- Para los clientes; las comunicaciones con los familiares se efectuarán a través de nuestro aplicativo App SENIOR CARE, o también podrá efectuarlo vía web, fan page, correos, teléfonos, donde se ofrecerá los servicios según sus requerimientos, así como los descuentos por campañas promocionales durante todo el año, siendo a elección del cliente para evaluar y decidir la mejor opción que le convenga.

- Se contará con un proveedor de (Enfermeras calificadas) que nos permita garantizar nuestros servicios a los clientes, que cuente con años de experiencia laboral y especialización en la rama de geriatría.

\section{Proceso Operativo:}

- Nuestro equipo de enfermeros deberá estar en constante interacción con el App SENIOR CARE, revisando si cuentan con algún requerimiento un día antes a partir de las 6:00 pm en adelante. 
- Los enfermeros se encuentran disponibles en diversos horarios, si alguno de ellos, tuviera inconvenientes para cubrir el servicio, deberá de comunicarlo con la debida anticipación a fin de tomar las medidas de necesarias, y cubrir el puesto con otra persona, previamente avisar 12 horas antes.

- Nuestro personal deberá de ser puntual con la llegada al domicilio del cliente, 10 minutos antes de realizar el servicio, lo que nos permitirá contar con la confiabilidad y seguridad que ofrecemos. Si tuviese inconvenientes en el camino podrá comunicarle al cliente con una tolerancia no mayor de 10 minutos.

- Nuestro personal una vez que llegue al domicilio de cliente, podrá comunicarlo a través del uso del App, ahí podrá registrar sus actividades realizadas antes, durante y después del servicio.

- El personal deberá ser cuidadoso al momento de realizar el servicio, deberá contar con la identificación respectiva, fotocheck, vestimenta respectiva de la empresa.

- El personal que culmine un servicio deberá efectuarlo por el App, a fin de contabilizar sus horas de servicio efectuado, para que sean pagadas de acuerdo a las horas contratadas.

- Las políticas en caso de fallecimiento y/o enfermedad terminal del usuario, las enfermeras cuentan con los protocolos internos de SENIOR CARE, es decir, llamar en primera instancia al familiar más cercano, así como seguir el procedimiento de cuidados de salud de una persona y seguir los procedimientos según las normas peruanas basados en la Ley 26842 (20/07/1997) Titulo Tercero, Fin de la vida.

- Las políticas para el caso de manipulación de material durante el servicio, para ello se seguirá el mismo procedimiento interno de los protocolos de cuidados de la salud de SENIOR CARE, en cuanto a la manipulación de todo tipo de material, y cumplir con lo indicado por la Ley 26841, Capitulo VII, De la higiene y seguridad en los ambientes de trabajo, Artículos 100, 1001 y 102.

\section{Proceso Soporte:}


- El administrador se hará cargo de contratar un proveedor que nos brinde el servicio de selección de enfermeras técnicas especialistas en geriatría y especialistas en diversas ramas de la medicina general, a fin de cubrir las necesidades de cada cliente.

- Nuestras enfermeras que ofrecen el servicio de cuidado al adulto mayor tomarán en cuenta las inquietudes del cliente con la finalidad de cubrir sus expectativas de atención al cliente.

- Para el cumplimiento de las políticas internas de SENIOR CARE, se deberá desempeñar con los tiempos pactados dentro de la fecha y horas acordadas por los clientes.

- Nuestro personal de SENIOR CARE, se encuentra comprometido con la empresa por los mismo, que deberá conocer la misión y visión, a ser aplicada desde los directivos hasta el último empleado de la empresa, con la finalidad de uniformizar la comunicación interna de la empresa.

\subsubsection{Planificación}

Dentro de los planes estratégicos anuales se encuentra el proceso de Planificación. El mismo que será monitoreada para medir el cumplimiento de la demanda real a través de las operaciones de la empresa.

Las operaciones de la empresa serán evaluadas y revisadas por los socios y gerentes en las oficinas administrativas, con la finalidad de conocer las actividades, frecuencia, responsables, y los participantes a cargo de cada actividad, durante el año de operaciones.

Los puntos a tratar en la empresa serán:

- Evaluación, revisión, control y monitoreo de la situación operativa de la empresa.

- Evaluación, revisión, control, monitoreo y cumplimiento de los indicadores de la operación en manera mensual.

- La toma de la mejor decisión sobre cambios o nuevos programas según los nuevos requerimientos de la empresa.

- Finalmente, revisión de los planes económicos y financieros de la empresa en forma mensual. 
SENIOR CARE, por ser una empresa que inicia sus operaciones con personal no mayor de 20 personas, se podrá ejecutar reuniones en forma semestral, las mismas que estarán a cargo del administrador o gerente de la empresa, dicha reunión se deberá contar con la presencia de los socios.

Asimismo, para la revisión de los indicadores, ejecución y cumplimiento de los objetivos operacionales y comerciales, estará a cargo del jefe de operaciones y el jefe de marketing.

Al término de cada reunión programada se elaborará un acta con los acuerdos tomados en reunión, con la finalidad de contar con un protocolo y seguimiento de las medidas adoptadas en la reunión y hacer seguimiento de los acuerdos comprometidos.

Tabla $n^{\circ}$ 16: Cronograma de las Actividades de Planificación (Fuente: Elaboración propia)

\begin{tabular}{|c|c|c|c|c|}
\hline \multirow{2}{*}{2018} & \multicolumn{4}{|c|}{ ACTIVIDADES } \\
\hline & Económicas & Indicadores & Toma de decisiones & Plan Estratégico \\
\hline Frecuencia & Trimestral & Mensual & Trimestral & Anual \\
\hline Enero & & 1 & & \\
\hline Febrero & & 1 & & \\
\hline Marzo & 1 & 1 & 1 & \\
\hline Abril & & 1 & & \\
\hline Mayo & & 1 & & \\
\hline Junio & 2 & 1 & 2 & \\
\hline Julio & & 1 & & \\
\hline Agosto & & 1 & & \\
\hline Setiembre & 3 & 1 & 3 & \\
\hline Octubre & & 1 & & \\
\hline Noviembre & & 1 & & \\
\hline Diciembre & 4 & 1 & 4 & 1 \\
\hline RESPONSABLES & Gerente General & $\begin{array}{c}\text { Responsable de } \\
\text { Operaciones y } \\
\text { Marketing }\end{array}$ & $\begin{array}{c}\text { Gerente General / } \\
\text { Socios }\end{array}$ & Gerente General \\
\hline Participación & $\begin{array}{c}\text { Gerente General / } \\
\text { Socios }\end{array}$ & Gerente General & $\begin{array}{c}\text { Gerente General / } \\
\text { Socios }\end{array}$ & $\begin{array}{c}\text { Gerente General / } \\
\text { Socios }\end{array}$ \\
\hline
\end{tabular}

\subsubsection{Inventarios}

La empresa SENIOR CARE, será un servicio profesional para el cuidado del adulto mayor, no se va requerir contar con mucha infraestructura física, salvo la oficina administrativa, que contará con muebles de oficina, sillas ergonómicas, escritorios, computadoras portátiles, pizarra, teléfono, impresora, siendo los iniciales inventarios primarios para el inicio de sus operaciones, durante el primer año. 


\subsection{Diseño de las instalaciones}

Para estar más cerca de nuestros clientes la empresa SENIOR CARE, tendrá una oficina administrativa en el distrito de SAN BORJA, ubicado en Av. De Las Artes Norte 509 San Borja, San Borja, Lima.

\subsubsection{Localización de las instalaciones}

La empresa SENIOR CARE, para iniciar sus operaciones necesitará contar con un local con una dimensión no mayor $60 \mathrm{~m} 2$, que funcionará como sus oficinas administrativas donde se gestionarán las operaciones de la empresa, la misma que se deberá elegir según los factores de mayor relevancia, entre ellos tenemos:

- Costo de los alquileres: Se tomará en cuenta los precios de los alquileres en las zonas que deseamos ubicar la oficina administrativa y gestión de operaciones, la misma que será considerada como gastos fijos mensual, y será programada en el flujo de caja proyectado.

- De fácil acceso: La ubicación es la clave principal para que nuestro personal interno y externo, tanto en la salida y llegada para cubrir un servicio solicitado. Se deberá considerar las principales vías de la ciudad para tener acceso al lugar.

- Seguridad de la zona: En estos días la seguridad es un factor de alto riesgo en todas partes, pero será considerada como una variable importante para elección del lugar.

- Ubicación céntrica: Contar con fácil acceso, también es un factor valioso para nosotros, porque nos permitirá estar frente a una zona comercial, accesos rápidos a hospitales, puntos de auxilios, comisarías, frente alguna contingencia que se pudiera presentar. 
Tabla $^{\circ}$ 17: Evaluación de los factores para la macro localización (Fuente: Elaboración propia)

\begin{tabular}{|l|c|c|c|c|c|c|c|}
\hline \multirow{2}{*}{ VARIABLES } & \multicolumn{7}{|c|}{ POSICION DE LOS FACTORES CLAVES } \\
\cline { 2 - 8 } & $\begin{array}{c}\text { Costo } \\
\text { Alquiler }\end{array}$ & $\begin{array}{c}\text { De fácil } \\
\text { acceso }\end{array}$ & $\begin{array}{c}\text { Seguridad en } \\
\text { la zona }\end{array}$ & $\begin{array}{c}\text { Ubicación } \\
\text { céntrica }\end{array}$ & $\begin{array}{c}\text { Asuntos } \\
\text { legales }\end{array}$ & PUNTAJE & $\%$ \\
\hline Costo alquiler & $\mathrm{X}$ & 0.5 & 0 & 1.5 & 1 & 3 & $30 \%$ \\
\hline De fácil acceso & 1 & $\mathrm{X}$ & 1 & 1 & 1 & 4 & $40 \%$ \\
\hline Seguridad en la zona & 1 & 0 & $\mathrm{X}$ & 0 & 1 & 2 & $20 \%$ \\
\hline Ubicación céntrica & 0 & 0 & 0 & $\mathrm{X}$ & 1 & 1 & $10 \%$ \\
\hline
\end{tabular}

Luego de efectuar la evaluación de los factores claves, se elaborará un cuadro comparativo de los distritos donde deberá de establecerse la ubicación de la empresa, cada uno de los distritos a ser evaluados cuentan con factores antes mencionados en el cuadro precedente, los mismo que se ha considerado una calificación de 0 , siendo la calificación más baja y el número 5 es la mejor opción.

Asimismo, para determinar la zona ideal del local de la empresa SENIOR CARE, siendo un local en la zona 6 y 7 de Lima Metropolitana, teniendo como base a los siguientes distritos: Pueblo Libre, Magdalena, San Miguel, Jesús María y se incluye a este grupo San Borja como una alternativa viable.

Tabla $\mathrm{n}^{\circ}$ 18: Cuadro comparativo de los cuatro distritos evaluados (Fuente: Elaboración propia)

\begin{tabular}{|c|c|c|c|c|c|c|c|c|c|c|}
\hline \multirow[b]{3}{*}{$\begin{array}{l}\text { Factores de } \\
\text { localización }\end{array}$} & \multicolumn{10}{|c|}{ CUADRO COMPARATIVO DE LOS 4 DISTRITOS EVALUADOS } \\
\hline & & & \multicolumn{2}{|c|}{ Opc 1 Pueblo Libre } & \multicolumn{2}{|c|}{ Opc 2 Magdalena } & \multicolumn{2}{|c|}{ Opc 3 San Miguel } & \multicolumn{2}{|c|}{ Opc 4 San Borja } \\
\hline & Peso & $\%$ & Calificación & $\begin{array}{l}\text { Calificación } \\
\text { ponderada }\end{array}$ & Calificación & $\begin{array}{l}\text { Calificación } \\
\text { ponderada }\end{array}$ & Calificación & $\begin{array}{l}\text { Calificación } \\
\text { ponderada }\end{array}$ & Calificación & $\begin{array}{l}\text { Calificación } \\
\text { ponderada }\end{array}$ \\
\hline Costo alquiler & 3 & $30 \%$ & 3 & 0.15 & 4 & 0.15 & 2 & 0.2 & 4 & 0.3 \\
\hline De fácil acceso & 4 & $30 \%$ & 4 & 0.1 & 3 & 0.2 & 4 & 0.15 & 5 & 0.1 \\
\hline Seguridad en la zona & 2 & $30 \%$ & 3 & 0.3 & 3 & 0.25 & 3 & 0.1 & 3 & 0.3 \\
\hline Ubicación céntrica & 1 & $30 \%$ & 3 & 0.2 & 3 & 0.15 & 2 & 0.15 & 3 & 0.15 \\
\hline & & & & 0.75 & & 0.75 & & 0.6 & & 0.85 \\
\hline
\end{tabular}

\begin{tabular}{|l|c|}
\hline CONCEPTOS & PUNTAUE \\
\hline Muy bueno & 5 \\
\hline Bueno & 4 \\
\hline Normal & 3 \\
\hline Malo & 2 \\
\hline Pésimo & 1 \\
\hline
\end{tabular}

Luego de efectuar el cuadro comparativo de los 4 distritos evaluados, la empresa SENIOR CARE, llega a la conclusión que la oficina administrativa y gestión operacional será en 
el distrito de San Borja, por ser un distrito con mayor puntaje (85\%) y por encontrarse en zonas comerciales y donde hay mayor afluencia de público.

Figura $\mathrm{n}^{\circ}$ 23: Vista interna de la oficina SENIOR CARE (Fuente: Elaboración propia)

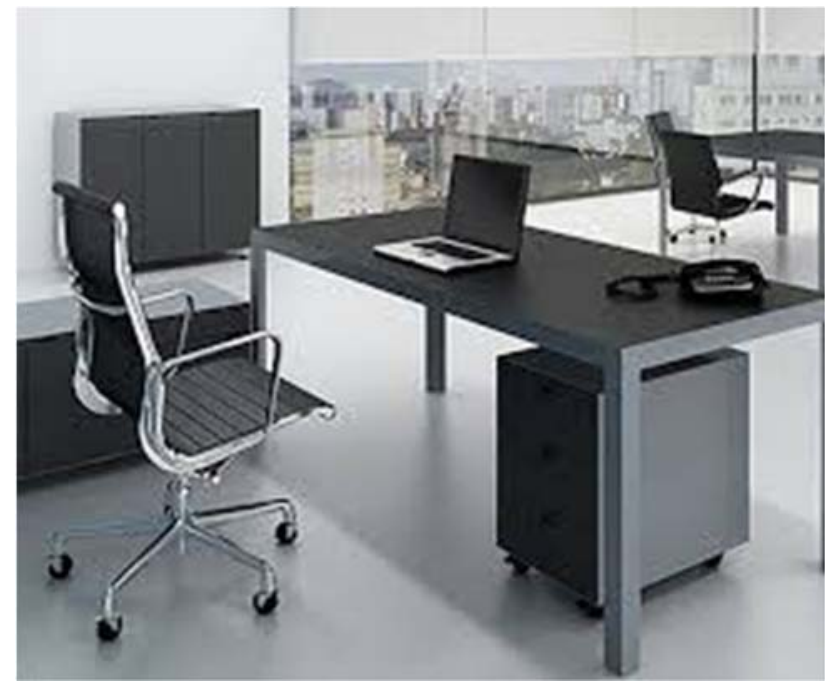

Figura $n^{\circ} 24:$ Vista interna de las oficinas administrativas (Fuente: Elaboración propia)

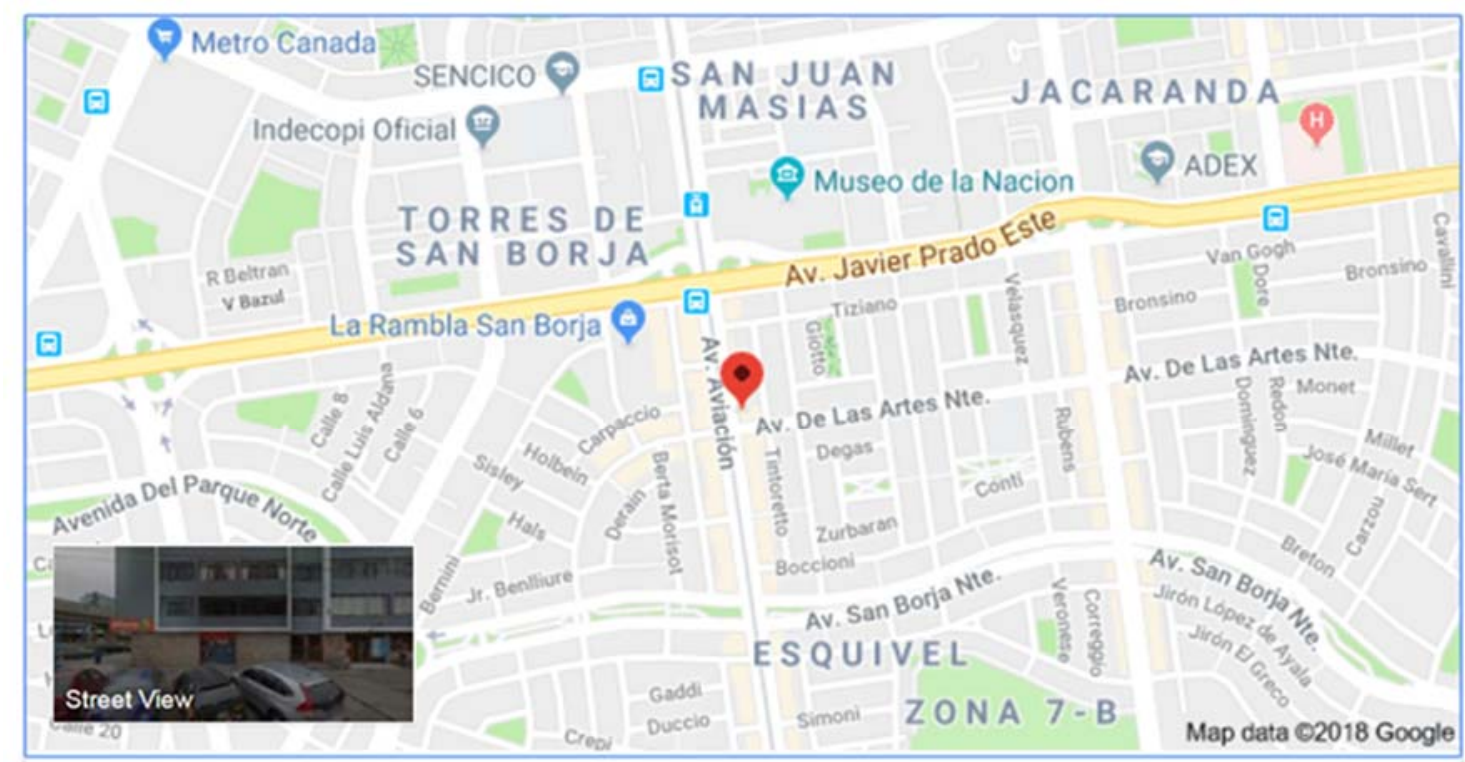

Av. De Las Artes Nte. 509

\subsubsection{Capacidad de las instalaciones}

La empresa SENIOR CARE, contará con una oficina alquilada para iniciar sus actividades propias de la empresa, que permitirá contar con la selección de personal, comunicaciones, para ellos se contará con los siguientes materiales de oficina. 
- 03 Escritorios de oficina

- 03 Computadoras portátil

- 01 Mesa mediana para reuniones

- 02 silla ergonómicas

- 01 Pizarra acrílica

- Materiales de oficina

- 01 Televisores 50" LED

- 01 Proyector para las presentaciones

- 02 Estantes de oficinas

- 10 silla de oficina para la mesa de reuniones

\subsubsection{Distribución de las instalaciones}

La empresa SENIOR CARE, se una empresa encargada de brindar servicios profesionales para el cuidado del adulto mayor, por lo que las enfermeras cuentan con un trabajo en otros puntos y estarán disponibles en el momento que se encuentren libres de otros centros de trabajos para poder cubrir la demanda.

Por ello, solo se necesitará el área administrativa, siendo el punto central para las gestiones administrativas del negocio y coordinaciones operacionales, ya que todo se hará a través del App.

El personal de marketing, operacional y apoyo podrá trabajar en la sala de reuniones, es decir, podrán acomodarse según vaya incrementado el giro del negocio. 
Figura $\mathrm{n}^{\circ} 25$ : Vista interna de la oficina SENIOR CARE (Fuente: Elaboración propia)

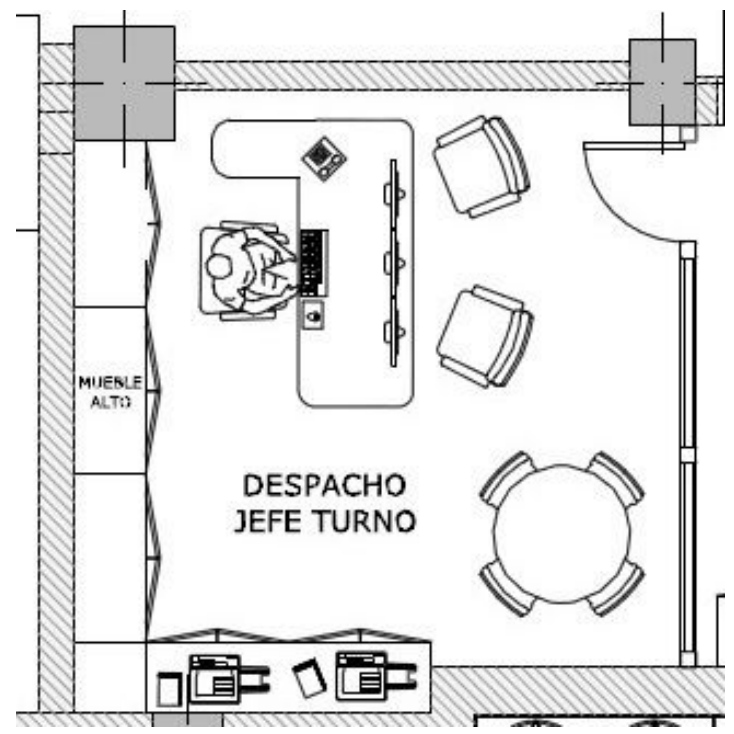

\subsection{Especificaciones Técnicas del Producto / Servicio}

\begin{tabular}{|c|c|}
\hline \multicolumn{2}{|r|}{ FICHA TÉCNICA DEL SERVICIO } \\
\hline EMPRESA & SENIOR CARE \\
\hline $\begin{array}{l}\text { Nombre del servicio } \\
\text { solicitado }\end{array}$ & Acompañamiento adulto mayor \\
\hline $\begin{array}{l}\text { Descripción } \\
\text { detallada del servicio }\end{array}$ & $\begin{array}{l}\text { El servicio profesional técnico de enfermeras especialistas en } \\
\text { geriatría a domicilio para cuidado y atención del adulto } \\
\text { mayor. }\end{array}$ \\
\hline Usuario final & $\begin{array}{l}\text { Familiares que cuentan con un adulto mayor en casa, puede } \\
\text { estar sano o con alguna enfermedad. }\end{array}$ \\
\hline Proceso operativo & $\begin{array}{l}\text { Se efectuará un registro inicial con los datos del usuario, } \\
\text { correo, nro. DNI, teléfono, datos de su familiar adulto } \\
\text { mayor, situación actual de salud, edad, horarios y fechas que } \\
\text { requiere el servicio, finalmente buscará el perfil del } \\
\text { profesional técnico de enfermeras que más se acomode a sus } \\
\text { necesidades, así como la forma de pago para cancelar el } \\
\text { servicio. }\end{array}$ \\
\hline Tiempos de espera & $\begin{array}{l}\text { Los tiempos de espera es en forma inmediata, debido que se } \\
\text { cuenta con técnicas enfermeras disponibles, las } 24 \text { horas, y/o } \\
\text { programar su cita cuando lo requiera. }\end{array}$ \\
\hline
\end{tabular}




\begin{tabular}{|c|l|}
\hline $\begin{array}{c}\text { Cargo del personal } \\
\text { responsable del } \\
\text { servicio }\end{array}$ & $\begin{array}{l}\text { Una técnica enfermera según la solicitud del cliente (con } \\
\text { nombre propio), quién se hará cargo del servicio a domicilio, } \\
\text { brindando un atención empática con el cliente y están } \\
\text { dispuesta a disolver cualquier problema de los usuarios. }\end{array}$ \\
\hline Horarios de atención & $\begin{array}{l}\text { Técnicas: en los turnos de } 3,6 \text { y } 12 \text { horas, incluidos los } \\
\text { sábados y domingos. }\end{array}$ \\
\hline $\begin{array}{c}\text { Registro de las } \\
\text { atenciones } \\
\text { efectuadas }\end{array}$ & $\begin{array}{l}\text { Se tiene un registro de atención de cada adulto mayor, donde } \\
\text { el cliente, puede visualizar a través del app o web, con su } \\
\text { usuario y contraseña, ahí podrá ver las anotaciones de las } \\
\text { enfermeras sobre la atención recibida a su familiar adulto } \\
\text { mayor y si presenta alguna dificultad. }\end{array}$ \\
\hline
\end{tabular}

\subsubsection{Diseño del App SENIOR CARE}

Figura ${ }^{\circ}$ 26: Diseño del App SENIOR CARE (Fuente: Elaboración propia)
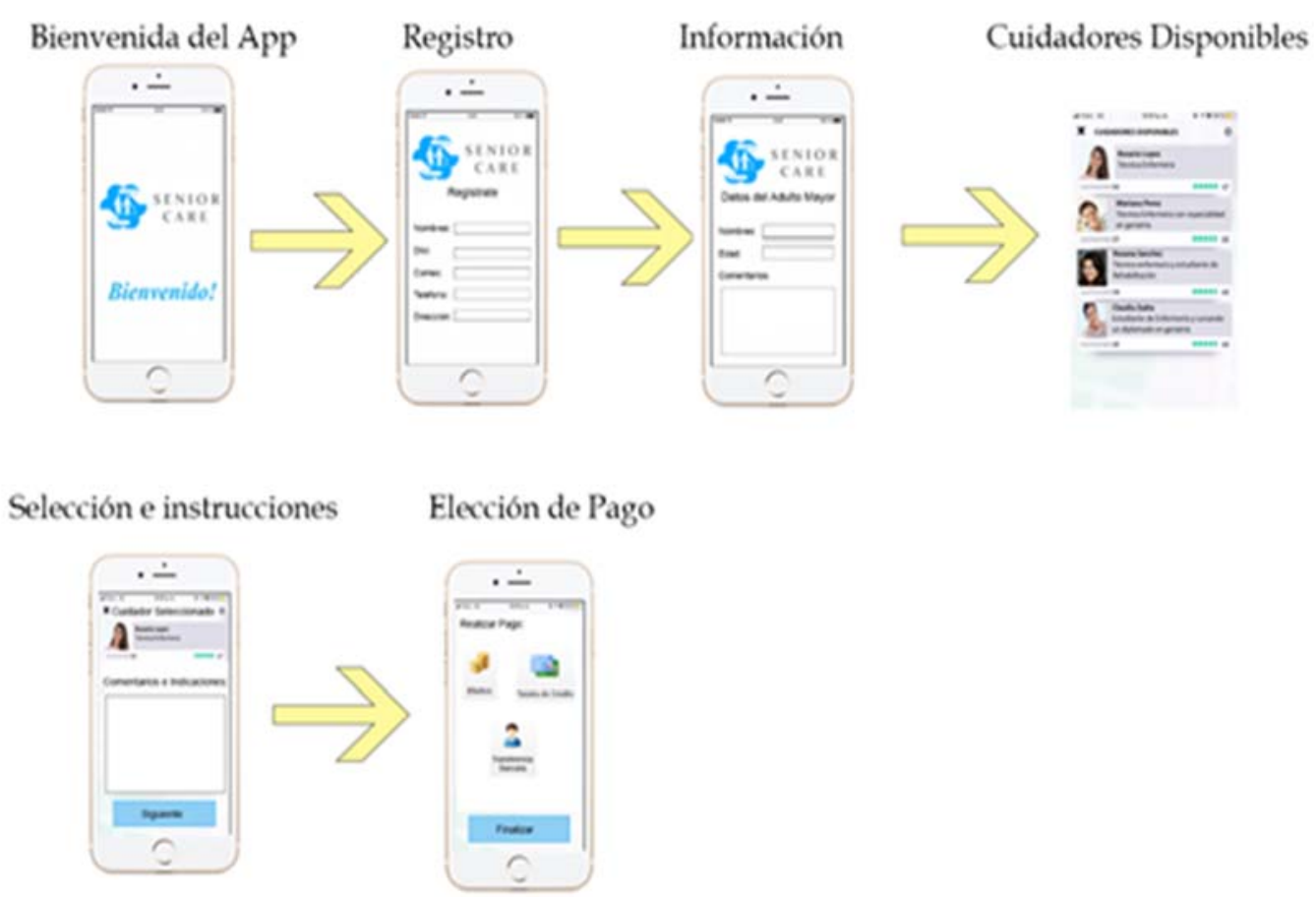


\subsubsection{Diseño de la web SENIOR CARE}

Figura $n^{\circ}$ 27: Página web (Fuente: Elaboración propia)

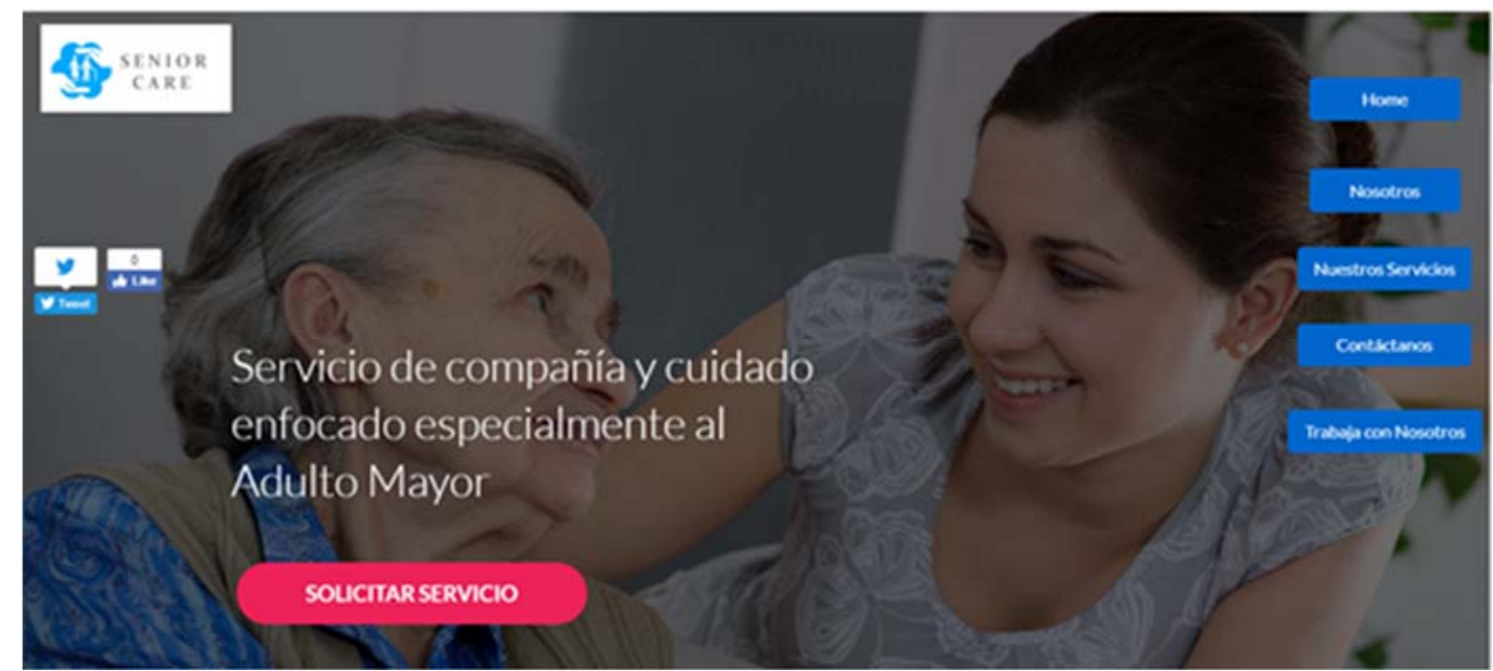

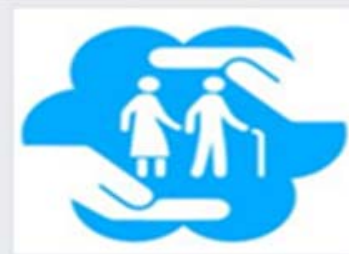

Senior Care

cseniorcareperu

Inicio

Publicaciones

Opiniones

Fotos

Informacion

Comunidad

Crear una pdigina

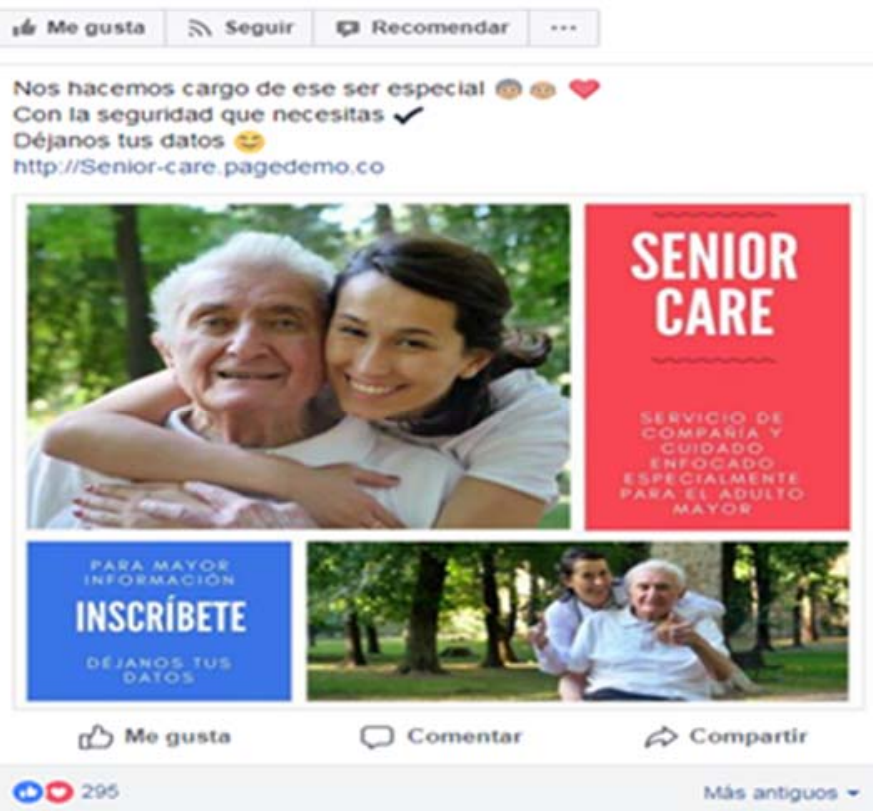




\subsubsection{Especificaciones técnicas del App}

ESPECIFICACIONES TÉCNICAS DE APP O APUICATIVO WEB

Android

iOs

\begin{tabular}{|c|c|c|}
\hline \multicolumn{3}{|c|}{ CARACTERISTICAS BASICAS } \\
\hline Codigo sistema & Sistema de codigo abierto & Sistema de código cerrado \\
\hline Adaptabilidad & $\begin{array}{l}\text { Versatil, a pantallasy resoluciones, y } \\
\text { terminales que existen en el mercado }\end{array}$ & $\begin{array}{l}\text { Es un sistema A pple Inc., los sistema para } \\
\text { computadoras de Apple basod en Unix. }\end{array}$ \\
\hline Nucleo del sistema & Kernel de Linux & Unix \\
\hline Almacenamiento datos & Utiliza SQLite para datos & $\begin{array}{l}\text { No permite instalación de datos de } \\
\text { hardware a terceros }\end{array}$ \\
\hline Navegador & Web basado Webkit incluido & $\begin{array}{l}\text { Sistema privado, solo por desarrol ladores } \\
\text { de apps. }\end{array}$ \\
\hline Soporte & HTML, HTML5, Adobe Flas Player etc & $\begin{array}{l}\text { Se necesita jailbreak para poder instalar } \\
\text { aplicaciones a terceros. }\end{array}$ \\
\hline Tools & herramientas, para memoria, sonido & $\begin{array}{l}\text { Laversion iOS } 8 \text {, ya permite uso de adobe } \\
\text { flash, pero debe estar actualizada. }\end{array}$ \\
\hline \multicolumn{3}{|c|}{ TERMINALESY DISPOSITIVOS MOVILES } \\
\hline Tipos de dispositivos & Nexus & \multirow{2}{*}{$\begin{array}{l}\text { Solo entre el los se puede ejecutar el } \\
\text { sistema operativo iOs. }\end{array}$} \\
\hline & Samsung & \\
\hline & Sony & iPhone 4, 5, 6 etc \\
\hline & Huawey & iPad, iP admini \\
\hline & etc & iPod nano, iPod shuffle \\
\hline Desarrollo app en android & \begin{tabular}{|l|} 
Se deberá de genera un app estándar para \\
asegurar su visibilidad y uso
\end{tabular} & \\
\hline \multicolumn{3}{|c|}{ HERRAMIENTAS NECESARIAS } \\
\hline Desarrollo app & Mirosof window & Kit de desarrollo SDK \\
\hline & $\operatorname{Mac} \mathrm{OS} \mathrm{X}$ & Aplicaciones Iphone \\
\hline & Linux & ipod Touch \\
\hline & Aplicaciones android & Xcode (programa para Iphone SDK) \\
\hline & Bibliotecas en lenguaje C & Aplicaciones \\
\hline & Emulador Android & Iphone simultar (develover program) \\
\hline \multicolumn{3}{|c|}{ COSTO PARA DESARROLLO APP (dólares) } \\
\hline Licencia & 25 & 99 \\
\hline Dispositivo móvil estandar & 536 & 639 \\
\hline Ordenador & 350 & 549 \\
\hline Costo aproximado dólares & $\$ 911.00$ & $\$ 1,287.00$ \\
\hline
\end{tabular}

Fuente de caracteristicastecnicas de app

https//www.yeeply.com/blog/desarrollo-de-aplicaciones-moviles-bases-tecnicas/

https//www.oanda.com/lang/es/currency/converter/

Fuente tipo de cambio de euro a dólar

\subsection{Especificaciones Técnicas del Producto / Servicio}

A continuación, se presenta el mapa de procesos de la empresa SENIOR CARE: 
Figura $n^{\circ} 28$ : Mapa de procesos (Fuente: Elaboración propia)

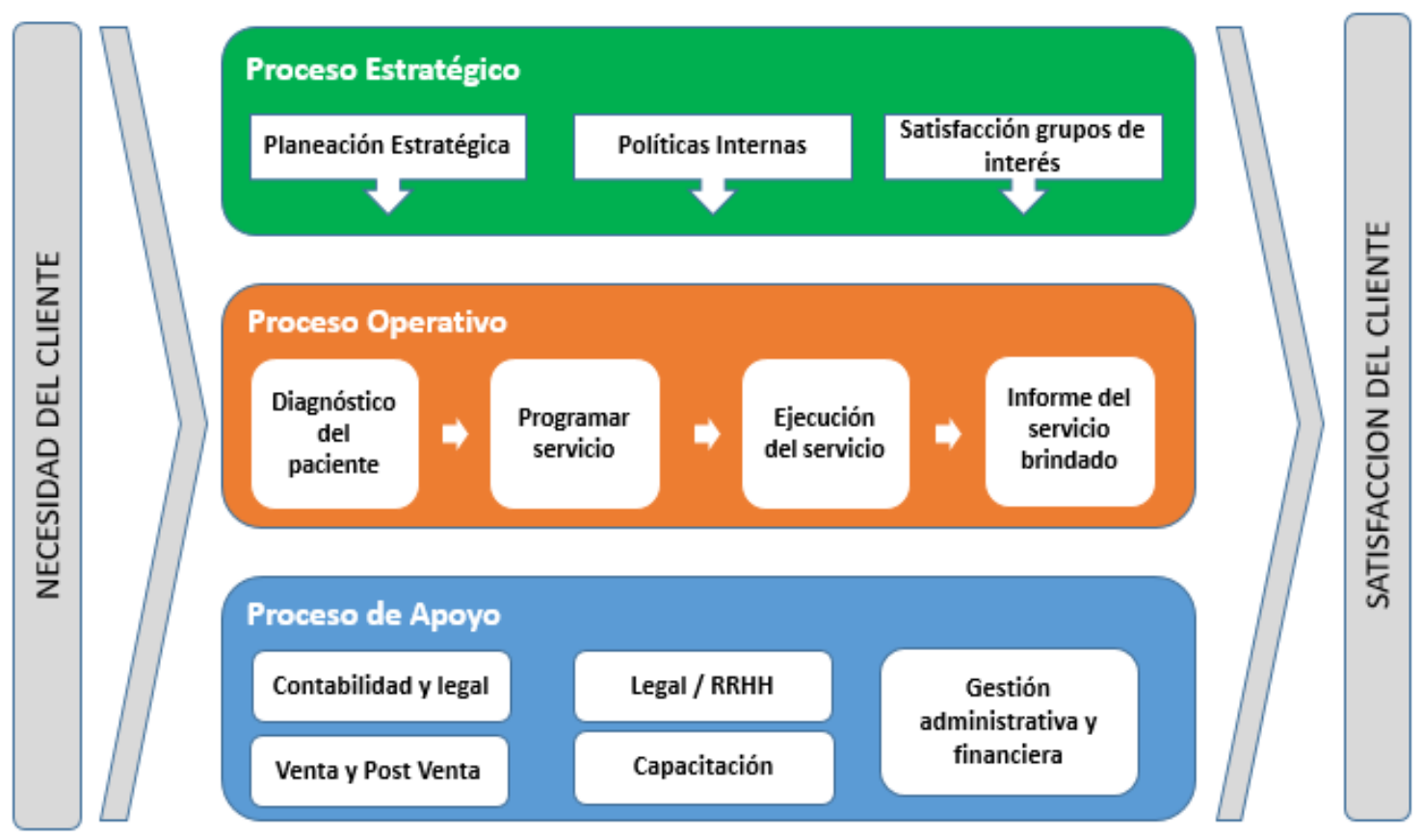

\section{Mapa de procesos}

El mapa de proceso diseñado, cuenta con tres pilares fundamentales en SENIOR CARE, la propuesta de valor a entregar al cliente, las operaciones del negocio, y las necesidades del cliente requiere. Asimismo, este mapa de procesos cuenta con tres grandes definiciones de procesos: los procesos estratégicos, proceso operativo, y proceso de soporte, todas ellas, van a desarrollar una función específica en la cadena de valor del negocio. La misma que deberá de cumplirse a fin de llegar a alcanzar los objetivos planteados y obtener la satisfacción del cliente, para fidelizarlo y obtener nuevos clientes.

Nuestro mapa de procesos se encuentra comprendido de la siguiente manera:

Proceso Estratégico: Todas las decisiones del negocio son ejecutadas por los directivos de la empresa, los socios, gerentes o administradores, para la mejor toma de decisiones que permita incrementar los ingresos a través de los activos o patrimonios de los accionistas, llevándose a cabo las inversiones del capital. Todo ello, con la finalidad de contar con los recursos humanos y materiales en forma eficiente y eficaz.

Dentro de las políticas de la empresa, para iniciar las operaciones, se deberá ser austero y de bajos costos, posteriormente se podrá seguir invirtiendo de acuerdo a la demanda alcanzada. 
Por ello, todo tipo de publicidad y marketing del negocio será minuciosamente analizado por los directivos, a fin de evitar cualquier publicidad engañosa o desacreditar a la empresa, que nos llevará al fracaso. Se tendrá una buena comunicación con los proveedores y clientes para el buen funcionamiento del negocio en forma normal.

Proceso Operativo: Está dirigido a cumplir con los objetivos principales de los demás procesos. Dentro de estos procesos, el proceso operativo es el corazón del negocio, donde se debe tomar en cuenta los detalles para iniciar las actividades con normalidad. El servicio de acompañamiento de adulto mayor, revisión de pruebas de la app, web, fan page deberán ser uniformes y llegar a mostrar una sola idea al cliente, mantenimiento de las plataformas de web, inversión en el uso de tecnologías a fin de ser más versátil para el cliente.

Proceso de Soporte: Toda empresa va requerir el soporte de otras áreas para el funcionamiento de los demás procesos, llevando a cabo las funciones específicas del negocio. Este proceso va estar ligado a la experiencia del cliente interno, y externo, cubrir las necesidades, con el área administrativa que verá la contratación del proveedor de selección de enfermeras, así como, el área financiera quien velará el cumplimiento de las operaciones económicas y financieras de la empresa, pago de impuestos según las normas legales vigentes.

A continuación, se presenta los siguientes diagramas de flujo de los procesos de servicio de requerimiento de solicitud y proceso de pago. 
Figura $n^{\circ} 29$ : Flujo de procesos (Fuente: Elaboración propia)
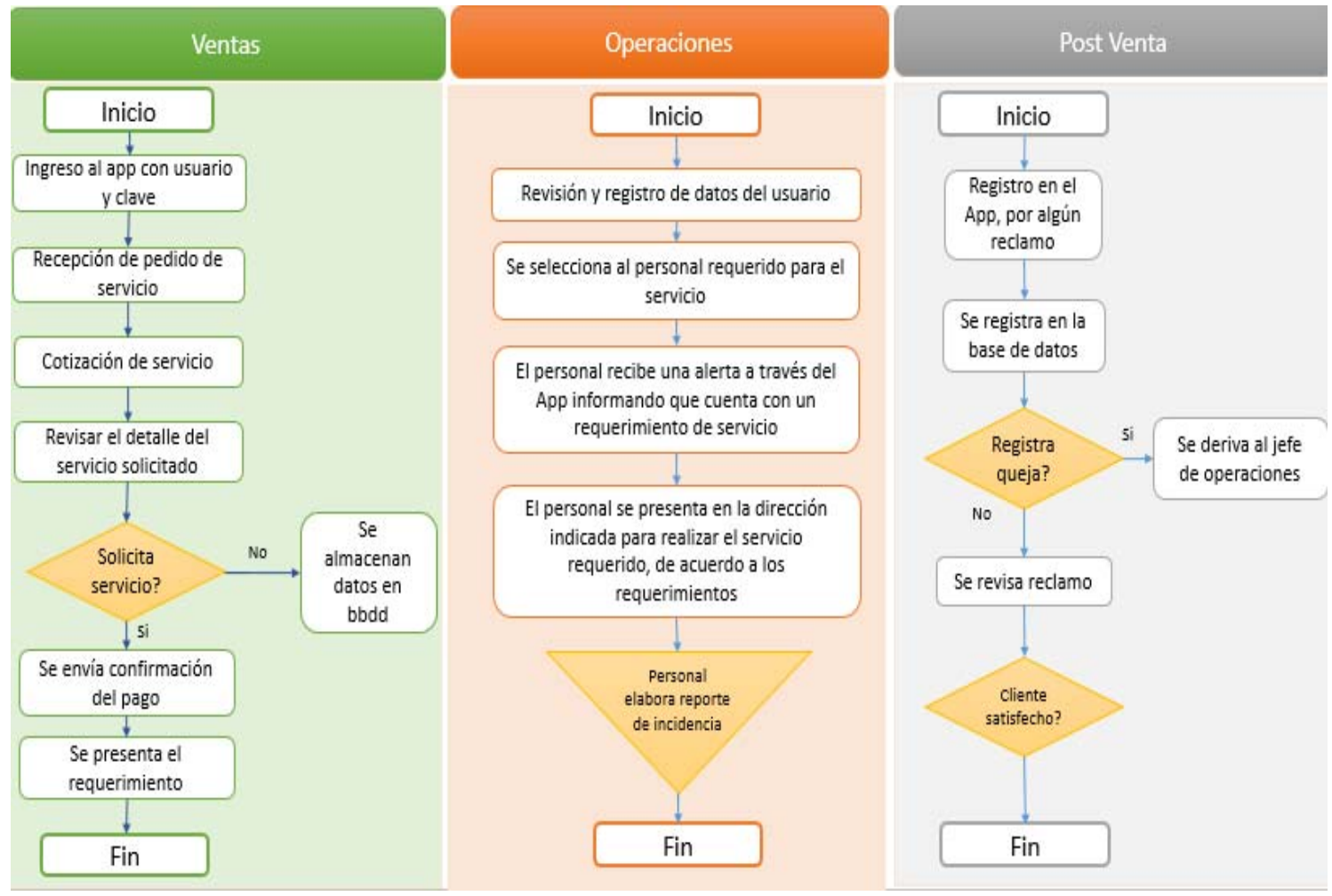

Se ha elaborado el diagrama de PERT que nos brindará los tiempos para iniciar las operaciones de la empresa:

Figura $\mathrm{n}^{\circ}$ 30: Tabla de actividades de la empresa (Fuente: Elaboración propia)

\begin{tabular}{|c|c|l|c|}
\hline & $\begin{array}{c}\text { Activiad } \\
\text { preodente }\end{array}$ & \multicolumn{1}{|c|}{ Actividades } & $\begin{array}{c}\text { Duraciónen } \\
\text { dias }\end{array}$ \\
\hline A & - & Elaboración y planificación de desarrollo del neg ocio & 8 \\
\hline B & A & Desarrollo del APP y web & 3 \\
\hline C & A & Formulación y elaboración del phan de Marke ting y publicidad & 12 \\
\hline D & A & Lanzamiento de inicio de plan de Marke ting y publicidad & 8 \\
\hline E & B,C & Protocolos previo al inicio del servicio & 6 \\
\hline F & E & Formulación de servicios a los clientes & 6 \\
\hline G & A & Asignación de inventarios de oficina & 4 \\
\hline H & F & Instalar los sistemas operativos de la back office & 2 \\
\hline & & Inicio de las operacions de SENIOR CARE & 27 \\
\hline
\end{tabular}


Figura $n^{\circ}$ 31: Diagrama PERT (Fuente: Elaboración propia)

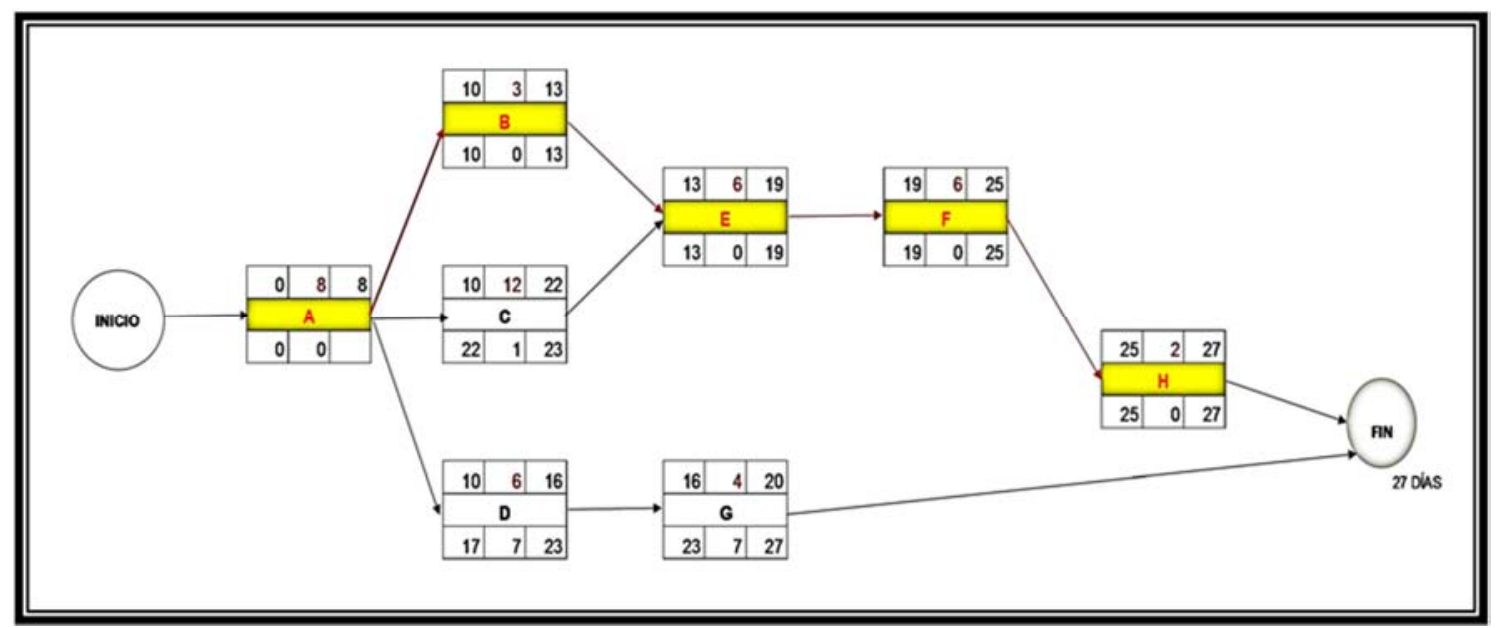

Para iniciar el negocio se tomará 27 días, teniendo como rutas críticas, las actividades de A, B, E, F y H.

\subsection{Especificaciones Técnicas del Producto / Servicio}

\subsubsection{Gestión de compras y stock}

No aplica

\subsubsection{Gestión de la calidad}

Se requiere realizar constantemente capacitaciones o feed back para los acompañantes calificados de la empresa con personas especializadas en geriatría, de tal manera que el personal pueda adquirir nuevos conocimientos para dar un servicio óptimo al cliente. 


\subsection{Inversión en activos fijos vinculados al proceso productivo}

Tabla $n^{\circ}$ 19: Inversión en activos fijos (Fuente: Elaboración propia)

\begin{tabular}{|c|c|c|c|}
\hline \multicolumn{4}{|c|}{ ACTIVOS FIJOS TAGIBLES } \\
\hline Equipos Informaticos & Unidades & Costo Unitario & Costo Total \\
\hline Computadoras portátil & 3 & $1,500.00$ & $4,500.00$ \\
\hline Impresora & 1 & 800.00 & 800.00 \\
\hline Televisor 50" Led & 1 & $2,500.00$ & $2,500.00$ \\
\hline \multirow[t]{2}{*}{ Proyec tor para presentaciones } & 1 & $1,800.00$ & $1,800.00$ \\
\hline & & SUB TOTAL & $9,600.00$ \\
\hline Muebles de oficina & Unidades & Costo Unitario & Costo Total \\
\hline Escritorio de ofic ina & 3 & $1,100.00$ & $3,300.00$ \\
\hline Mesa de reuniones & 1 & $3,500.00$ & $3,500.00$ \\
\hline Sillas ergonomic as & 3 & $2,400.00$ & $7,200.00$ \\
\hline Pizarra acrilica & 1 & $1,200.00$ & $1,200.00$ \\
\hline Estantes de oficina & 2 & 700.00 & $1,400.00$ \\
\hline \multirow[t]{2}{*}{ Sillas para reuniones } & 10 & 250.00 & $2,500.00$ \\
\hline & & SUB TOTAL & $19,100.00$ \\
\hline & & & \\
\hline TOTAL ACTIVOS & FIJOS TANC & BLES & $28,700.00$ \\
\hline
\end{tabular}

\subsection{Estructura de costos de producción y gastos operativos}

Para el desarrollo del proyecto se determinó que nuestra oficina se ubicará en el distrito de San Borja lo cual genera un gasto de alquiler de s/ 2500 donde realizaremos nuestras operaciones.

La planilla que hemos considerado es de 7 personas operativas para el desarrollo de funciones administrativas y tareas operativa.

A continuación, procederemos a detallar la planilla mensual y nuestros gastos operativos: 
Tabla $\mathrm{n}^{\circ}$ 20: Estructura de costos de producción y gastos operativos (Fuente:

Elaboración propia)

Personal en Planilla

\begin{tabular}{|c|c|c|c|c|c|c|}
\hline Puesto & $\mathrm{N}^{\circ}$ de Persona & Suelc & $\begin{array}{l}\text { do mensual } \\
\text { (soles) }\end{array}$ & $\begin{array}{l}\text { Sueldo Bruto } \\
\text { (Anual en soles) }\end{array}$ & EsSalud (9\%) & Total Anual \\
\hline Gerente General & 1 & S/ & $3,000.00$ & S/ $36,000.00$ & S/ $3,240.00$ & $39,240.00$ \\
\hline Gerente de Finanzas & 1 & S/ & $2,500.00$ & $30,000.00$ & S/ $2,700.00$ & $32,700.00$ \\
\hline Gerente de Bienestar & 1 & S/ & $2,500.00$ & $30,000.00$ & S/ $2,700.00$ & $32,700.00$ \\
\hline Getente de Marketing & 1 & S/ & $2,500.00$ & $30,000.00$ & S/ $2,700.00$ & $32,700.00$ \\
\hline Jefe de Operaciones & 1 & S/ & $2,000.00$ & $24,000.00$ & S/ $2,160.00$ & $26,160.00$ \\
\hline Asistente de Ventas y Marke & 1 & S/ & 930.00 & $11,160.00$ & S/ $1,004.40$ & $12,164.40$ \\
\hline Practicante de Selección & 1 & S/ & 930.00 & S/ $\quad 11,160.00$ & S/ $1,004.40$ & S/ $\quad 12,164.40$ \\
\hline Total & 7 & s/ & $14,360.00$ & S/ $172,320.00$ & S/ $15,508.80$ & S/ $187,828.80$ \\
\hline
\end{tabular}

Servicio externo

\begin{tabular}{|l|c|cr|rr|}
\hline \multicolumn{1}{|c|}{ Puesto } & $N^{\circ}$ de Persona & \multicolumn{2}{|c|}{$\begin{array}{c}\text { Pago por } \\
\text { Servicio } \\
\text { (Mensual) }\end{array}$} & Total Anual \\
\hline Asesor contable & 1 & S/ & 700.00 & S/ & $8,400.00$ \\
\hline Asesor Legal & 1 & S/ & 900.00 & S/ & $10,800.00$ \\
\hline Total & $\mathbf{2}$ & S/ & $\mathbf{1 , 6 0 0 . 0 0}$ & S/ & $\mathbf{1 9 , 2 0 0 . 0 0}$ \\
\hline
\end{tabular}

\begin{tabular}{|c|c|c|c|}
\hline GASTOS OPERATIVOS MENSUALES & \multicolumn{2}{|c|}{ MENSUAL } & ANUAL \\
\hline Alquiler de oficina & S/ & $2,500.00$ & $30,000.00$ \\
\hline Publicidad & S/ & $2,000.00$ & S/ $24,000.00$ \\
\hline Agua & S/ & 230.00 & $2,760.00$ \\
\hline Luz & S/ & 350.00 & $4,200.00$ \\
\hline Paquete internet y telfono & S/ & 260.00 & $3,120.00$ \\
\hline Seguro & S/ & 500.00 & $6,000.00$ \\
\hline Lineas de celulares $* 4$ & S/ & 210.00 & $2,520.00$ \\
\hline Mantenimiento pag web(100 euros) & S/ & 385.00 & $4,620.00$ \\
\hline Uso de servidor & S/ & 530.00 & $6,360.00$ \\
\hline Licencia de sofware (USD 2,198) & S/ & $7,187.46$ & S/ $86,249.52$ \\
\hline Total & S/ & $14,152.46$ & S/ $169,829.52$ \\
\hline
\end{tabular}




\section{CAPITULO 7: ESTRUCTURA \\ ORGANIZACIONAL Y RECURSOS HUMANOS}

\subsection{Objetivos Organizacionales}

Nuestros objetivos organizacionales van enfocados a nuestra propuesta de valor que deseamos brindar al adulto mayor, donde buscamos mantenerlos integrados en la comunidad de una forma segura y darle el apoyo necesario para que puedan realizar sus actividades diarias de la manera más independiente con una adecuada supervisión de su salud, con referencia al familiar directo que contratará nuestros servicios buscamos brindarle un accesos rápido a una plataforma virtual donde podrá encontrar personal especializado en el cuidado del adulto mayor.

- Generar la cultura de servicio hacia nuestros clientes finales.

- Mantener como parte del staff a los mejores profesionales.

- Desarrollar una red de especialistas en el cuidado del adulto mayor que estén altamente capacitados y brinden un servicio de alta calidad.

- Contar con los mejores canales de conexión entre nuestros clientes y los especialistas.

- Crear lazos entre nuestra empresa con los familiares directos.

- Mantener nuestra plataforma virtual amigable y eficiente para nuestros clientes.

\subsection{Naturaleza de la Organización}

SENIOR CARE es una empresa fundada por cuatro socios, la cual tendrá la denominación SAC (Sociedad Anónima Cerrada).

La empresa estará conformada por 7 personas en planilla: 1 gerente general, 4 gerentes (Gerente de Finanzas, Gerente de Bienestar, Gerente de Administración y Gerente de Marketing), 1 Practicante de RRHH, 1 Asistente de marketing y ventas y como parte de nuestras áreas de staff contaremos con un asesor contable y un asesor legal. Los especialistas serán prestadores de servicios que emitirán recibos por honorarios. 


\subsubsection{Organigrama}

El tipo de organigrama que se maneja en SENIOR CARE será jerárquico vertical.

Figura $n^{\circ} 32$ : Organigrama (Fuente: Elaboración propia)

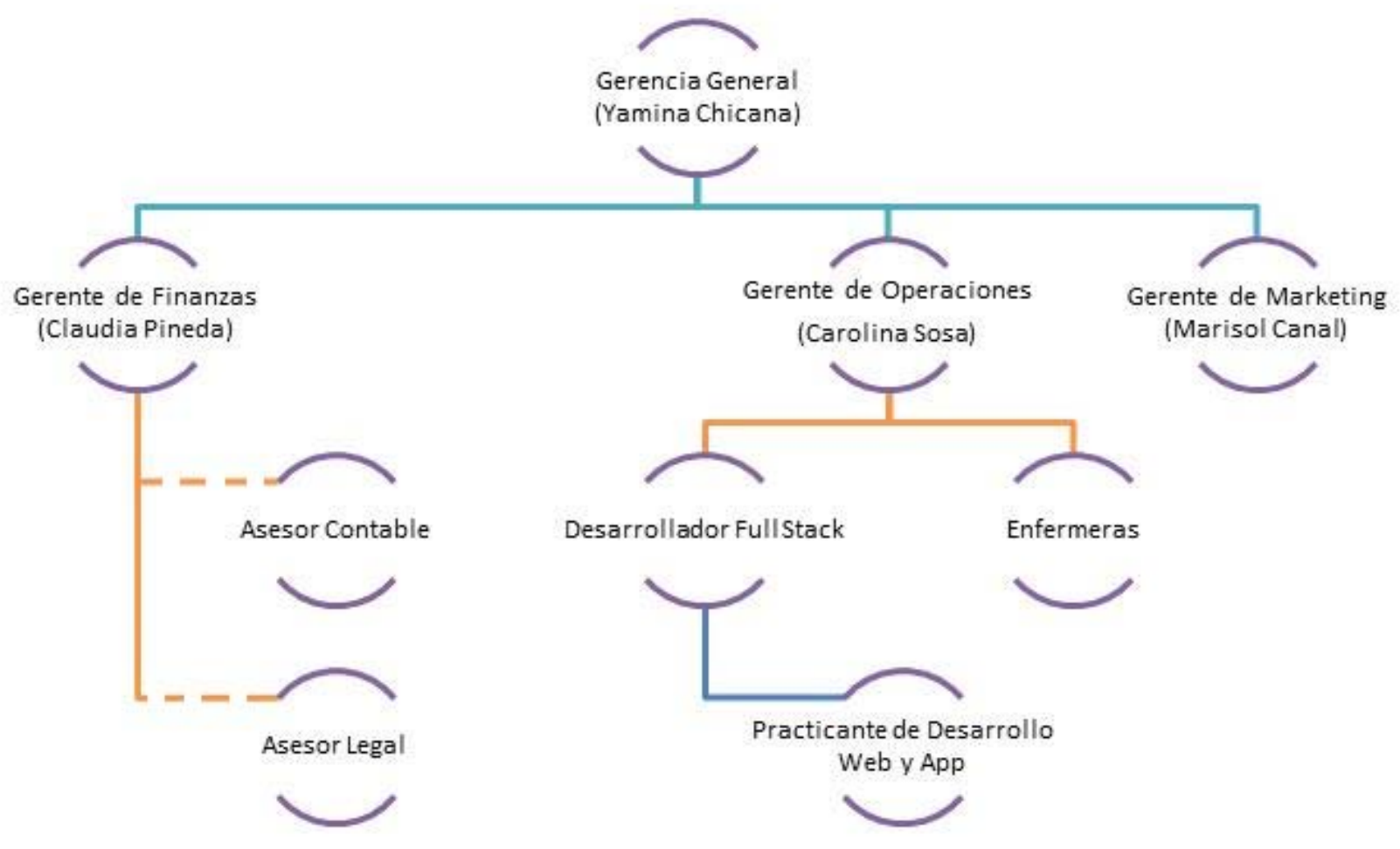

\subsubsection{Diseño de Puestos y Funciones}

Puesto: $\quad$ Gerente General 
DESCRIPCION DEL PUESTO

\begin{tabular}{|c|c|c|}
\hline NOMBRE DEL PUESTO & \multicolumn{2}{|l|}{ GERENTE GENERAL } \\
\hline PAIS & \multicolumn{2}{|l|}{ PERÚ } \\
\hline SUPERVISARA A & \multicolumn{2}{|l|}{ RELACION DIRECTA CON GERENTES DE ÁREAS } \\
\hline \multicolumn{3}{|c|}{ MISION DEL PUESTO } \\
\hline \multicolumn{3}{|c|}{$\begin{array}{l}\text { Responsable de planificar, dirigir y supervisar todos los recursos de la empresa. Así como también velar por la } \\
\text { rentabilidad del negocio e implementar acciones que permitan alcanzar los objetivos de la empresa. }\end{array}$} \\
\hline \multicolumn{3}{|c|}{ PRINCIPALES FUNCIONES } \\
\hline \multicolumn{3}{|c|}{ Representar legalmente a la empresa } \\
\hline \multicolumn{3}{|c|}{ Dirigir, coordinar y controlar los sistemas de tesorería, contabilidad y personal. } \\
\hline \multicolumn{3}{|c|}{ Programar y dirigir las actividades propias de los sistemas administrativos. } \\
\hline \multicolumn{3}{|c|}{ Supervisar el cumplimiento de las normas y procedimientos de las diferentes áreas. } \\
\hline \multicolumn{3}{|c|}{ Las demás funciones afines a su cargo. } \\
\hline \multicolumn{3}{|c|}{ II. PERFIL DEL PUESTO } \\
\hline Competencias & Educación & Experiencia \\
\hline $\begin{array}{l}\text { Capacidad de planificación y } \\
\text { organización }\end{array}$ & $\begin{array}{l}\text { Título Profesional Universitario que incluya } \\
\text { estudios relacionados con la especialidad. }\end{array}$ & \multirow{3}{*}{$\begin{array}{l}3 \text { años o más en puestos } \\
\text { similares }\end{array}$} \\
\hline Orientación a los resultados & \multirow{2}{*}{ Cursos de especialización en finanzas } & \\
\hline Liderazgo & & \\
\hline
\end{tabular}

Puesto: Gerente de Finanzas

\section{DESCRIPCION DEL PUESTO}

\begin{tabular}{|l|l|}
\hline NOMBRE DEL PUESTO & GERENTE DE FINANZAS \\
\hline PAIS & PERÚ \\
\hline REPORTA A & GERENTE GENERAL \\
\hline SUPERVISARAA & ASESOR CONTABLE Y ASESOR LEGAL \\
\hline
\end{tabular}

\section{MISION DEL PUESTO}

Gestionar y administrar las finanzas de la empresa, asesorar en la viabilidad financiera de otros proyectos

Administrar el proceso contable de la empresa

Proponer políticas generales relacionados con la gestión financiera

Proponer políticas contables, financieras, crediticias

Coordinar y evaluar alternativas de financiamiento para las activadades que la empresa desarrolle Proveer los reportes contables, financieros de acuerdo a los requerimientos de la gerencia

Las demás funciones a fines a su cargo que le sean asignadas por el gerente general

\begin{tabular}{|c|c|c|}
\hline \multicolumn{3}{|c|}{ II. PERFIL DEL PUESTO } \\
\hline Competencias & Educación & Experiencia \\
\hline Capacidad Analítica & Egresado o estudiante de últimos ciclos en & Mínimo 6 meses de experiencia en \\
\hline Creatividad & Marketing, Ingeniería Industral, Administración o & labores relacionadas \\
\hline Proactividad & afines & \\
\hline
\end{tabular}

Puesto: $\quad$ Gerente de Operaciones 


\section{DESCRIPCION DEL PUESTO}

\begin{tabular}{|l|l|}
\hline NOMBRE DEL PUESTO & JEFE DE OPERACIONES \\
\hline PAIS & PERÚ \\
\hline \multicolumn{2}{|l|}{} \\
\hline REPORTAA & GERENTE GENERAL \\
\hline SUPERVISARAA & ENFERMERAS \\
\hline
\end{tabular}

MISION DEL PUESTO

Manejar las operaciones diarias de la empresa. Proveer métodos efectivos para las operaciones de la empresa.

\section{PRINCIPALES FUNCIONES}

Supervisar y aprobar las instrucciones operativas.

Supervisar que los servicios se brinden de una manera óptima y eficiente.

Controlar la relación entre paciente - enfermera

Controlar que los procesos se brinden de acuerdo a las políticas de la empresa

Las demás funciones a fines a su cargo que le sean asignadas por el Gerente General

\begin{tabular}{|l|c|c|}
\hline \multicolumn{1}{|c|}{ Competencias } & \multicolumn{1}{|c|}{ II. PERFIL DEL PUESTO } \\
\hline $\begin{array}{l}\text { Capacidad de planificación y } \\
\text { organización }\end{array}$ & \multirow{2}{*}{$\begin{array}{c}\text { Título Profesional Universitario en Marketing, } \\
\text { Ingeniería Industral, Administración o afines }\end{array}$} & 3 años o más en puestos similares \\
\cline { 1 - 1 } Orientación a los resultados & & \\
\cline { 1 - 1 } Proactividad & &
\end{tabular}

Puesto: Gerente de Marketing

DESCRIPCION DEL PUESTO

\begin{tabular}{|l|l|}
\hline NOMBRE DEL PUESTO & GERENTE DE MARKETING \\
\hline PAIS & PERÚ \\
\hline REPORTA A & GERENTE GENERAL \\
\hline SUPERVISARA A & ASISTENTE DE VENTAS Y MARKETING \\
\hline
\end{tabular}

\section{MISION DEL PUESTO}

Planificar, organizar, dirigir, controlar y coordinar el sistema comercial, diseñando estrategias que permitan el logro de los objetivos empresariales

PRINCIPALES FUNCIONES

Definir, proponer, coordinar y ejecutar las políticas de comercialización orientadas al logro de una mayor y mejor posición en el mercado

Definir y proponer los planes de marketing, y venta de la empresa

Implementar un adecuado sistema de venta de servicios a cargo de la empresa y de terceros a

nivel nacional

Evaluar la creación de nuevos servicios identificando nuevas oportunidades de negocio. Controlar que los objetivos, planes y programas se cumplan en los plazos y condiciones

Establecer ventajas competitivas donde se ofrezcan servicios de la Empresa, procurando obtener las mejores participaciones en el mercado.

Las demás funciones a fines a su cargo que le sean asignadas por el gerente general

\begin{tabular}{|c|c|c|}
\hline \multicolumn{3}{|c|}{ II. PERFIL DEL PUESTO } \\
\hline Competencias & Educación & Experiencia \\
\hline Trabajo en equipo & Egresado o estudiante de últimos ciclos en & Mínimo 6 meses de \\
\hline Creatividad & Marketing, Ingeniería Industral, & experiencia en labores \\
\hline Proactividad & Administración o afines & relacionadas \\
\hline
\end{tabular}

Puesto: Asesor Contable 
DESCRIPCION DEL PUESTO

\begin{tabular}{|l|l|}
\hline NOMBRE DEL PUESTO & ASESOR CONTABLE \\
\hline PAIS & PERÚ \\
\hline \multicolumn{2}{|l|}{} \\
\hline REPORTA A & GERENTE DE FINANZAS \\
\hline SUPERVISARA A & NO APLICA \\
\hline
\end{tabular}

\section{MISION DEL PUESTO}

Elaborar y presentar trimestralmente los Estados financieros de la empresa, la cual es presentada al Gerente de Finanzas

\section{PRINCIPALES FUNCIONES}

Revisar reportes o estados financieros y demás documentos contables resultados de la gestión

Preparar y verificar la información contable de la empresa para fines tributarios

Elaboración de Reportes Gerenciales que faciliten la interpretación correcta de la información contable financiera

Las demás funciones a fines a su cargo que le sean asignadas por el Gerente de Finanzas

\begin{tabular}{|l|c|c|}
\hline \multicolumn{1}{|c|}{ Competencias } & Educación & \multicolumn{2}{c|}{ Experiencia } \\
\cline { 1 - 1 } Responsabilidad & \multirow{2}{*}{$\begin{array}{c}\text { Título Profesional Universitario en Marketing, } \\
\text { Ingeniería Industral, Administración o afines }\end{array}$} & $\begin{array}{c}3 \text { años o más en puestos } \\
\text { similares }\end{array}$ \\
\cline { 1 - 1 } Orientación a los resultados & & \\
\cline { 1 - 3 } Proactividad & &
\end{tabular}

Puesto: $\quad$ Asesor Legal

SENIOR CARE

\section{DESCRIPCION DEL PUESTO}

\begin{tabular}{|l|l|}
\hline NOMBRE DEL PUESTO & ASESOR LEGAL \\
\hline PAIS & PERÚ \\
\hline REPORTA A & GERENTE DE FINANZAS \\
\hline SUPERVISARA A & NO APLICA \\
\hline
\end{tabular}

\section{MISION DEL PUESTO}

Apoyar en los temas jurídico / legal al gerente de la empresa

\section{PRINCIPALES FUNCIONES}

Ejecutar labores de asesoría en los campos profesionales que requiera el Gerente Apoyar en la firma de contratos de la empresa

Asesor al Gerente General en el desarrollo de los procesos legales

Apoyar y absolver consultas de la gerencia, presentando alternativas de solución

Las demás funciones a fines a su cargo que le sean asignadas por el Gerente de Finanzas

\begin{tabular}{|c|c|c|}
\hline \multicolumn{3}{|c|}{ II. PERFIL DEL PUESTO } \\
\hline Competencias & Educación & Experiencia \\
\hline $\begin{array}{l}\text { Capacidad de planificación y } \\
\text { organización }\end{array}$ & \multirow{3}{*}{$\begin{array}{l}\text { Título Profesional Universitario en } \\
\text { Marketing, Ingeniería Industral, } \\
\text { Administración o afines }\end{array}$} & \multirow{3}{*}{$\begin{array}{c}3 \text { años o más en puestos } \\
\text { similares }\end{array}$} \\
\hline Orientación a los resultados & & \\
\hline Proactividad & & \\
\hline
\end{tabular}

Puesto: $\quad$ Enfermeras 
DESCRIPCION DEL PUESTO

\begin{tabular}{|c|c|}
\hline NOMBRE DEL PUESTO & ENFERMERAS \\
\hline PAIS & PERÚ \\
\hline REPORTAA & JEFE DE OPERACIONES \\
\hline SUPERVISARA A & NO APLICA \\
\hline
\end{tabular}

\begin{tabular}{|l|}
\hline \multicolumn{1}{|c|}{ MISION DEL PUESTO } \\
\hline Ofrecer servicios de acompañamiento a adultos mayores que necesitan supervisión o cuidado especial \\
\hline PRINCIPALES FUNCIONES \\
\hline Control de medicinas \\
\hline Apoyo en la higiene personal \\
\hline Ayuda en la alimentación \\
\hline Mantener en actividad al adulto mayor \\
\hline Atender con cariño y respeto al adulto mayor \\
\hline
\end{tabular}

\begin{tabular}{|l|c|c|}
\hline \multicolumn{2}{|c|}{ II. PERFIL DEL PUESTO } \\
\hline \multicolumn{1}{|c|}{ Competencias } & Educación & Experiencia \\
\hline Empatía & \multirow{2}{*}{ Técnico o Universitario Completo en Enfermería } & $\begin{array}{c}\text { Mínimo 1 año de expericiencia en } \\
\text { clínica u hospitales }\end{array}$ \\
\hline Habilidad en comunicación & & Proactividad
\end{tabular}

Puesto: Desarrollador FullStack

\section{DESCRIPCION DEL PUESTO}

\begin{tabular}{|l|l|}
\hline NOMBRE DEL PUESTO & DESARROLLADOR FULLSTACK \\
\hline PAIS & PERÚ \\
\hline REPORTA A & GERENTE DE OPERACIONES \\
\hline SUPERVISARA A & NO APLICA \\
\hline
\end{tabular}

\begin{tabular}{|l|}
\hline \multicolumn{1}{|c|}{ PRINCIPALES FUNCIONES } \\
\hline Desarrollo front-end para sitios web responsive \\
\hline Desarrollo front-end para aplicaciones web \\
\hline Implementación de pruebas en servidores \\
\hline Las demás funciones a fines a su cargo que le sean asignadas por gerencia \\
\hline
\end{tabular}

\begin{tabular}{|c|c|c|}
\hline \multicolumn{3}{|c|}{ II. PERFIL DEL PUESTO } \\
\hline Competencias & Educación & Experiencia \\
\hline Responsabilidad & \multirow{3}{*}{$\begin{array}{l}\text { Título Profesional Universitario en Ingeniería de } \\
\text { sistemas, informática o afines }\end{array}$} & \multirow{3}{*}{$\begin{array}{c}3 \text { años en desarrollo de } \\
\text { software }\end{array}$} \\
\hline Orientación a los resultados & & \\
\hline Proactividad & & \\
\hline
\end{tabular}

Puesto: $\quad$ Practicante de Desarrollo Web y App 


\section{DESCRIPCION DEL PUESTO}

\begin{tabular}{|l|l|}
\hline NOMBRE DEL PUESTO & PRACTICANTE DE DESARROLLO WEB Y APP \\
\hline PAIS & PERÚ \\
\hline
\end{tabular}

\begin{tabular}{|l|l|}
\hline REPORTA A & GERENTE DE OPERACIONES \\
\hline SUPERVISARA A & NO APLICA \\
\hline
\end{tabular}

\begin{tabular}{|l|}
\hline \multicolumn{1}{|c|}{ PRINCIPALES FUNCIONES } \\
\hline Implementar desarrollos en plataforma Android y IOS \\
\hline Diseñar nuevas funcionalidades basadas en requerimientos de usuario \\
\hline Dar mantenimiento a las aplicaciones web Implementar \\
\hline Apoyar en la administración de servicios web y móviles \\
\hline
\end{tabular}

\begin{tabular}{|c|c|c|}
\hline \multicolumn{3}{|c|}{ II. PERFIL DEL PUESTO } \\
\hline Competencias & Educación & Experiencia \\
\hline Responsabilidad & \multirow{3}{*}{$\begin{array}{c}\text { Estudiante, egresado, técnico o Bachiller en } \\
\text { ingeniería de sistemas, informática, industrial o } \\
\text { afines }\end{array}$} & \multirow{3}{*}{$\begin{array}{c}3 \text { años en desarrollo de } \\
\text { software }\end{array}$} \\
\hline Orientación a los resultados & & \\
\hline Proactividad & & \\
\hline
\end{tabular}

\subsection{Políticas Organizacionales}

\section{Política de horarios, permisos}

Horarios:

La jornada laboral del área administrativa será de lunes a viernes de 9:00 am a 6:00 pm, y los sábados de 9:00 am a 1:00 pm, debiendo marcar su asistencia de manera diaria.

El personal operativo no tendrá un horario fijo ya que podrán tener turnos las 24 durante los 7 días de la semana.

Permisos:

Se brindarán permisos especiales en los siguientes casos:

- Por fallecimiento del cónyuge, hijos, padres o familiar cercano, hasta 2 días calendario.

- Por matrimonio del trabajador hasta 2 días calendario. 
- Por nacimiento de un hijo.

\section{Política de remuneración:}

Los pagos al área administrativa se realizarán de manera mensual mediante depósito en cuenta de ahorros del trabajador.

Se realizarán los descuentos de ley, los cuales estarán indicados en la boleta de pago que será entregada cada fin de mes.

\section{Política de vestimenta:}

Todos los trabajadores deben mantener una apariencia e imagen profesional.

Es de uso obligatorio para las enfermeras portar uniforme durante los servicios que se les asigne, salvo por situaciones especiales o razones de fuerza mayor no fuera posible.

En el caso de las damas el aspecto correcto debe ser :

- Cabello peinado y recogido

- Maquillaje sencillo

- No usar accesorios muy llamativos

- Uñas cortas, limpias y con esmalte discreto

En el caso de los varones:

- Mantener el cabello corto y limpio

- Barba afeitada

- Uñas cortas y limpias

Figura $n^{\circ} 33$ : Uso correcto del uniforme (Fuente: Elaboración propia) 


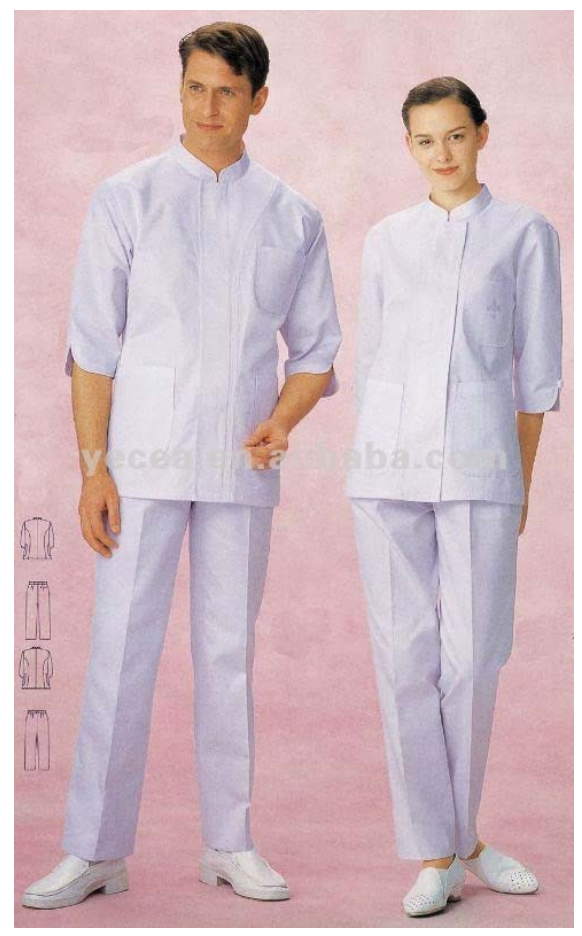

Política de confidencialidad de datos:

Con el fin de mantener la credibilidad de nuestros clientes nos basaremos en la Ley $\mathrm{N}^{\circ}$ 29733, el cual establece el derecho de mantener en privado los datos de los clientes, proveedores, socios y demás.

\subsection{Gestión Humana}

\subsubsection{Reclutamiento}

El proceso de reclutamiento del personal estará a cargo del Gerente de Operaciones.

\section{Requerimiento de personal}

\section{Gerente de cada área}

Solicitará el requerimiento de personal con la justificación respectiva, la cual debe de estar orientada a cubrir las necesidades de la empresa, y se puede solicitar por los siguientes motivos: 
- Para cubrir vacantes por renuncias y/o despidos.

- Para cubrir un cargo nuevo debido a cambios en la estructura de la organización.

\section{Gerente General}

Aprobará o rechazará el requerimiento del personal, y remitirá la solicitud al Gerente de Operaciones.

\section{Reclutamiento de personal}

El Gerente de Operaciones revisará los currículos recopilados de las bases de datos de las páginas de bolsa de empleo, y también de los documentos recepcionados físicamente.

\subsubsection{Selección, contratación e inducción}

El proceso de selección y contratación estará a cargo del Gerente de Operaciones, y el flujo será el siguiente:

Figura $n^{\circ} 34$ : Proceso de selección y contratación (Fuente: Elaboración propia)

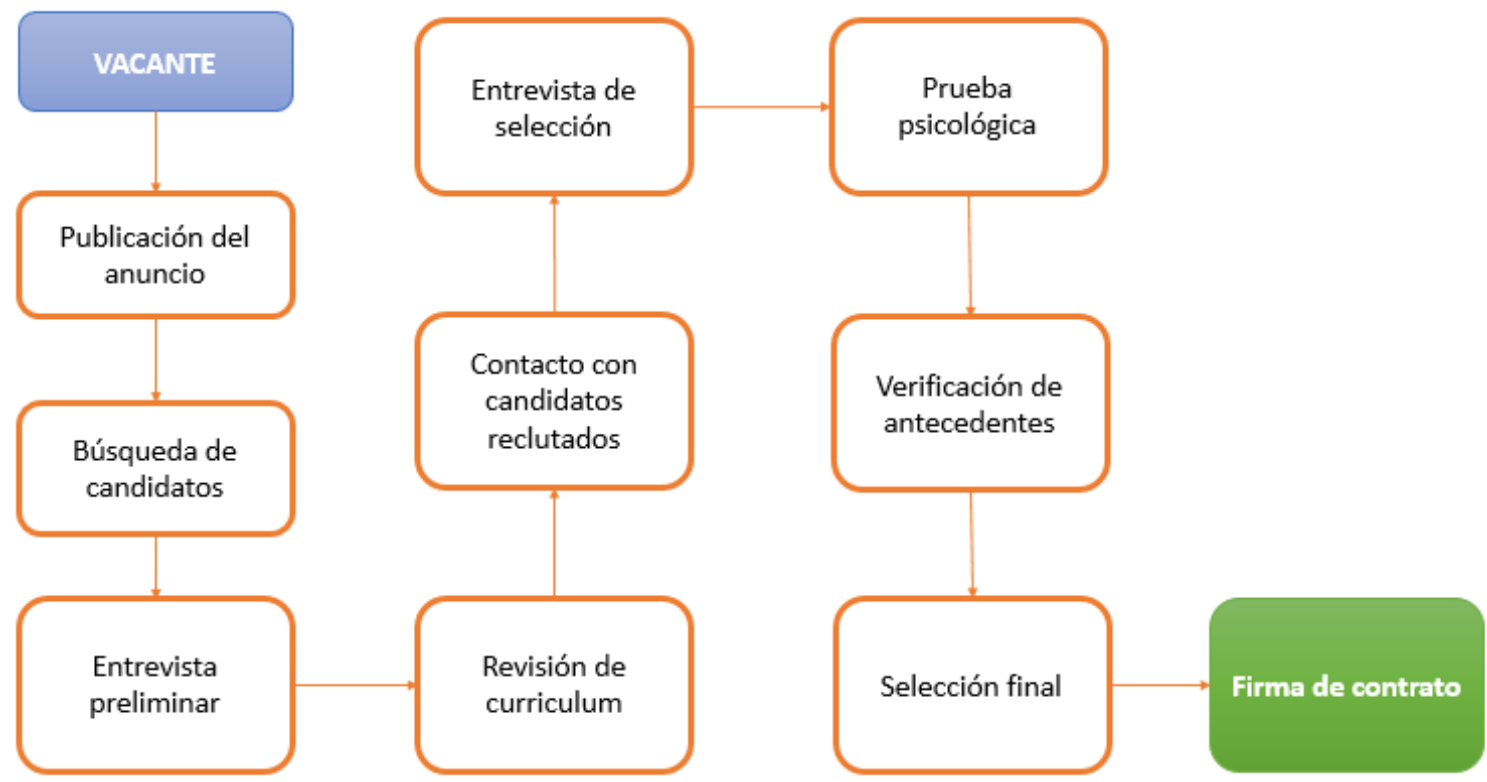

\section{Proceso de inducción}

- El Gerente de Operaciones informará sobre la incorporación del nuevo personal. 
- Se informará a las áreas involucradas, la incorporación de nuevo personal para facilitar los diferentes recursos necesarios para su gestión. Además, deberá coordinar la ejecución del plan de inducción general con las áreas involucradas.

- El Gerente de Operaciones, informará al nuevo trabajador sobre los beneficios sociales a los que tiene derecho.

El plan de inducción constará de los siguientes puntos:

- Historia y evolución de la organización, misión, visión y objetivos.

- Visita a cada una de las áreas.

- Información sobre sistemas informáticos de apoyo, medios de comunicación.

- Confirmación del organigrama.

- Perfil del cargo a desempeñar.

- Reglamento interno.

\subsubsection{Capacitación, desarrollo y evaluación del desempeño}

En SENIOR CARE se realizarán capacitaciones constantes con el fin de poder contar con el personal altamente calificado para cada una de las labores dentro de la empresa.

En el caso de las enfermeras será obligatorio asistir a las capacitaciones que se realicen, esto con el fin de mantener el estándar de calidad en servicio.

\section{Objetivo de la Capacitación:}

Brindar actualizaciones a las enfermeras para que mediante acciones básicas de atención y asistencia puedan mantener una mejor relación y cuidado al adulto mayor, buscamos mejorar la capacidad de trabajar en equipo, tolerancia y eficiencia.

Temas a tratar:

- Procesos fisiológicos del adulto mayor

- Alimentación y nutrición del adulto mayor

- Cuidados del adulto mayor dependiente

- Enfermedades típicas del adulto mayor. 
- Maso terapia del adulto mayor

- Prevención y tratamientos básicos.

- Psicología del adulto mayor

Utilizaremos la evaluación de desempeño para poder medir el desempeño de cada trabajador.

Figura n 35: Evaluación de Desempeño Laboral (Fuente: Elaboración propia)

\section{EVALUACIÓN DEL DESEMPEÑO LABORAL}

EVALUADO:

PUESTO:

\begin{tabular}{|c|c|c|c|c|c|c|}
\hline \multirow{2}{*}{ AREA DEL DESEMPENOO } & Murano & EANO & MCOERADO & ALTO & MUY ALTO & \multirow{2}{*}{ PUNTANE } \\
\hline & 1 & 2 & 3 & 4 & 5 & \\
\hline \multicolumn{7}{|l|}{ ORIENTACIÓN DE RESULTADOS } \\
\hline \multicolumn{7}{|l|}{ Termins su trabajo oportunamente } \\
\hline \multicolumn{7}{|c|}{ Oumple con les taress que se le encomienda } \\
\hline \multicolumn{7}{|c|}{ Reslizs un volumen sdecusdo de trabajo } \\
\hline \multicolumn{7}{|l|}{ CAUDAD } \\
\hline \multicolumn{7}{|l|}{ No Requiere de supervisión frecuente } \\
\hline \multicolumn{7}{|l|}{ Se muestra profesional en el trabajo } \\
\hline \multicolumn{7}{|c|}{ Se muestra respetuoso y amable en el trato } \\
\hline \multicolumn{7}{|l|}{ RELACIONES INTERPERSONALES } \\
\hline \multicolumn{7}{|c|}{$\begin{array}{l}\text { Se muestrs cortéz con los clientes y con suz } \\
\text { compsineros }\end{array}$} \\
\hline \multicolumn{7}{|c|}{ Brinds uns sdecusda orientsción a los clientes } \\
\hline \multicolumn{7}{|l|}{ Evita los conflictos dentro del equipo } \\
\hline \multicolumn{7}{|l|}{ INICIATIVA. } \\
\hline \multicolumn{7}{|c|}{$\begin{array}{l}\text { Muestra nuevas idess pars mejorar los } \\
\text { procesos }\end{array}$} \\
\hline \multicolumn{7}{|l|}{ Se anticips a las dificultades } \\
\hline \multicolumn{7}{|c|}{ Tiene gran copsoidad para resolver problemss } \\
\hline \multicolumn{7}{|l|}{ TRABANO EN EQUIPO } \\
\hline \multicolumn{7}{|c|}{ Muestra sptitud para integrarse sl equipo } \\
\hline \multicolumn{7}{|c|}{$\begin{array}{l}\text { Se identifica fácilmente con los objetivos del } \\
\text { equipo }\end{array}$} \\
\hline \multicolumn{7}{|l|}{ ORGANIZACIÓN } \\
\hline \multicolumn{7}{|l|}{ Planifica sus actividades } \\
\hline \multicolumn{7}{|l|}{ Hace uso de indicadores } \\
\hline Se preocupa por alcanzar las metas & & & & & & \\
\hline
\end{tabular}




\subsubsection{Motivación}

Al ser una empresa intermediaria en los servicios de las enfermeras, necesitamos generar una relación sólida con estas personas con el fin de poder asegurar una atención de alta calidad, y obtener la confianza de los clientes.

Como parte de la medición de calidad en cada uno de los servicios, los clientes tendrán la opción de poder calificar a cada una de las enfermeras, con estrellas del 1 al 5.

Las enfermeras que obtengan la mejor calificación cada mes serán recompensadas con premios y reconocimientos.

Adicionalmente, las mejores enfermeras podrán aparecer en los primeros lugares en la búsqueda de los clientes, de esta forma tienen más posibilidades de conseguir un mayor número de servicios.

\subsubsection{Sistema de Remuneración}

SENIOR CARE cuenta con 7 trabajadores en planilla quienes recibirán todos los beneficios de acuerdo a ley.

Los pagos al área administrativa se realizarán de manera mensual mediante depósito en cuenta de ahorros del trabajador.

En el caso de las enfermeras se pagará un porcentaje de los servicios brindados, se remuneran de acuerdo a las horas trabajadas y estos pagos se realizarán de forma semanal.

\subsection{Estructura de gastos de RRHH}

La planilla de SENIOR CARE está conformada por 7 personas, las cuales tendrán contrato por tiempo indeterminado y 1 practicante de RRHH. Asimismo, contaremos con servicios de asesoría externa para el área contable y legal.

Tabla $n^{\circ}$ 21: Estructura de gastos RRHH (Fuente: Elaboración propia) 


\begin{tabular}{|c|c|c|c|c|c|c|c|}
\hline \multirow{9}{*}{ 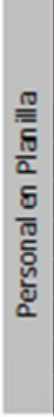 } & Puesto & $\mathrm{N}^{0}$ Personas & $\begin{array}{c}\text { Sueldo } \\
\text { Mensual(S/) }\end{array}$ & $\begin{array}{c}\text { Sueldo Bruto } \\
\text { Anual (S/) }\end{array}$ & SubTotal(S/) & | Essalud (9\%) & $\begin{array}{c}\text { Total Anual } \\
\text { (S/) }\end{array}$ \\
\hline & Gerencia General & 1 & S/. $3,000.00$ & S/. $36,000.00$ & S/. $\quad 36,000.00$ & S/. 3,240.00 & S/. $\quad 39,240.00$ \\
\hline & Gerente de Finanzas & 1 & S/. 2,500.00 & S/. $30,000.00$ & S/. $30,000.00$ & S/. 2,700.00 & s/. $32,700.00$ \\
\hline & Gerente de Bienestar & 1 & S/. $2,500.00$ & $S / .30,000.00$ & S/. $30,000.00$ & S/. $2,700.00$ & S/. $32,700.00$ \\
\hline & Gerente de Marketing & 1 & S/. $2,500.00$ & S/. $30,000.00$ & S/. $30,000.00$ & $\mathrm{~S} / .2,700.00$ & S/. $\quad 32,700.00$ \\
\hline & Jefe de Operaciones & 1 & S/. 2,000.00 & S/. $24,000.00$ & S/. $\quad 24,000.00$ & S/. $2,160.00$ & S/. $26,160.00$ \\
\hline & Asistente de Ventasy Mark & 1 & S/. $\quad 930.00$ & S/. $11,160.00$ & S/. $\quad 11,160.00$ & S/. $1,004.40$ & $12,164.40$ \\
\hline & Practicante de Selección & 1 & 930.00 & S/. $11,160.00$ & S/. $\quad 11,160.00$ & S/. $1,004.40$ & $12,164.40$ \\
\hline & \multicolumn{6}{|c|}{ TOTAL } & S/. $187,828.80$ \\
\hline
\end{tabular}

\begin{tabular}{|c|c|c|c|c|}
\hline \multirow{4}{*}{ 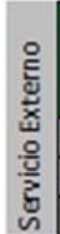 } & Puesto & $N^{0}$ Personas & $\begin{array}{l}\text { Pago por } \\
\text { Servicio } \\
\text { Mensual }\end{array}$ & Total Anual \\
\hline & Asesor Contable & 1 & s/. $\quad 700.00$ & S/. $8,400.00$ \\
\hline & Asesor Legal & 1 & S/. $\quad 900.00$ & S/. $10,800.00$ \\
\hline & & & & S/. 19,200.00 \\
\hline
\end{tabular}




\section{CAPITULO 8: PLAN ECONOMICO Y FINANCIERO}

\subsection{Supuestos}

\begin{tabular}{|c|c|c|c|c|c|c|c|}
\hline Supuestos & & & Año & & & & \\
\hline & Datos & Horizonte & 1 & 2 & 3 & 4 & 5 \\
\hline Proyecto & & & & & & & \\
\hline Tipo de Moneda & Soles & & & & & & \\
\hline Crecimiento & & & & $10 \%$ & $12 \%$ & $15 \%$ & $20 \%$ \\
\hline Precio & & & & & & & \\
\hline Inflacion & & & & & & & \\
\hline Variacion año a año & $1.0 \%$ & & & & & & \\
\hline Servicio & 13.5 & & & 13.635 & 13.77135 & 13.90906 & 14.04815 \\
\hline Impuesto & $29.50 \%$ & & & & & & \\
\hline Depreciacion & Lineal & & & & & & \\
\hline Costo Variable & Costo & Margen & Total & & & & \\
\hline Servicio & 0.7 & & & & & & \\
\hline Impuesto & $29.50 \%$ & & & & & & \\
\hline Beta & 1.10 & & & & & & \\
\hline Riesgo Pais & $2.85 \%$ & & & & & & \\
\hline
\end{tabular}

FUENTE: ELABORACIÓN PROPIA

Para la elaboración del proyecto se ha considerado los siguientes supuestos más relevantes:

- El horizonte del proyecto será de 5 años.

- Impuesto Genera a las Ventas: 29.5\%

- Crecimiento anual: $10 \%, 12 \%, 15 \%$, y $20 \%$ según la inflación

- El tipo de depreciación será lineal según normativa de SUNAT

- El tipo de moneda: soles

- Los ingresos se encuentran plasmados según las ventas 


\subsection{Inversión en activos (fijos e intangibles) y depreciación}

\section{Inversión en Activos Fijos (Importe en Soles)}

\begin{tabular}{|c|c|c|c|c|c|}
\hline Descripción & Cantidad & $\begin{array}{c}\text { Costo } \\
\text { Unitario }\end{array}$ & Valor Total & I.G.V. & Total Precio \\
\hline \multicolumn{3}{|c|}{ Operaciones } & S/. $\quad 1,500.00$ & S/. $\quad 270.00$ & S/. $1,770.00$ \\
\hline Laptop & 1 & $1,500.00$ & $1,500.00$ & 270.00 & $1,770.00$ \\
\hline \multicolumn{3}{|c|}{ Administración } & S/.21,000.00 & S/. $3,780.00$ & S/. 24,780.00 \\
\hline Televisor 50" Led & 1 & $2,500.00$ & $2,500.00$ & 450.00 & $2,950.00$ \\
\hline Proyector para presentaciones & 1 & $1,800.00$ & $1,800.00$ & 324.00 & $2,124.00$ \\
\hline Mesa de Reuniones & 1 & $3,500.00$ & $3,500.00$ & 630.00 & $4,130.00$ \\
\hline Pizarra Acrilica & 1 & $1,200.00$ & $1,200.00$ & 216.00 & $1,416.00$ \\
\hline Sillas ergonomicas & 3 & $2,400.00$ & $7,200.00$ & $1,296.00$ & $8,496.00$ \\
\hline Escritorio para oficina & 3 & $1,100.00$ & $3,300.00$ & 594.00 & $3,894.00$ \\
\hline Laptop & 1 & $1,500.00$ & $1,500.00$ & 270.00 & $1,770.00$ \\
\hline \multicolumn{3}{|c|}{ Ventas } & S/. $1,500.00$ & S/. 270.00 & S/. $\quad 1,770.00$ \\
\hline Laptop & 1 & $1,500.00$ & $1,500.00$ & 270.00 & $1,770.00$ \\
\hline \multicolumn{3}{|c|}{ TOTAL ACTIVO FIJO } & S/. 24,000.00 & S/. 4,320.00 & S/. 28,320.00 \\
\hline
\end{tabular}

FUENTE: ELABORACIÓN PROPIA

Dentro de los Activos Fijos Tangibles, se va considerar los equipos de cómputo y muebles de oficina que nos va generar un importe de S/. 28,320.

\section{Inversión en Activos Intangibles}

\section{(Importes en Soles)}

\begin{tabular}{|l|r|r|r|}
\hline \multicolumn{1}{|c|}{ Concepto } & \multicolumn{1}{c|}{ Valor } & \multicolumn{1}{c|}{ I.G.V. } & \multicolumn{1}{c|}{ Importe } \\
\hline Software & S/. 20,940.86 & S/. 3,769.35 & S/. 24,710.21 \\
\hline Desarrollo de web con personalización & $6,500.00$ & $1,170.00$ & $7,670.00$ \\
Desarrollo del APP & $7,253.40$ & $1,305.61$ & $8,559.01$ \\
Licencia de software & $7,187.46$ & $1,293.74$ & $8,481.20$ \\
\hline TOTAL GASTOS INTANGIBLES & S/.20,940.86 & S/. 3,769.35 & S/. 24,710.21 \\
\hline
\end{tabular}

FUENTE: ELABORACIÓN PROPIA 
Para los Activos Fijos Intangibles, se tiene contemplado el desarrollo de la web, desarrollo del app y las licencias de softwares, para el desarrollo de las operaciones internas y sujeta a la Norma Internacional de Contabilidad $n^{\circ} 38$ (NIC 38) Activos intangibles. La inversión para dichos activos fijos intangibles representa S/. 24,710.21.

\section{Gastos Pre Operativos}

\section{(Importes en Soles)}

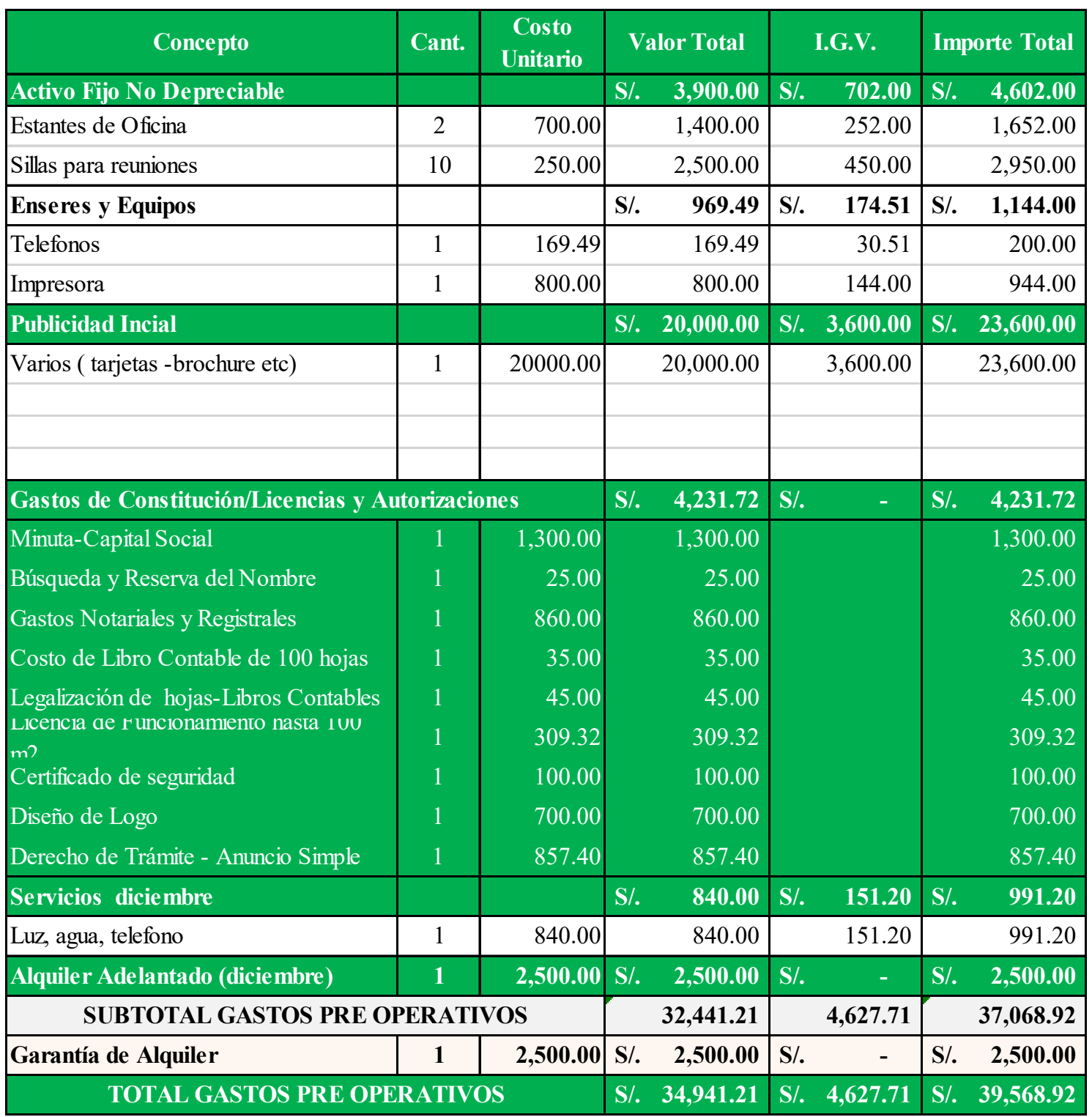

FUENTE: ELABORACIÓN PROPIA 
Dentro de los gastos pre operativos de SENIOR CARE, antes de iniciar en marcha el proyecto será de S/. 39,568.92, y se encuentran comprendido en los gastos de constitución, licencias, autorizaciones y adelanto de alquiler del mes de diciembre.

\section{Depreciación}

\section{(Importes en Soles)}

\begin{tabular}{|l|r|r|r|r|r|}
\hline \multicolumn{1}{|c|}{ Concepto } & \multicolumn{1}{c|}{2018} & \multicolumn{1}{c|}{2019} & \multicolumn{1}{c|}{2020} & \multicolumn{1}{c|}{2021} & \multicolumn{1}{c|}{2022} \\
\hline Operaciones & $\mathbf{3 7 5 . 0 0}$ & $\mathbf{3 7 5 . 0 0}$ & $\mathbf{3 7 5 . 0 0}$ & $\mathbf{3 7 5 . 0 0}$ & $\mathbf{0 . 0 0}$ \\
\hline Laptop & 375.00 & 375.00 & 375.00 & 375.00 & 0.00 \\
\hline Adminis tración & $\mathbf{5 0 0 . 0 0}$ & $\mathbf{5 0 0 . 0 0}$ & $\mathbf{5 0 0 . 0 0}$ & $\mathbf{5 0 0 . 0 0}$ & $\mathbf{5 0 0 . 0 0}$ \\
\hline Televisor 50" Led & 500.00 & 500.00 & 500.00 & 500.00 & 500.00 \\
Proyector para presentaciones & 360.00 & 360.00 & 360.00 & 360.00 & 360.00 \\
Mesa de Reuniones & 700.00 & 700.00 & 700.00 & 700.00 & 700.00 \\
Pizarra Acrilica & 240.00 & 240.00 & 240.00 & 240.00 & 240.00 \\
Sillas ergonomicas & $1,440.00$ & $1,440.00$ & $1,440.00$ & $1,440.00$ & $1,440.00$ \\
Escritorio para oficina & 660.00 & 660.00 & 660.00 & 660.00 & 660.00 \\
Laptop & 375.00 & 375.00 & 375.00 & 375.00 & 0.00 \\
\hline Ventas & $\mathbf{3 7 5 . 0 0}$ & $\mathbf{3 7 5 . 0 0}$ & $\mathbf{3 7 5 . 0 0}$ & $\mathbf{3 7 5 . 0 0}$ & $\mathbf{0 . 0 0}$ \\
\hline Laptop & 375.00 & 375.00 & 375.00 & 375.00 & 0.00 \\
\hline \multicolumn{1}{|c|}{ Total Depreciación } & $\mathbf{1 , 2 5 0 . 0 0}$ & $\mathbf{1 , 2 5 0 . 0 0}$ & $\mathbf{1 , 2 5 0 . 0 0}$ & $\mathbf{1 , 2 5 0 . 0 0}$ & $\mathbf{5 0 0 . 0 0}$ \\
\hline
\end{tabular}

FUENTE: ELABORACIÓN PROPIA

En SENIOR CARE se ha considerado invertir S/. 1250 anual, para la depreciación de 5 años para los equipos de oficina y 4 años para los equipos de cómputo. Las mismas que nos va generar una inversión de S/. 5,500 Soles, cumpliendo con las Normas Internacionales (NIC) Y Normas Internacionales Financieras (NIF). . 


\section{Amortización}

\section{(Importes en Soles)}

\begin{tabular}{|c|c|c|c|c|c|}
\hline Concepto & 2018 & 2019 & 2020 & 2021 & 2022 \\
\hline \multirow[t]{2}{*}{ Amortización } & $4,188.12$ & $4,188.12$ & $4,188.12$ & $4,188.12$ & $4,188.12$ \\
\hline & 0.00 & 0.00 & 0.00 & 0.00 & 0.00 \\
\hline Total Amortización & $4,188.12$ & $4,188.12$ & $4,188.12$ & $4,188.12$ & $4,188.12$ \\
\hline
\end{tabular}

FUENTE: ELABORACIÓN PROPIA

La inversión de amortización va representar S/. 4188.12 anual, a lo largo de los 5 años del proyecto será de 20,940.60 Soles.

\subsection{Proyección de ventas}

\section{Crecimiento}

\section{(Importes en Soles)}

\begin{tabular}{|c|c|r|r|r|c|}
\hline TIPO & 2018 & 2019 & 2020 & 2021 & \multicolumn{1}{|c|}{2022} \\
\hline Ventas Promedio horas & $\mathbf{1 3 8 , 8 7 5}$ & $\mathbf{1 5 2 , 7 6 3}$ & $\mathbf{1 7 1 , 0 9 4}$ & $\mathbf{1 9 6 , 7 5 8}$ & $\mathbf{2 3 6 , 1 1 0}$ \\
\hline & & & & & \\
\hline TOTALES & $\mathbf{1 3 8 , 8 7 5}$ & $\mathbf{1 5 2 , 7 6 3}$ & $\mathbf{1 7 1 , 0 9 4}$ & $\mathbf{1 9 6 , 7 5 8}$ & $\mathbf{2 3 6 , 1 1 0}$ \\
\hline Crecimiento & & $10.00 \%$ & $12.00 \%$ & $15.00 \%$ & $20.00 \%$ \\
\hline
\end{tabular}

FUENTE: ELABORACIÓN PROPIA

Se ha previsto considerar el crecimiento anual del negocio de acuerdo a la demanda que será de $10 \%, 12 \%, 15 \%$ y $20 \%$ al finalizar el proyecto.

\section{Ingresos por Ventas}

\section{(Importes en Soles)}

\begin{tabular}{|l|l|c|c|c|c|}
\hline \multicolumn{1}{|c|}{ RUBRO } & 2018 & 2019 & 2020 & 2021 & \multicolumn{1}{c|}{2022} \\
\hline Ventas Promed & $\mathbf{1 , 8 7 4 , 8 1 3}$ & $\mathbf{2 , 0 8 2 , 9 1 7}$ & $\mathbf{2 , 3 5 6 , 1 9 5}$ & $\mathbf{2 , 7 3 6 , 7 2 1}$ & $\mathbf{3 , 3 1 6 , 9 0 6}$ \\
Total Ventas & $\mathbf{1 , 8 7 4 , 8 1 3}$ & $\mathbf{2 , 0 8 2 , 9 1 7}$ & $\mathbf{2 , 3 5 6 , 1 9 5}$ & $\mathbf{2 , 7 3 6 , 7 2 1}$ & $\mathbf{3 , 3 1 6 , 9 0 6}$ \\
\hline
\end{tabular}


FUENTE: ELABORACIÓN PROPIA

Las ventas se verán reflejadas de acuerdo al valor de las ventas por horas por año, esto incluye el precio de las tarifas establecidas.

Figura $\mathrm{n}^{\circ} 35$ : Ventas a lo largo del tiempo del proyecto

\begin{tabular}{|c|c|c|c|c|c|}
\hline RUBRO & 2018 & 2019 & 2020 & 2021 & 2022 \\
\hline Ventas Promedio horas & $\mathbf{1 , 8 7 4 , 8 1 3}$ & $\mathbf{2 , 0 8 2 , 9 1 7}$ & $\mathbf{2 , 3 5 6 , 1 9 5}$ & $\mathbf{2 , 7 3 6 , 7 2 1}$ & $\mathbf{3 , 3 1 6 , 9 0 6}$ \\
\hline
\end{tabular}

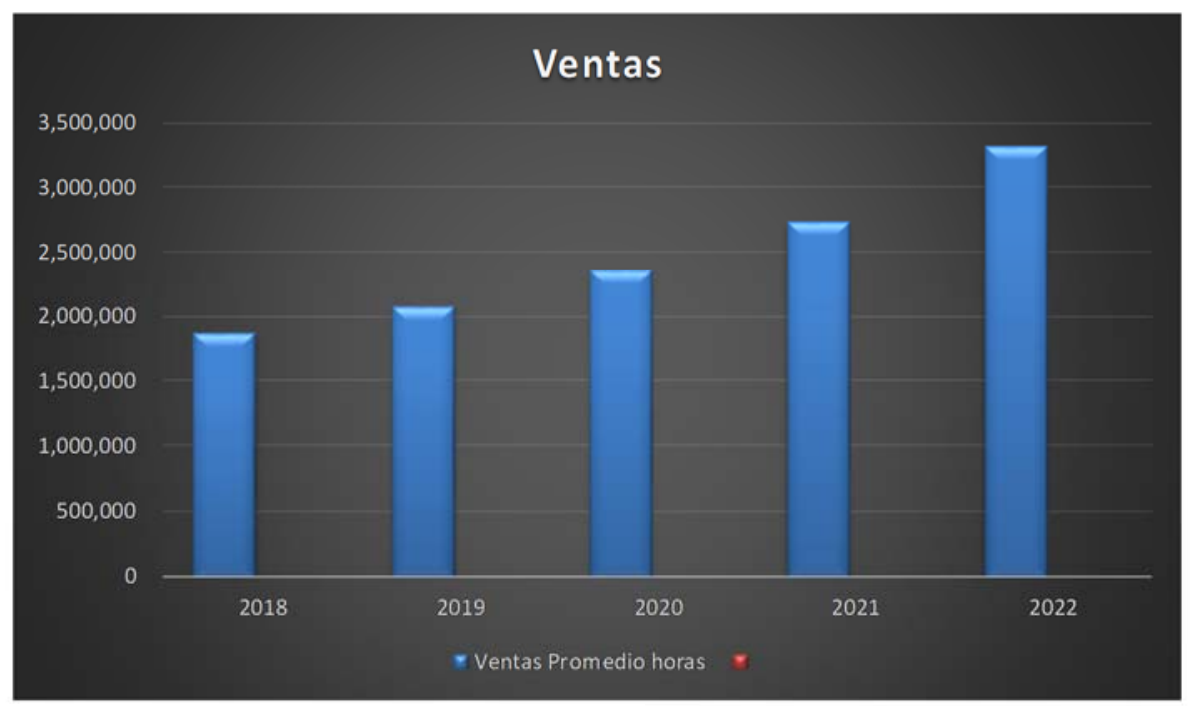

FUENTE: ELABORACIÓN PROPIA

\section{Costos Variables}

\section{(Importes en Soles)}

\begin{tabular}{|c|c|c|c|c|c|}
\hline Concepto & 2018 & 2019 & 2020 & 2021 & 2022 \\
\hline Servidor virtual & 981.00 & 981.00 & 981.00 & 981.00 & 981.00 \\
\hline Mantenimiento y mejoras de la aplicación & $9,617.65$ & $9,617.65$ & $9,617.65$ & $9,617.65$ & $9,617.65$ \\
\hline Pago tiendas virtuales (Istore, Google play) & 405.48 & 323.73 & 323.73 & 323.73 & 323.73 \\
\hline Servicio Google Maps & $46,630.20$ & $46,630.20$ & $46,630.20$ & $46,630.20$ & $46,630.20$ \\
\hline Costo & $1,312,368.75$ & $1,318,930.59$ & $1,325,492.44$ & $1,333,366.65$ & $1,342,553.23$ \\
\hline Total sin IGV & $1,370,003.08$ & $1,376,483.17$ & $1,383,045.01$ & $1,390,919.23$ & $1,400,105.81$ \\
\hline
\end{tabular}

\section{TOTAL $6,920,556.30$}

FUENTE: ELABORACIÓN PROPIA 
Entre los principales costos variables podemos mencionar: el servidor virtual, mantenimiento y mejoras de aplicación, pago tiendas virtuales (Istore, Google play), servicios de google map. En total se va generar 6 millones de inversión para los costos variables.

\subsection{Cálculo del capital de trabajo}

El capital de trabajo será de S/. 28,805 Soles y el método utilizado es el máximo déficit mensual acumulado. Las mismas que se considerara en los gastos corrientes mensual según los cuadros siguientes. 


\section{Inversión en Capital de Trabajo (Método de Déficit Acumulado de Caja)}

(Importes en Soles)

\begin{tabular}{|c|c|c|c|c|c|c|c|c|c|c|c|c|c|}
\hline Concepto & & Mes 1 & Mes 2 & Mes 3 & Mes 4 & Mes 5 & Mes 6 & Mes 7 & Mes 8 & Mes 9 & Mes 10 & Mes 11 & Mes 12 \\
\hline Total Ingresos en Efectivo & & 91,750 & 91,750 & $110,099 \mid$ & 128,449 & $128,449 \mid$ & $128,449 \mid$ & 110,099 & 165,149 & 220,199 & 238,549 & $220,199 \mid$ & 201,849 \\
\hline Ventas mensuales & & 93,741 & 93,741 & 112,489 & 131,237 & 131,237 & 131,237 & 112,489 & 168,733 & 224,978 & 243,726 & 224,978 & 206,229 \\
\hline Total Egresos en Efectivo & & 104,027 & 101,227 & 114,369 & 124,542 & 127,382 & 124,542 & 121,764 & 150,826 & 190,254 & 203,396 & 195,224 & 184,976 \\
\hline Total x Mes & & 70,421 & 70,421 & 83,545 & 96,669 & 96,669 & 96,669 & 83,545 & 122,916 & 162,287 & 175,411 & 162,287 & 149,163 \\
\hline \multicolumn{14}{|l|}{ Personal } \\
\hline Personal Administrativo & & 10,000 & 10,000 & 10,000 & 10,000 & 10,000 & 10,000 & 10,000 & 10,000 & 10,000 & 10,000 & 10,000 & 10,000 \\
\hline Personal de Ventas & & 5,730 & 5,730 & 5,730 & 5,730 & 5,730 & 5,730 & 5,730 & 5,730 & 5,730 & 5,730 & 5,730 & 5,730 \\
\hline Gratificación & & & & & & & & 7,865 & & & & & 7,865 \\
\hline CTS & & & & & & 2,840 & & & & & & 4,970 & \\
\hline ESSALUD & & 1,534 & 1,534 & 1,534 & 1,534 & 1,534 & 1,534 & 1,534 & 1,534 & 1,534 & 1,534 & 1,534 & 1,534 \\
\hline \multicolumn{14}{|l|}{ Servicios } \\
\hline Energía eléctrica & & 350 & 350 & 350 & 350 & 350 & 350 & 350 & 350 & 350 & 350 & 350 & 350 \\
\hline Agua & & 230 & 230 & 230 & 230 & 230 & 230 & 230 & 230 & 230 & 230 & 230 & 230 \\
\hline Teléfomo e Internet & & 260 & 260 & 260 & 260 & 260 & 260 & 260 & 260 & 260 & 260 & 260 & 260 \\
\hline Alquiler del local & & 1,250 & 1,250 & 1,250 & 1,250 & 1,250 & 1,250 & 1,250 & 1,250 & 1,250 & 1,250 & 1,250 & 1,250 \\
\hline Mantenimiento & & 1,498 & 1,198 & 1,198 & 1,198 & 1,198 & 1,198 & 1,198 & 1,198 & 1,198 & 1,198 & 1,198 & 1,198 \\
\hline \multicolumn{14}{|l|}{ Promoción y Publicidad } \\
\hline Gastos de Prom. y Publicidad & & 11,950 & 9,450 & 9,450 & 6,480 & 6,480 & 6,480 & 8,980 & 6,480 & 6,480 & 6,480 & 6,480 & 6,480 \\
\hline \multicolumn{14}{|l|}{ Préstamo e Imprevistos } \\
\hline Cuotas del Préstamo & & 0 & 0 & 0 & 0 & 0 & 0 & 0 & 0 & 0 & 0 & 0 & 0 \\
\hline Imprevistos & $0.1 \%$ & 94 & 94 & 112 & 131 & 131 & 131 & 112 & 169 & 225 & 244 & 225 & 206 \\
\hline Saldo Inicial de Caja & & 0 & $(12,277)$ & $(21,754)$ & $(26,024)$ & $(22,116)$ & $(21,048)$ & $(17,141)$ & $(28,805)$ & $(14,483)$ & 15,463 & 50,615 & 75,590 \\
\hline Ingreso & & 91,750 & 91,750 & 110,099 & 128,449 & 128,449 & 128,449 & 110,099 & 165,149 & 220,199 & 238,549 & 220,199 & 201,849 \\
\hline Egresos & & $(104,027)$ & $(101,227)$ & $(114,369)$ & $(124,542)$ & $(127,382)$ & $(124,542)$ & $(121,764)$ & $(150,826)$ & $(190,254)$ & $(203,396)$ & $(195,224)$ & $(184,976)$ \\
\hline Saldo Final & & $(12,277)$ & $(21,754)$ & $(26,024)$ & $(22,116)$ & $(21,048)$ & $(17,141)$ & $(28,805)$ & $(14,483)$ & 15,463 & 50,615 & 75,590 & 92,463 \\
\hline Máximo Déficit Mensual Acumul. & & $(28,805)$ & & & & & & & & & & & \\
\hline Inversión en Capital de Trabajo & & $(28,805)$ & & & & & & & & & & & \\
\hline
\end{tabular}

FUENTE: ELABORACIÓN PROPIA 


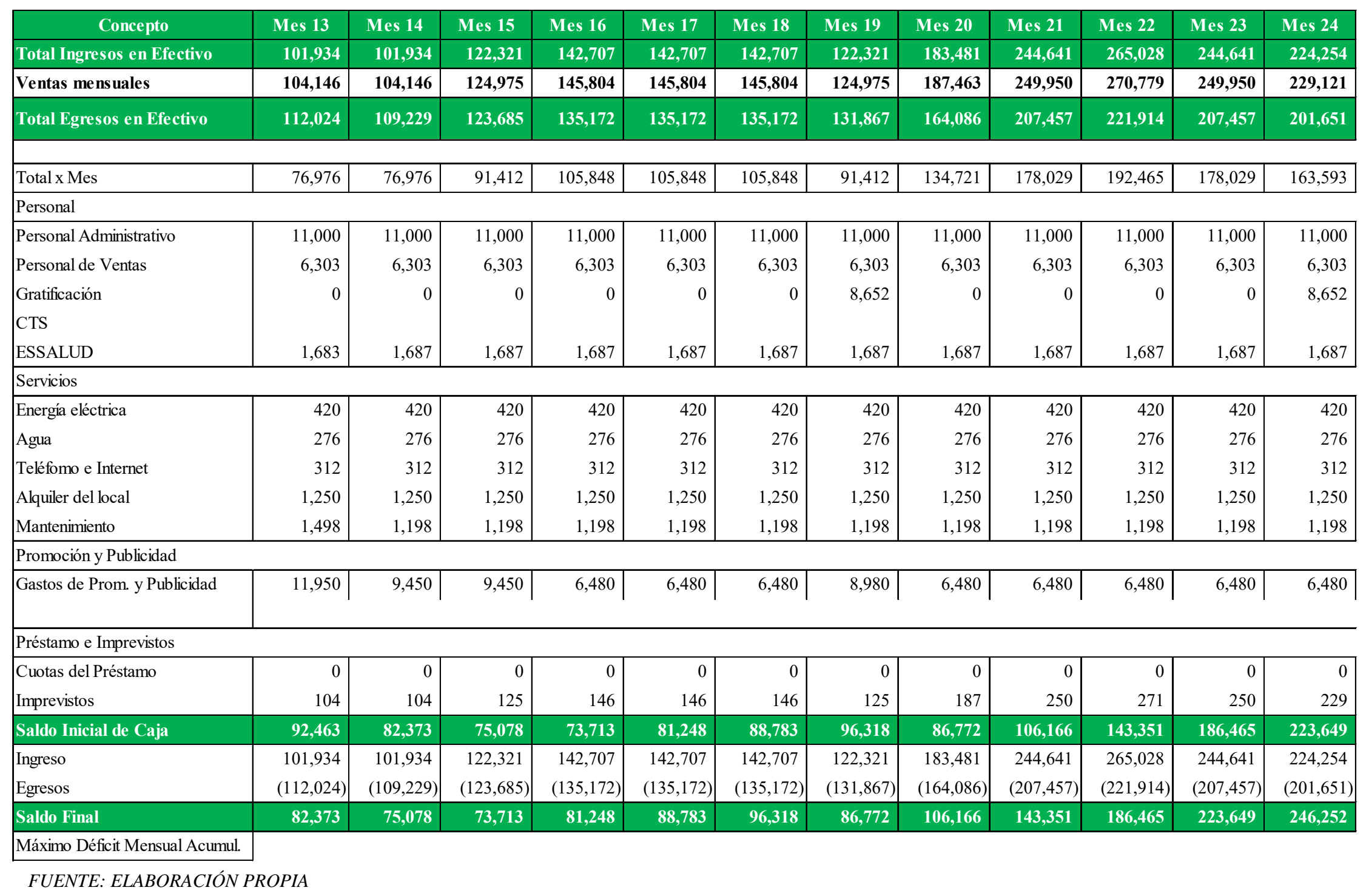




\begin{tabular}{|c|c|c|c|c|c|c|c|c|c|c|c|c|}
\hline Concepto & Mes 25 & Mes 26 & Mes 27 & Mes 28 & Mes 29 & Mes 30 & Mes 31 & Mes 32 & Mes 33 & Mes 34 & Mes 35 & Mes 36 \\
\hline Total Ingresos en Efectivo & 115,307 & 115,307 & 138,369 & 161,430 & 161,430 & 161,430 & 138,369 & 207,553 & 276,738 & 299,799 & 276,738 & 253,676 \\
\hline Ventas mensuales & 117,810 & 117,810 & 141,372 & 164,934 & 164,934 & 164,934 & 141,372 & 212,058 & 282,743 & 306,305 & 282,743 & 259,181 \\
\hline Total Egresos en Efectivo & 122,850 & 120,055 & 136,247 & 149,469 & 149,469 & 149,469 & 145,293 & 181,853 & 230,428 & 246,620 & 230,428 & 223,753 \\
\hline Total x Mes & 85,638 & 85,638 & 101,806 & 117,975 & 117,975 & 117,975 & 101,806 & 150,311 & 198,817 & 214,985 & 198,817 & 182,648 \\
\hline \multicolumn{13}{|l|}{ Personal } \\
\hline Personal Administrativo & 12,100 & 12,100 & 12,100 & 12,100 & 12,100 & 12,100 & 12,100 & 12,100 & 12,100 & 12,100 & 12,100 & 12,100 \\
\hline Personal de Ventas & 6,933 & 6,933 & 6,933 & 6,933 & 6,933 & 6,933 & 6,933 & 6,933 & 6,933 & 6,933 & 6,933 & 6,933 \\
\hline Gratificación & 0 & 0 & 0 & 0 & 0 & 0 & 9,517 & 0 & 0 & 0 & 0 & 9,517 \\
\hline \multicolumn{13}{|l|}{ CTS } \\
\hline ESSALUD & 1,851 & 1,856 & 1,856 & 1,856 & 1,856 & 1,856 & 1,856 & 1,856 & 1,856 & 1,856 & 1,856 & 1,856 \\
\hline \multicolumn{13}{|l|}{\begin{tabular}{|l|} 
Servicios \\
\end{tabular}} \\
\hline Energía eléctrica & 504 & 504 & 504 & 504 & 504 & 504 & 504 & 504 & 504 & 504 & 504 & 504 \\
\hline Agua & 331 & 331 & 331 & 331 & 331 & 331 & 331 & 331 & 331 & 331 & 331 & 331 \\
\hline Teléfomo e Internet & 374 & 374 & 374 & 374 & 374 & 374 & 374 & 374 & 374 & 374 & 374 & 374 \\
\hline Alquiler del local & 1,250 & 1,250 & 1,250 & 1,250 & 1,250 & 1,250 & 1,250 & 1,250 & 1,250 & 1,250 & 1,250 & 1,250 \\
\hline Mantenimiento & 1,498 & 1,198 & 1,198 & 1,198 & 1,198 & 1,198 & 1,198 & 1,198 & 1,198 & 1,198 & 1,198 & 1,198 \\
\hline \multicolumn{13}{|l|}{ Promoción y Publicidad } \\
\hline Gastos de Prom. y Publicidad & 11,950 & 9,450 & 9,450 & 6,480 & 6,480 & 6,480 & 8,980 & 6,480 & 6,480 & 6,480 & 6,480 & 6,480 \\
\hline \multicolumn{13}{|l|}{ Préstamo e Imprevistos } \\
\hline Cuotas del Préstamo & 0 & 0 & 0 & 0 & 0 & 0 & 0 & 0 & 0 & 0 & 0 & 0 \\
\hline Imprevistos & 118 & 118 & 141 & 165 & 165 & 165 & 141 & 212 & 283 & 306 & 283 & 259 \\
\hline Saldo Inicial de Caja & 246,252 & 238,710 & 233,962 & 236,085 & 248,046 & 260,008 & 271,970 & 265,045 & 290,746 & 337,056 & 390,235 & 436,544 \\
\hline Ingreso & 115,307 & 115,307 & 138,369 & 161,430 & 161,430 & 161,430 & 138,369 & 207,553 & 276,738 & 299,799 & 276,738 & 253,676 \\
\hline Egresos & $(122,850)$ & $(120,055)$ & $(136,247)$ & $(149,469)$ & $(149,469)$ & $(149,469)$ & $(145,293)$ & $(181,853)$ & $(230,428)$ & $(246,620)$ & $(230,428)$ & $(223,753)$ \\
\hline Saldo Final & 238,710 & 233,962 & 236,085 & 248,046 & 260,008 & 271,970 & 265,045 & 290,746 & 337,056 & 390,235 & 436,544 & 466,468 \\
\hline
\end{tabular}

FUENTE: ELABORACIÓN PROPIA 


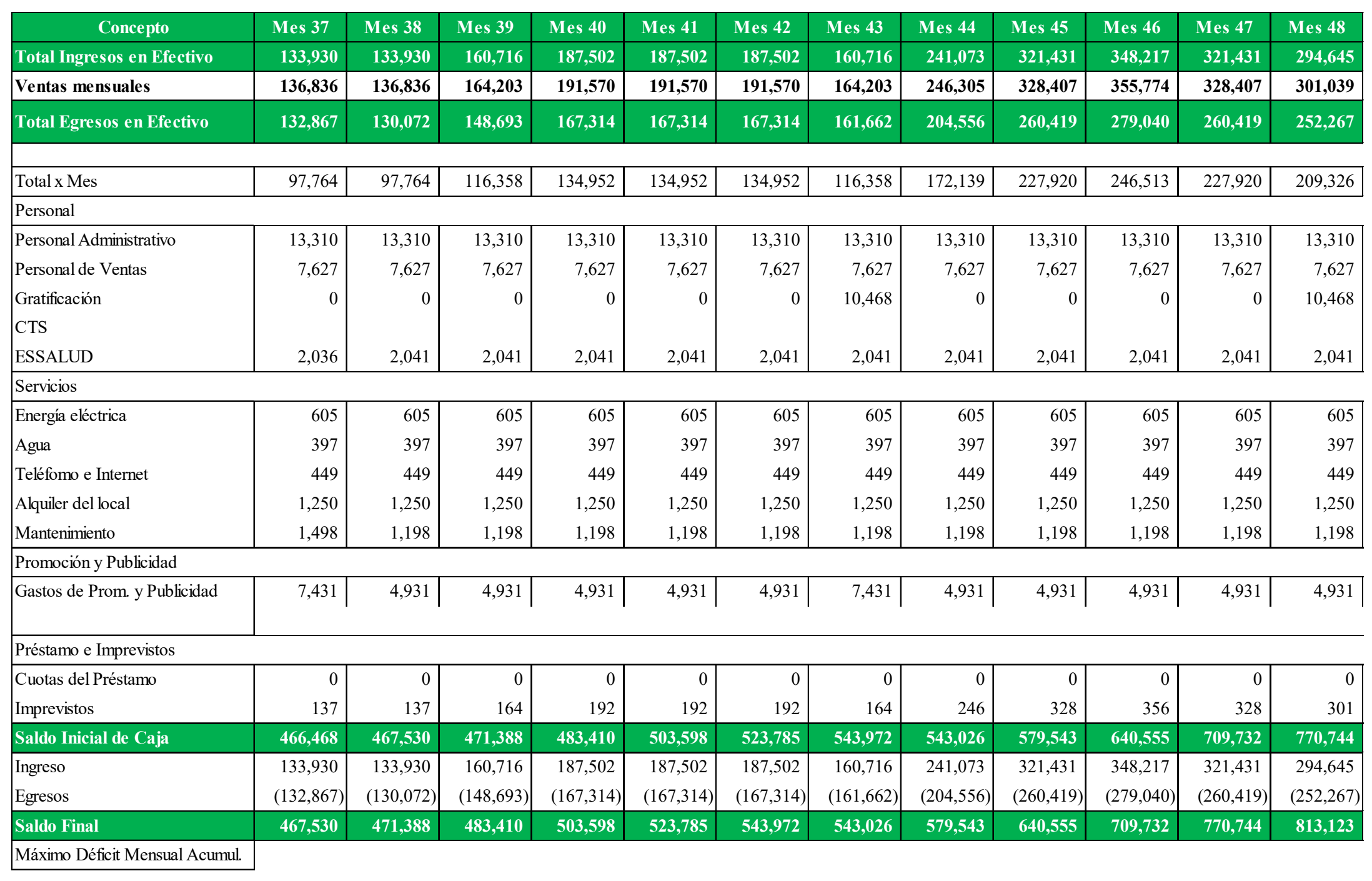

FUENTE: ELABORACIÓN PROPIA 


\begin{tabular}{|c|c|c|c|c|c|c|c|c|c|c|c|c|}
\hline Concepto & Mes 49 & Mes 50 & Mes 51 & Mes 52 & Mes 53 & Mes 54 & Mes 55 & Mes 56 & Mes 57 & Mes 58 & Mes 59 & Mes 60 \\
\hline Total Ingresos en Efectivo & 162,323 & 162,323 & 194,787 & 227,252 & 227,252 & 227,252 & 194,787 & 292,181 & 389,575 & 422,039 & 389,575 & 357,110 \\
\hline Ventas mensuales & 165,845 & 165,845 & 199,014 & 232,183 & 232,183 & 232,183 & 199,014 & 298,522 & 398,029 & 431,198 & 398,029 & 364,860 \\
\hline Total Egresos en Efectivo & 154,450 & 151,356 & 173,701 & $196,047 \mid$ & 196,047 & $196,047 \mid$ & 187,716 & 240,738 & 307,774 & 330,120 & 307,774 & 296,944 \\
\hline Total x Mes & 116,358 & 116,358 & 138,670 & 160,983 & 160,983 & 160,983 & 138,670 & 205,607 & 272,544 & 294,857 & 272,544 & 250,232 \\
\hline \multicolumn{13}{|l|}{ Personal } \\
\hline Personal Administrativo & 14,641 & 14,641 & 14,641 & 14,641 & 14,641 & 14,641 & 14,641 & 14,641 & 14,641 & 14,641 & 14,641 & 14,641 \\
\hline Personal de Ventas & 8,389 & 8,389 & 8,389 & 8,389 & 8,389 & 8,389 & 8,389 & 8,389 & 8,389 & 8,389 & 8,389 & 8,389 \\
\hline Gratificación & 0 & 0 & 0 & 0 & 0 & 0 & 11,515 & 0 & 0 & 0 & 0 & 11,515 \\
\hline \multicolumn{13}{|l|}{ CTS } \\
\hline ESSALUD & 2,240 & 2,245 & 2,245 & 2,245 & 2,245 & 2,245 & 2,245 & 2,245 & 2,245 & 2,245 & 2,245 & 2,245 \\
\hline \multicolumn{13}{|l|}{ Servicios } \\
\hline Energía eléctrica & 726 & 726 & 726 & 726 & 726 & 726 & 726 & 726 & 726 & 726 & 726 & 726 \\
\hline Agua & 477 & 477 & 477 & 477 & 477 & 477 & 477 & 477 & 477 & 477 & 477 & 477 \\
\hline Teléfomo e Internet & 539 & 539 & 539 & 539 & 539 & 539 & 539 & 539 & 539 & 539 & 539 & 539 \\
\hline Alquiler del local & 1,250 & 1,250 & 1,250 & 1,250 & 1,250 & 1,250 & 1,250 & 1,250 & 1,250 & 1,250 & 1,250 & 1,250 \\
\hline Mantenimiento & 1,798 & 1,198 & 1,198 & 1,198 & 1,198 & 1,198 & 1,198 & 1,198 & 1,198 & 1,198 & 1,198 & 1,198 \\
\hline \multicolumn{13}{|l|}{ Promoción y Publicidad } \\
\hline Gastos de Prom. y Publicidad & 7,431 & 4,931 & 4,931 & 4,931 & 4,931 & 4,931 & 7,431 & 4,931 & 4,931 & 4,931 & 4,931 & 4,931 \\
\hline \multicolumn{13}{|l|}{ Préstamo e Imprevistos } \\
\hline Cuotas del Préstamo & 0 & 0 & 0 & 0 & 0 & 0 & 0 & 0 & 0 & 0 & 0 & 0 \\
\hline Imprevistos & 166 & 166 & 199 & 232 & 232 & 232 & 199 & 299 & 398 & 431 & 398 & 365 \\
\hline Saldo Inicial de Caja & 813,123 & 820,996 & 831,963 & 853,049 & 884,254 & 915,459 & 946,665 & 953,736 & $1,005,179$ & $1,086,979$ & $1,178,899$ & $1,260,699$ \\
\hline Ingreso & 162,323 & 162,323 & 194,787 & 227,252 & 227,252 & 227,252 & 194,787 & 292,181 & 389,575 & 422,039 & 389,575 & 357,110 \\
\hline Egresos & $(154,450)$ & $(151,356)$ & $(173,701)$ & $(196,047)$ & $(196,047)$ & $(196,047)$ & $(187,716)$ & $(240,738)$ & $(307,774)$ & $(330,120)$ & $(307,774)$ & $(296,944)$ \\
\hline Saldo Final & 820,996 & 831,963 & 853,049 & 884,254 & 915,459 & 946,665 & 953,736 & $1,005,179$ & $1,086,979$ & $1,178,899$ & $1,260,699$ & $1,320,865$ \\
\hline
\end{tabular}

FUENTE: ELABORACIÓN PROPIA 


\subsection{Estructura de financiamiento: Tradicional y no tradicional}

En el caso del financiamiento se utilizará el método no tradicional, por ser un proyecto nuevo que no cuenta con un historial crediticio dentro del sistema financiero convencional. Para ello, se efectuará la inversión entre los 4 socios con un $20 \%$ cada uno y un inversionista tercero tendrá el $20 \%$ como aporte de capital a cambio de participaciones.

\section{Estructura de Inversiones}

\section{(Importes en Soles)}

\begin{tabular}{|l|r|r|}
\hline \multicolumn{1}{|c|}{ Rubro } & $\begin{array}{c}\text { Inversión } \\
\text { sin IGV }\end{array}$ & \multicolumn{1}{c|}{$\%$} \\
\hline Activo Fijo & 24,000 & $22 \%$ \\
Activo Intangibles & 20,941 & $19 \%$ \\
Capital de Trabajo & 28,805 & $27 \%$ \\
Gastos Pre Operativos & 34,941 & $32 \%$ \\
\hline \multicolumn{1}{|c|}{ TOTAL } & 108,687 & $100 \%$ \\
\hline
\end{tabular}

FUENTE: ELABORACIÓN PROPIA

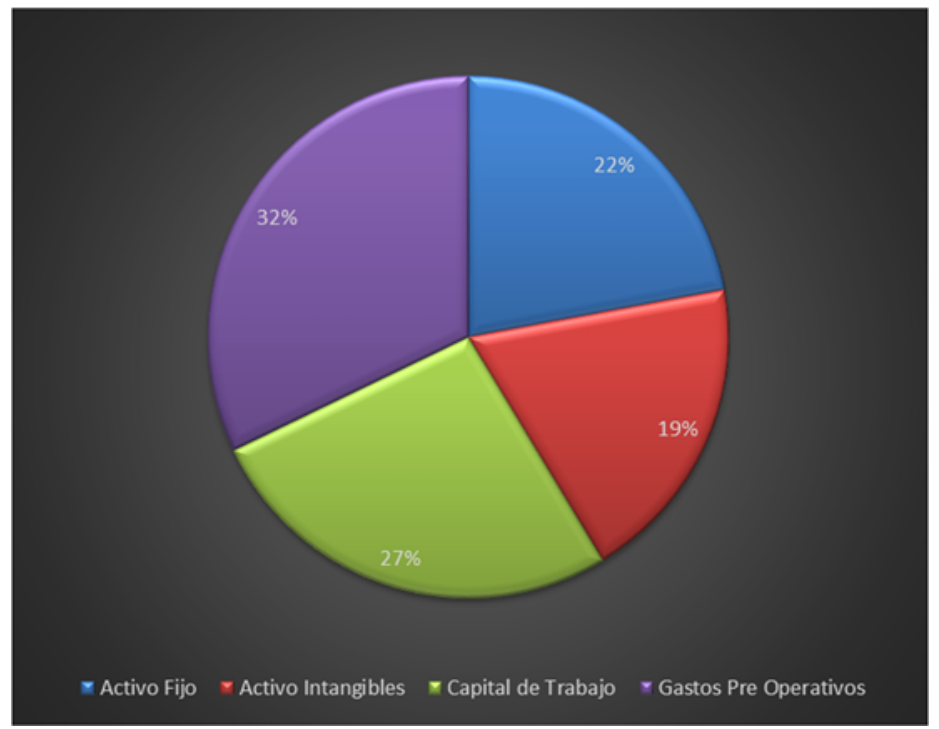

FUENTE: ELABORACIÓN PROPIA 


\section{Estructura del Financiamiento}

\section{(Importes en Soles)}

FUENTE: ELABORACIÓN PROPIA

\begin{tabular}{|l|r|c|}
\hline \multicolumn{1}{|c|}{ Tipo } & \multicolumn{1}{|c|}{ Monto } & \multicolumn{1}{c|}{$\%$} \\
\hline Total & & \\
\hline TOTAL & 108,687 & $100 \%$ \\
\hline
\end{tabular}

\begin{tabular}{|c|c|}
\hline Número de Socios $\Rightarrow$ & 5 \\
\hline \multicolumn{2}{|c|}{$\begin{array}{l}\text { APORTE DE CADA SOCIO } \\
\text { (En Nuevos Soles) }\end{array}$} \\
\hline Socio 1 & 21,737 \\
\hline Socio 2 & 21,737 \\
\hline Socio 3 & 21,737 \\
\hline Socio 4 & 21,737 \\
\hline Inversionista & 21,737 \\
\hline TOTAL & 108,687 \\
\hline
\end{tabular}

El capital de los terceros será de S/. 21,737 y los socios harán un aporte de S/. 86,948.

\subsection{Estados financieros (Balance General, Estado de GGPP, Flujo de Caja)}

\begin{tabular}{|c|c|c|c|c|c|}
\hline Años & Año 1 & Año 2 & Año 3 & Año 4 & Año 5 \\
\hline Activo & S/. 184,503 & S/.293,807 & S/. 450,321 & S/. 697,319 & S/. 1,062,036 \\
\hline Efectivo & S/. $110,058.88$ & $\mathrm{~S} / .224,801.12$ & $\mathrm{~S} / .386,752.85$ & S/. 639,189.26 & S/. 1,008,594.68 \\
\hline Activo Fijo & $\mathrm{S} / .24,000.00$ & S/. 24,000.00 & $\mathrm{S} / .24,000.00$ & $\mathrm{~S} / .24,000.00$ & S/. 24,000.00 \\
\hline Gastos pagagos por Antic & S/. 55,882.07 & $\mathrm{S} / .55,882.07$ & S/. 55,882.07 & $\mathrm{S} / .55,882.07$ & S/. 55,882.07 \\
\hline Depreciación & $-\mathrm{S} / .1,250.00$ & $-\mathrm{S} / .2,500.00$ & $-\mathrm{S} / .3,750.00$ & $-\mathrm{S} / .5,000.00$ & $-\mathrm{S} / .5,500.00$ \\
\hline Amortización de intangibles & $-\mathrm{S} / .4,188.12$ & -S/. 8,376.24 & $-\mathrm{S} / .12,564.36$ & $-\mathrm{S} / .16,752.48$ & $-\mathrm{S} / .20,940.60$ \\
\hline
\end{tabular}

\begin{tabular}{|c|c|c|c|c|c|}
\hline Pasivo y Patrimonio & S/.184,503 & S/.293,807 & S/.450,321 & S/.697,319 & S/.1,062,036 \\
\hline Pasivo & S/.0.00 & S/.0.00 & S/.0 & S/.0 & S/.0.00 \\
\hline Patrimonio & S/.184,502.83 & S/.293,806.95 & S/.450,320.56 & S/.697,318.85 & S/.1,062,036.15 \\
\hline Patrimonio & S/. 108,687.40 & S/. 108,687.40 & S/. 108,687.40 & S/. 108,687.40 & S/. 108,687.40 \\
\hline Resultado Acumulado & S/.0.00 & S/.75,815.43 & S/. 185,119.55 & S/.341,633.16 & S/. 588,631.44 \\
\hline Resultado del Ejercicio & S/.75,815.43 & S/.109,304.12 & S/.156,513.61 & S/.246,998.28 & S/.364,717.30 \\
\hline
\end{tabular}

FUENTE: ELABORACIÓN PROPIA 


\begin{tabular}{|l|r|r|r|r|r|}
\cline { 2 - 6 } \multicolumn{1}{c|}{} & \multicolumn{1}{c|}{ Año 1 } & \multicolumn{1}{c|}{ Año 2 } & \multicolumn{1}{c|}{ Año 3 } & \multicolumn{1}{c|}{ Año 4 } & \multicolumn{1}{c|}{ Año 5 } \\
\hline ROA & $41.09 \%$ & $37.20 \%$ & $34.76 \%$ & $35.42 \%$ & $34.34 \%$ \\
\hline ROE & $69.76 \%$ & $100.57 \%$ & $144.00 \%$ & $227.26 \%$ & $335.57 \%$ \\
\hline
\end{tabular}

FUENTE: ELABORACIÓN PROPIA

\section{Ratio de Rentabilidad Económica (ROA)}

A lo largo del horizonte del proyecto el ROA se inicia en $41 \%$, lo que permitirá que el proyecto se mantenga con flujo de efectivo para el manejo de toda la operación con normalidad y cubrir sus obligaciones corrientes. El administrador o gerente que trabaje en forma eficiente y eficaz con los mismos recursos disponibles podrá tener un ROA positivo, pero si a lo largo de los años el ROA disminuye se deberá aumentar las ventas y reducir los activos, así como incrementar los precios y reducir los costos, a fin de aumentar el rendimiento.

\section{Ratio Rentabilidad Financiera (ROE)}

En el caso del ROE, se inicia con $69 \%$ que nos va medir el alto rendimiento de la administración de la empresa, esto nos mide la productividad de la empresa en relación a su capital de trabajo. Para incrementar el ROE se deberá aumentar el margen, aumentar la rotación de activos, aumentar el apalancamiento que permita invertir en nuevos fondos para obtener una mayor rentabilidad. 


\section{Estado de Ganancias y Pérdidas con Gastos Financieros y Escudo Fiscal}

\section{(Importes en Soles)}

\begin{tabular}{|c|c|c|c|c|c|}
\hline Rubro & 2018 & 2019 & 2020 & 2021 & 2022 \\
\hline Ventas & $1,874,813$ & $2,082,917$ & $2,356,195$ & $2,736,721$ & $3,316,906$ \\
\hline (-) Costo de Ventas & $(1,370,003)$ & $(1,501,158)$ & $(1,674,391)$ & $(1,916,917)$ & $(2,288,789)$ \\
\hline (-) Costo Variable & $(1,370,003)$ & $(1,501,158)$ & $(1,674,391)$ & $(1,916,917)$ & $(2,288,789)$ \\
\hline Utilidad Bruta & 504,809 & 581,758 & 681,804 & 819,804 & $1,028,116$ \\
\hline (-) Gastos Operativos & $(397,270)$ & $(426,717)$ & $(459,799)$ & $(469,452)$ & $(510,787)$ \\
\hline (-) Administrativos & $(199,928)$ & $(219,991)$ & $(242,597)$ & $(268,105)$ & $(297,234)$ \\
\hline (-) De Ventas & $(191,904)$ & $(201,288)$ & $(211,765)$ & $(195,909)$ & $(208,865)$ \\
\hline (-) Depreciación & $(1,250)$ & $(1,250)$ & $(1,250)$ & $(1,250)$ & $(500)$ \\
\hline (-) Amortización de Intangibles & $(4,188)$ & $(4,188)$ & $(4,188)$ & $(4,188)$ & $(4,188)$ \\
\hline EBIT o Resultado Operativo & 107,540 & 155,041 & 222,005 & 350,352 & 517,330 \\
\hline (+) Ingresos Financieros & 0 & 0 & 0 & 0 & 0 \\
\hline (-) Gastos Financieros & 0 & 0 & 0 & 0 & 0 \\
\hline (+) Otros Ingresos & 0 & 0 & 0 & 0 & 0 \\
\hline Resultado antes de I. Renta & 107,540 & 155,041 & 222,005 & 350,352 & $\mathbf{5 1 7 , 3 3 0}$ \\
\hline (-) Impuesto a la Renta & 31,724 & 45,737 & 65,492 & 103,354 & 152,612 \\
\hline Resultado Neto & 75,815 & 109,304 & 156,514 & 246,998 & 364,717 \\
\hline Escudo Fiscal & $\mathbf{0}$ & $\mathbf{0}$ & $\mathbf{0}$ & $\mathbf{0}$ & $\mathbf{0}$ \\
\hline
\end{tabular}

FUENTE: ELABORACIÓN PROPIA

La utilidad neta se presenta positivo a lo largo de los años, esto quiere decir que en el primer año se contará con S/. 75 mil soles y se culminará con un flujo de S/. 364 mil soles. 


\section{Estado de Ganancias y Pérdidas con Gastos Financieros y Escudo Fiscal}

\section{(Importes en Soles)}

\begin{tabular}{|c|c|c|c|c|c|c|}
\hline Ventas & año 0 & $\begin{array}{c}2018 \\
1,874,813\end{array}$ & $\begin{array}{c}2019 \\
2,082,917\end{array}$ & $\begin{array}{c}2020 \\
2,356,195\end{array}$ & $\begin{array}{c}2021 \\
2,736,721\end{array}$ & $\begin{array}{c}2022 \\
3,316,906\end{array}$ \\
\hline (-) Costo de Ventas & & $(1,370,003)$ & $(1,501,158)$ & $(1,674,391)$ & $(1,916,917)$ & $(2,288,789)$ \\
\hline (-) Costo Variable & & $(1,370,003)$ & $(1,501,158)$ & $(1,674,391)$ & $(1,916,917)$ & $(2,288,789)$ \\
\hline (-) Costos Indirectos & & 0 & 0 & 0 & 0 & 0 \\
\hline Utilidad Bruta & & 504,809 & 581,758 & 681,804 & 819,804 & $1,028,116$ \\
\hline (-) Gastos Operativos & & $(397,270)$ & $(426,717)$ & $(459,799)$ & $(469,452)$ & $(510,787)$ \\
\hline (-) Administrativos & & $(199,928)$ & $(219,991)$ & $(242,597)$ & $(268,105)$ & $(297,234)$ \\
\hline (-) De Ventas & & $(191,904)$ & $(201,288)$ & $(211,765)$ & $(195,909)$ & $(208,865)$ \\
\hline (-) Depreciación & & $(1,250)$ & $(1,250)$ & $(1,250)$ & $(1,250)$ & $(500)$ \\
\hline (-) Amortización de Intangibles & & $(4,188)$ & $(4,188)$ & $(4,188)$ & $(4,188)$ & $(4,188)$ \\
\hline EBIT o Resultado Operativo & & 107,540 & 155,041 & 222,005 & 350,352 & 517,330 \\
\hline (-) Impuesto a la Renta & $29.50 \%$ & 31,724 & 45,737 & 65,492 & 103,354 & 152,612 \\
\hline$(+)$ Depreciación & & 1,250 & 1,250 & 1,250 & 1,250 & 500 \\
\hline (+) Amortización de Intangibles & & 4,188 & 4,188 & 4,188 & 4,188 & 4,188 \\
\hline Flujo de Caja Operativo & & 81,254 & 114,742 & 161,952 & 252,436 & 369,405 \\
\hline Inversión en Activo Fijo & $-24,000$ & 0 & 0 & 0 & 0 & 0 \\
\hline Inversión en Intangibles & $-20,941$ & 0 & 0 & 0 & 0 & 0 \\
\hline Capital de Trabajo & $-28,805$ & 0 & 0 & 0 & 0 & 28,805 \\
\hline Gastos Pre Operativos & $-34,941$ & 0 & 0 & 0 & 0 & 0 \\
\hline Recuperación Garantía de Alquiler & & & & & & \\
\hline Flujo de Caja Economico & \#\#\#\#\# & 81,254 & 114,742 & 161,952 & 252,436 & 398,211 \\
\hline
\end{tabular}

FUENTE: ELABORACIÓN PROPIA

En el flujo económico a lo largo del horizonte del proyecto se va incrementando año tras año, se inicia con un monto de S/. 81 mil soles para el primer año y al termino del quinto año termina con S/. 398 mil soles. Esto nos muestra que tendremos flujo de caja para la continuidad normal del proyecto. 


\subsection{Flujo Financiero}

\section{Estado de Ganancias y Pérdidas con Gastos Financieros y Escudo Fiscal}

\section{(Importes en Soles)}

\begin{tabular}{|c|c|c|c|c|c|c|}
\hline Rubro & aก๊̃o 0 & 2018 & 2019 & 2020 & 2021 & 2022 \\
\hline Ventas & & $1,874,813$ & $2,082,917$ & $2,356,195$ & $2,736,721$ & $3,316,906$ \\
\hline (-) Costo de Ventas & & $(1,370,003)$ & $(1,501,158)$ & $(1,674,391)$ & $(1,916,917)$ & $(2,288,789)$ \\
\hline (-) Costo Variable & & $(1,370,003)$ & $(1,501,158)$ & $(1,674,391)$ & $(1,916,917)$ & $(2,288,789)$ \\
\hline (-) Mano de Obra & & 0 & 0 & 0 & 0 & 0 \\
\hline (-) Costos Indirectos & & 0 & 0 & 0 & 0 & 0 \\
\hline Utilidad Bruta & & 504,809 & 581,758 & 681,804 & 819,804 & $1,028,116$ \\
\hline (-) Gastos Operativos & & $(397,270)$ & $(426,717)$ & $(459,799)$ & $(469,452)$ & $(510,787)$ \\
\hline (-) Administrativos & & $(199,928)$ & $(219,991)$ & $(242,597)$ & $(268,105)$ & $(297,234)$ \\
\hline (-) De Ventas & & $(191,904)$ & $(201,288)$ & $(211,765)$ & $(195,909)$ & $(208,865)$ \\
\hline (-) Depreciación & & $(1,250)$ & $(1,250)$ & $(1,250)$ & $(1,250)$ & $(500)$ \\
\hline (-) Amortiz. Gasto Pre Operativo & & 0 & 0 & 0 & 0 & 0 \\
\hline (-) Amortización de Intangibles & & $(4,188)$ & $(4,188)$ & $(4,188)$ & $(4,188)$ & $(4,188)$ \\
\hline EBIT o Resultado Operativo & & 107,540 & 155,041 & 222,005 & 350,352 & 517,330 \\
\hline (-) Impuesto a la Renta & $29.50 \%$ & 31,724 & 45,737 & 65,492 & 103,354 & 152,612 \\
\hline (+) Depreciación & & 1,250 & 1,250 & 1,250 & 1,250 & 500 \\
\hline (+) Amortiz. Gasto Pre Operativo & & 0 & 0 & 0 & 0 & 0 \\
\hline (+) Amortización de Intangibles & & 4,188 & 4,188 & 4,188 & 4,188 & 4,188 \\
\hline Flujo de Caja Operativo & & 81,254 & 114,742 & 161,952 & 252,436 & 369,405 \\
\hline Inversión en Activo Fijo & $-24,000$ & 0 & 0 & 0 & 0 & 0 \\
\hline Inversión en Intangibles & $-20,941$ & 0 & 0 & 0 & 0 & 0 \\
\hline Capital de Trabajo & $-28,805$ & 0 & 0 & 0 & 0 & 0 \\
\hline Gastos Pre Operativos & $-34,941$ & 0 & 0 & 0 & 0 & 0 \\
\hline Recuperación Garantía de Alquiler & & & & & & \\
\hline Flujo de Caja Economico & $(108,687)$ & 81,254 & 114,742 & 161,952 & 252,436 & 369,405 \\
\hline Préstamo & & 0 & 0 & 0 & 0 & 0 \\
\hline (-) Cuotas de reembolso del préstamo & & 0 & 0 & 0 & 0 & 0 \\
\hline$(+)$ Escudo Fiscal & & 0 & 0 & 0 & 0 & 0 \\
\hline Flujo de Caja Financiero & $(108,687)$ & 81,254 & 114,742 & 161,952 & 252,436 & 369,405 \\
\hline
\end{tabular}

\begin{tabular}{|l|r|r|r|r|r|r|}
\hline Saldo Inicial de Caja & & 28,805 & 110,059 & 224,801 & 386,753 & 639,189 \\
\hline Saldo Final de Caja & & 110,059 & 224,801 & 386,753 & 639,189 & $1,008,595$ \\
\hline
\end{tabular}

FUENTE: ELABORACIÓN PROPIA 


\subsection{Tasa de descuento accionistas y WACC}

Para obtener la tasa de descuento para los accionistas se tomó en cuenta los indicadores de EEUU y de Perú, para ello se va utilizar la metodología CAPM para hallar la tasa de descuento de accionistas.

Luego de buscar toda la información se obtiene la tasa de descuento del costo de financiamiento del accionista, con dicha tasa servirá para medir el riesgo y tiempo de la inversión del proyecto el COK será 33\%.

\begin{tabular}{|c|c|c|c|}
\hline Concepto & Base & Sigla & Dato \\
\hline Rendimiento del Mercado & Rendimiento USA (S\&P 500) - Damodaran & $\mathrm{RM}$ & $11.45 \%$ \\
\hline Tasa Libre de Riesgo & Tasa USA (T-Bonds) - Damodaran & TLR & $7.08 \%$ \\
\hline Beta & Diversified & $\mathrm{B}$ & 1.10 \\
\hline \% Capital Propio & Estructura de financiamiento del proyecto & $\mathrm{E}$ & $100.00 \%$ \\
\hline$\%$ Financiamiento & Estructura de financiamiento del proyecto & $\mathrm{D}$ & $0.00 \%$ \\
\hline Tasa Impuesto a la Renta & Leagislación Vigente & I & $29.50 \%$ \\
\hline Beta Desapalancada & $\mathrm{BD}=\mathrm{B} /\left\{[1+(\mathrm{D} / \mathrm{E})]^{*}(1-\mathrm{I})\right\}$ & $\mathrm{BD}$ & 1.566 \\
\hline Riesgo País & $\mathrm{BCR}$ & $\mathrm{RP}$ & $2.85 \%$ \\
\hline Beta Apalancado & $\mathrm{BA}=\mathrm{BD}^{*}\left\{[1+(\mathrm{D} / \mathrm{E})]^{*}(1-\mathrm{I})\right\}$ & BA & 1.10 \\
\hline Costo Capital Propio a/ & $\mathbf{K P}=\mathrm{TLR}+[\mathrm{BA} *(\mathbf{R M}-\mathrm{TLR})]+\mathbf{R P}$ & KP & $14.75 \%$ \\
\hline Riesgo Tamaño del Negocio & $80 \%: \quad \mathrm{RTN}=\mathrm{KP} * 0.80$ & RTN & $11.80 \%$ \\
\hline Riesgo Know How & $50 \%: \quad \mathrm{RN}=\mathrm{KP} * 0.50$ & $\mathrm{RN}$ & $7.37 \%$ \\
\hline Costo Capital Propio Ajustado b & $\mathrm{KP}_{1}=\mathrm{KP}+\mathrm{RTN}+\mathrm{RN}$ & $\mathrm{KP}_{1}$ & $33.918 \%$ \\
\hline
\end{tabular}

a/ Aplicando el método CAPM (valuación de activos de capital)

b/ El Costo del Capital Propio Ajustado se empleará para descontar el Flujo Financiero.

FUENTE: ELABORACIÓN PROPIA 
Luego para obtener el WACC se consideró las siguientes variables para obtener la tasa de WACC para aplicar al flujo efectivo financiero

\begin{tabular}{|c|c|c|c|}
\hline Concepto & Base & Sigla & Dato \\
\hline Rendimiento del Mercado & Rendimiento USA (S\&P 500) - Damodaran & $\mathrm{RM}$ & $11.45 \%$ \\
\hline Tasa Libre de Riesgo & Tasa USA (T-Bonds) - Damodaran & TLR & $7.08 \%$ \\
\hline Beta & Diversified & $\mathrm{B}$ & 1.10 \\
\hline$\%$ Capital Propio & Estructura de financiamiento del proyecto & $\mathrm{E}$ & $100.00 \%$ \\
\hline$\%$ Financiamiento & Estructura de financiamiento del proyecto & $\mathrm{D}$ & $0.00 \%$ \\
\hline Tasa Impuesto a la Renta & Leagislación Vigente & I & $29.50 \%$ \\
\hline Beta Desapalancada & $\mathrm{BD}=\mathrm{B} /\left\{[1+(\mathrm{D} / \mathrm{E})]^{*}(1-\mathrm{I})\right\}$ & $\mathrm{BD}$ & 1.5659 \\
\hline Riesgo País & BCR & $\mathrm{RP}$ & $2.85 \%$ \\
\hline Beta Apalancado & $\mathrm{BA}=\mathrm{BD}^{*}\left\{[1+(\mathrm{D} / \mathrm{E})]^{*}(1-\mathrm{I})\right\}$ & BA & 1.1039 \\
\hline Costo Capital Propio a & $K P=T L R+\left[B A^{*}(R M-T L R)\right]+R P$ & KP & $14.75 \%$ \\
\hline Riesgo Tamaño del Negocio & $80 \%: \quad \mathrm{RTN}=\mathrm{KP} * 0.80$ & RTN & $11.80 \%$ \\
\hline Riesgo Know How & $50 \%: \quad \mathrm{RN}=\mathrm{KP} * 0.50$ & $\mathrm{RN}$ & $7.37 \%$ \\
\hline Costo Capital Propio Ajustado b/ & $\mathrm{KP}_{1}=\mathrm{KP}+\mathrm{RTN}+\mathbf{R N}$ & $\mathrm{KP}_{1}$ & $33.918 \%$ \\
\hline Costo de la Deuda & T.E.A del Préstamo & $\mathrm{CD}$ & $0.00 \%$ \\
\hline Costo Efectivo de Deuda & $\mathrm{CE}=\mathrm{CD}^{*}(1-\mathrm{I})$ & $\mathrm{CE}$ & $0.00 \%$ \\
\hline Costo Promedio de Capital $\underline{\mathrm{c} /}$ & WACC $=\left\{\mathrm{KP}_{1} *[\mathrm{E} /(\mathrm{E}+\mathrm{D})]\right\}+\{\mathrm{CD} *(1-\mathrm{I}) *[\mathrm{D} /(\mathrm{E}+\mathrm{D})]\}$ & WACC & $33.918 \%$ \\
\hline
\end{tabular}

\footnotetext{
a/ Aplicando el método CAPM (valuación de activos de capital)

b/ El Costo del Capital Propio Ajustado se empleará para descontar el Flujo Financiero.

c/ El Costo Promedio Ponderado de Capital (WACC) se emplea para descontar el Flujo Económico.
}

FUENTE: ELABORACIÓN PROPIA 


\subsection{Indicadores de rentabilidad}

\begin{tabular}{|c|c|c|c|c|c|c|}
\hline CONCEPTO & Año 0 & 2018 & 2019 & 2020 & 2021 & 2022 \\
\hline FLUJO ECONOMICO & $(108,687)$ & 81,254 & 114,742 & 161,952 & 252,436 & 398,211 \\
\hline
\end{tabular}

a. VANE

\begin{tabular}{l|r|} 
VANE & $\mathbf{2 5 4 , 3 4 0}$ \\
\hline
\end{tabular}

b. TIRE

\begin{tabular}{l|l|} 
TIRE & $\mathbf{1 0 6 . 8 6} \%$ \\
\hline
\end{tabular}

c. TIR Modificado (TIRM) $\underline{a}$ /

\begin{tabular}{|l|l|} 
TIRME & $\mathbf{6 8 . 4 6} \%$ \\
\hline
\end{tabular}

a/ Considerando una tasa del $29.5 \%$ para las Reinversiones

d. Período de Recuperación a partir de Flujos Descontados

\begin{tabular}{|c|c|c|c|c|c|c|}
\hline CONCEPTO & Año 0 & 2018 & 2019 & 2020 & 2021 & 2022 \\
\hline Flujo Económico Descontado & $(108,687)$ & 60,674 & 63,980 & 67,433 & 78,487 & 92,453 \\
\hline Acumulado & $(108,687)$ & $(48,013)$ & 15,967 & 83,400 & 161,887 & 254,340 \\
\hline
\end{tabular}

Análisis Beneficio/Costo (B/C)

Relación B/C Económico:

3.34

FUENTE: ELABORACIÓN PROPIA

El proyecto presenta un VPN positivo con un valor de S/. 254,340 a lo largo del horizonte del tiempo, por ser un valor positivo el proyecto se considera viable.

La TIR tiene un valor de $106 \%$, lo que significa que el proyecto es viable y es mayor que el COK.

La TIRM (Modificado) es un método de valoración de inversiones de rentabilidad en términos porcentajes, con la única finalidad de eliminar la inconsistencia que pueda 
originar al aplicar la TIR, para el proyecto se tiene una TIRM de $68 \%$ mayor que el COK de $33 \%$, por lo tanto el proyecto es rentable.

El proyecto tendrá un periodo de recupero de 1.75 años para el retorno de las inversiones a ser pagados a los inversionistas.

\begin{tabular}{|c|c|}
\hline & Económica \\
\hline VAN & $\mathrm{S} / . \quad 254,340$ \\
\hline TIR & $106.86 \%$ \\
\hline TIR Modificado & $68.46 \%$ \\
\hline Periodo de recuperacion (años) & 1.75 \\
\hline Ratio Beneficio Costo & 3.34 \\
\hline
\end{tabular}

FUENTE: ELABORACIÓN PROPIA
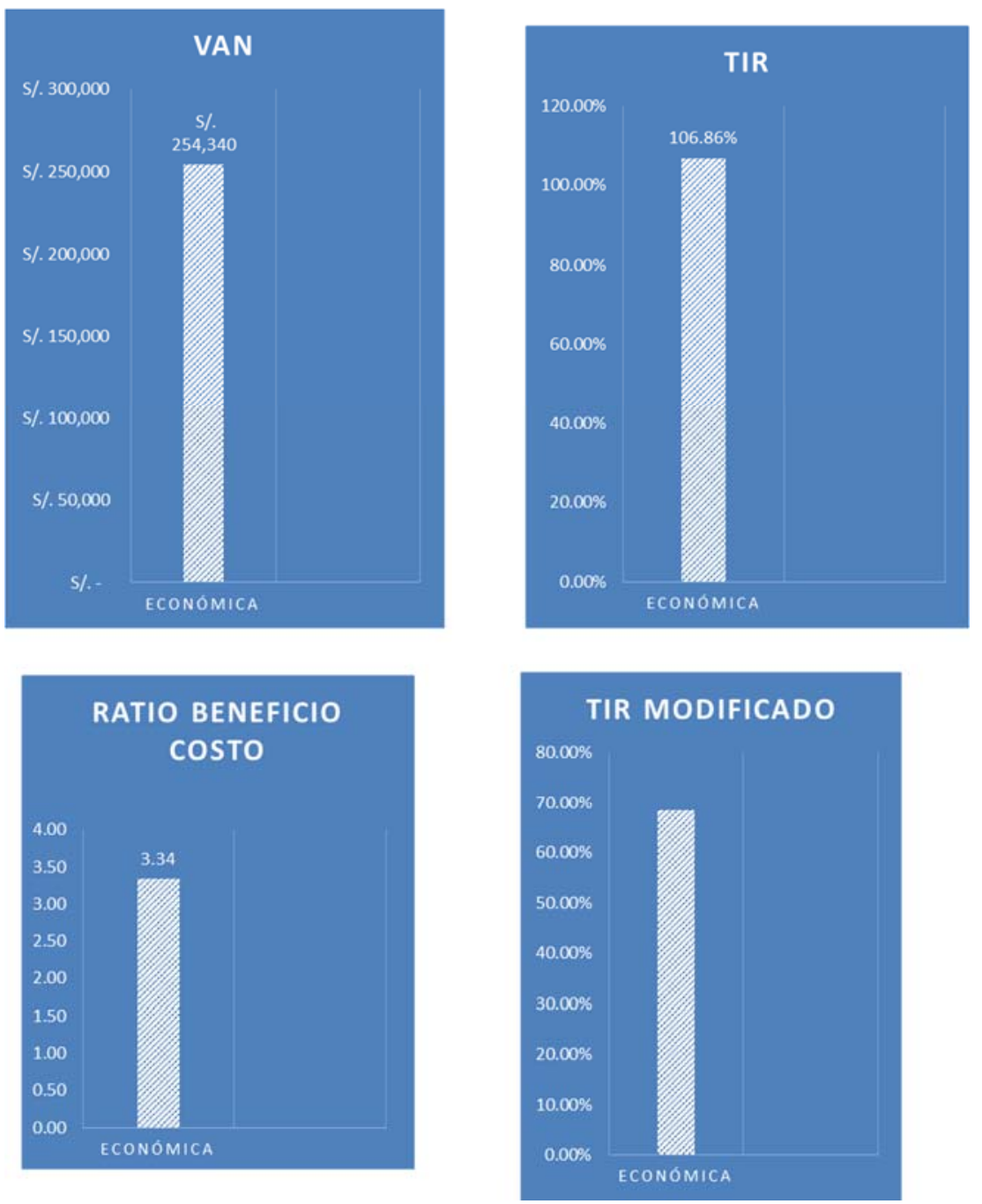

FUENTE: ELABORACIÓN PROPIA

Figura $n^{\circ} 36$ : Gráficos de los ratios rentabilidad 


\subsection{Análisis de riesgo}

\subsubsection{Análisis de sensibilidad}

Para medir la sensibilidad del proyecto se ha podido observar que la variable más relevante es el precio del servicio. Para el flujo pesimista se proyectó una disminución de la demanda de (-5\%) y en los costos variables se modificó el 5\%, luego de efectuar los cambios se puede obtener que el VPN es negativo de 188 mil soles, con una TIR de -19\%, lo que significa que el proyecto no será viable, porque la TIR es menor que el COK.

En el caso del flujo optimista, se cambió la demanda en 5\% y el costo de venta se mantiene, con esos datos se volvió a proyectar el flujo y nos dio como resultado un VPN de 512 mil soles con una TIR 186\%, lo que significa que el proyecto es viable.

Por lo tanto, se puede apreciar que la variable más sensible del proyecto es el "precio".

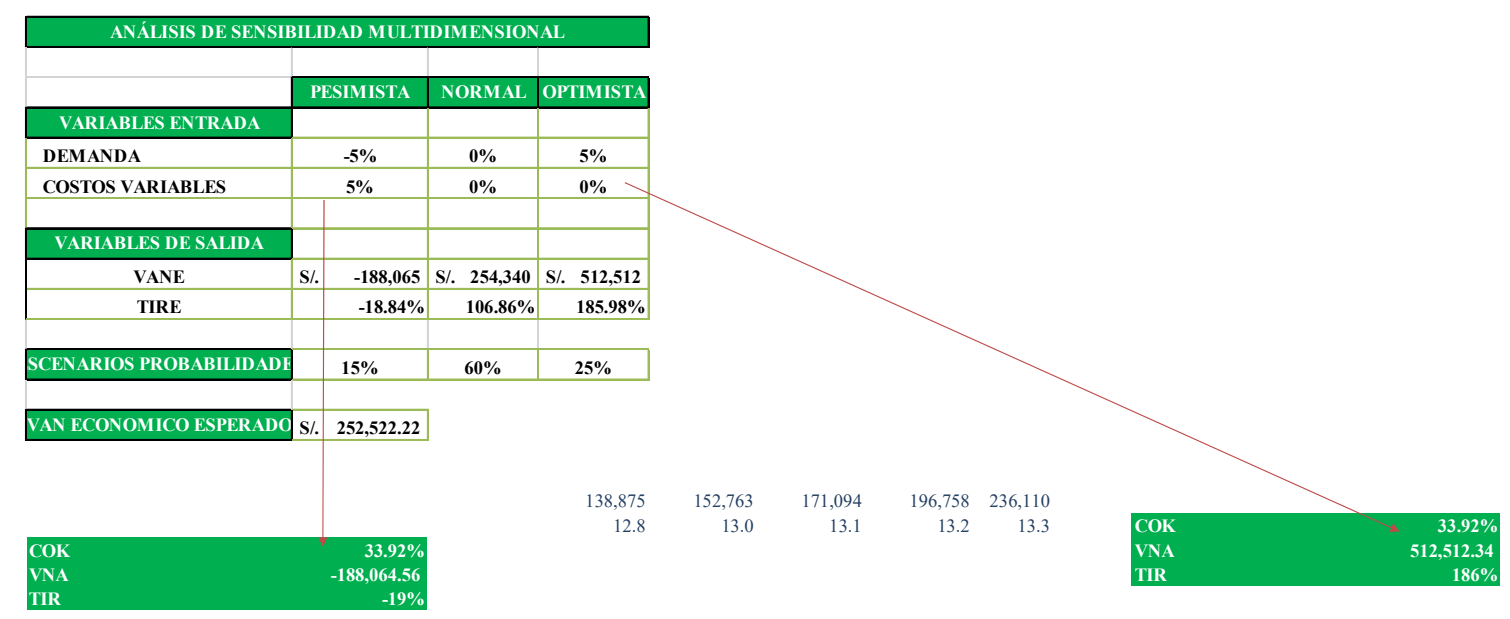

FUENTE: ELABORACIÓN PROPIA 


\section{Flujo de Efectivo - Pesimista}

\section{(Importes en Soles)}

\begin{tabular}{|c|c|c|c|c|c|c|}
\hline Rubro & aก̃o 0 & 2018 & 2019 & 2020 & 2021 & 2022 \\
\hline Ventas & & $1,781,072$ & $1,978,771$ & $2,238,386$ & $2,599,885$ & $3,151,060$ \\
\hline (-) Costo de Ventas & & $(1,438,503)$ & $(1,576,216)$ & $(1,758,110)$ & $(2,012,762)$ & $\overline{(2,403,229)}$ \\
\hline (-) Costo Variable & & $(1,438,503)$ & $(1,576,216)$ & $(1,758,110)$ & $(2,012,762)$ & $(2,403,229)$ \\
\hline (-) Mano de Obra & & 0 & 0 & 0 & 0 & 0 \\
\hline (-) Costos Indirectos & & 0 & 0 & 0 & 0 & 0 \\
\hline Utilidad Bruta & & 342,569 & 402,555 & 480,275 & 587,122 & 747,832 \\
\hline (-) Gastos Operativos & & $(397,270)$ & $(426,717)$ & $(459,799)$ & $(469,452)$ & $(510,787)$ \\
\hline (-) Administrativos & & $(199,928)$ & $(219,991)$ & $(242,597)$ & $(268,105)$ & $(297,234)$ \\
\hline (-) De Ventas & & $(191,904)$ & $(201,288)$ & $(211,765)$ & $(195,909)$ & $(208,865)$ \\
\hline (-) Depreciación & & $(1,250)$ & $(1,250)$ & $(1,250)$ & $(1,250)$ & $(500)$ \\
\hline (-) Amortiz. Gasto Pre Operativo & & 0 & 0 & 0 & 0 & 0 \\
\hline (-) Amortización de Intangibles & & $(4,188)$ & $(4,188)$ & $(4,188)$ & $(4,188)$ & $(4,188)$ \\
\hline EBIT o Resultado Operativo & & $(54,701)$ & $(24,162)$ & 20,476 & 117,670 & 237,045 \\
\hline (-) Impuesto a la Renta & $29.50 \%$ & 31,724 & 45,737 & 65,492 & 103,354 & 152,612 \\
\hline$(+)$ Depreciación & & 1,250 & 1,250 & 1,250 & 1,250 & 500 \\
\hline (+) Amortiz. Gasto Pre Operativo & & 0 & 0 & 0 & 0 & 0 \\
\hline (+) Amortización de Intangibles & & 4,188 & 4,188 & 4,188 & 4,188 & 4,188 \\
\hline Flujo de Caja Operativo & & $(80,987)$ & $(64,462)$ & $(39,578)$ & 19,755 & 89,121 \\
\hline Inversión en Activo Fijo & $-24,000$ & 0 & 0 & 0 & 0 & 0 \\
\hline Inversión en Intangibles & $-20,941$ & 0 & 0 & 0 & 0 & 0 \\
\hline Capital de Trabajo & $-28,805$ & 0 & 0 & 0 & 0 & 28,805 \\
\hline Gastos Pre Operativos & $-34,941$ & 0 & 0 & 0 & 0 & 0 \\
\hline Recuperación Garantía de Alquiler & & & & & & \\
\hline Flujo de Caja Economico & $(108,687)$ & $(80,987)$ & $(64,462)$ & $(39,578)$ & 19,755 & 117,926 \\
\hline
\end{tabular}

FUENTE: ELABORACIÓN PROPIA 


\section{Flujo de Efectivo - Optimista}

\section{(Importes en Soles)}

\begin{tabular}{|c|c|c|c|c|c|c|}
\hline Rubro & aก̃o 0 & 2018 & 2019 & 2020 & 2021 & 2022 \\
\hline Ventas & & $1,968,553$ & $2,187,063$ & $2,474,005$ & $2,873,557$ & $3,482,751$ \\
\hline (-) Costo de Ventas & & $(1,370,003)$ & $(1,501,158)$ & $(1,674,391)$ & $(1,916,917)$ & $(2,288,789)$ \\
\hline (-) Costo Variable & & $(1,370,003)$ & $(1,501,158)$ & $(1,674,391)$ & $(1,916,917)$ & $(2,288,789)$ \\
\hline (-) Mano de Obra & & 0 & 0 & 0 & 0 & 0 \\
\hline (-) Costos Indirectos & & 0 & 0 & 0 & 0 & 0 \\
\hline Utilidad Bruta & & 598,550 & 685,904 & 799,614 & 956,640 & $1,193,962$ \\
\hline (-) Gastos Operativos & & $(397,270)$ & $(426,717)$ & $(459,799)$ & $(469,452)$ & $(510,787)$ \\
\hline (-) Administrativos & & $(199,928)$ & $(219,991)$ & $(242,597)$ & $(268,105)$ & $(297,234)$ \\
\hline (-) De Ventas & & $(191,904)$ & $(201,288)$ & $(211,765)$ & $(195,909)$ & $(208,865)$ \\
\hline (-) Depreciación & & $(1,250)$ & $(1,250)$ & $(1,250)$ & $(1,250)$ & $(500)$ \\
\hline (-) Amortiz. Gasto Pre Operativo & & 0 & 0 & 0 & 0 & 0 \\
\hline (-) Amortización de Intangibles & & $(4,188)$ & $(4,188)$ & $(4,188)$ & $(4,188)$ & $(4,188)$ \\
\hline EBIT o Resultado Operativo & & 201,280 & 259,187 & 339,815 & 487,188 & 683,175 \\
\hline (-) Impuesto a la Renta & $29.50 \%$ & 31,724 & 45,737 & 65,492 & 103,354 & 152,612 \\
\hline (+) Depreciación & & 1,250 & 1,250 & 1,250 & 1,250 & 500 \\
\hline (+) Amortiz. Gasto Pre Operativo & & 0 & 0 & 0 & 0 & 0 \\
\hline (+) Amortización de Intangibles & & 4,188 & 4,188 & 4,188 & 4,188 & 4,188 \\
\hline Flujo de Caja Operativo & & 174,994 & 218,888 & 279,761 & 389,272 & 535,251 \\
\hline Inversión en Activo Fijo & $-24,000$ & 0 & 0 & 0 & 0 & 0 \\
\hline Inversión en Intangibles & $-20,941$ & 0 & 0 & 0 & 0 & 0 \\
\hline Capital de Trabajo & $-28,805$ & 0 & 0 & 0 & 0 & 28,805 \\
\hline Gastos Pre Operativos & $-34,941$ & 0 & 0 & 0 & 0 & 0 \\
\hline Recuperación Garantía de Alquiler & & & & & & \\
\hline Flujo de Caja Economico & $(108,687)$ & 174,994 & 218,888 & 279,761 & 389,272 & 564,056 \\
\hline
\end{tabular}

FUENTE: ELABORACIÓN PROPIA 


\subsubsection{Análisis por escenarios (por variables)}

\begin{tabular}{|c|c|r|r|r|r|}
\hline \multicolumn{7}{|c|}{ DATOS DE LA PROYECCIÓN INICIAL } \\
\hline Concepto & Año 1 & Año 2 & Año 3 & Año 4 & \multicolumn{1}{|c|}{ Año 5 } \\
\hline Precio promedio & 12.83 & 12.95 & 13.08 & 13.21 & 13.35 \\
\hline \multicolumn{7}{|c|}{ VANE } & & $\mathbf{2 5 4 , 3 4 0}$ \\
\hline \multicolumn{7}{|c|}{ TIRE } & $\mathbf{1 0 6 . 8 6 \%}$ \\
\hline PORCENTAJE DE DISMINUCIÓN DEL PRECIO & $-\mathbf{6 . 6 7 0 0 \%}$ \\
\hline Nuevo Precio promedio & 11.97 & 12.09 & 12.21 & 12.33 & 12.46 \\
\hline \multicolumn{7}{|c|}{ NUEVO VANE } & $\mathbf{0}$ \\
\hline NUEVO TIR & $\mathbf{3 3 . 9 2 \%}$ \\
\hline
\end{tabular}

Conclusión: El precio podría disminuir hasta en $6.67 \%$ y el Proyecto seguiría siendo viable

FUENTE: ELABORACIÓN PROPIA

\subsubsection{Análisis de punto de equilibrio}

\section{Punto de Equilibrio}

\section{(Importes en Soles)}

\begin{tabular}{|c|c|c|c|c|c|}
\hline Concepto & 2018 & 2019 & 2020 & 2021 & 2022 \\
\hline Ventas (en Soles) & $1,874,813$ & $2,082,917$ & $2,356,195$ & $2,736,721$ & $3,316,906$ \\
\hline Venta en Unidades & 138,875 & 152,763 & 171,094 & 196,758 & 236,110 \\
\hline Valor de Venta Promedio & 13.50 & 13.64 & 13.77 & 13.91 & 14.05 \\
\hline Costo variable & $1,299,664$ & $1,501,158$ & $1,674,391$ & $1,916,917$ & $2,288,789$ \\
\hline Costos Variables & $1,299,664$ & $1,501,158$ & $1,674,391$ & $1,916,917$ & $2,288,789$ \\
\hline Costo Variable Unitario Promedio & 9.36 & \begin{tabular}{l|l}
9.83 &
\end{tabular} & 9.79 & 9.74 & 9.69 \\
\hline Mano de Obra Directa & 0 & 0 & 0 & & \\
\hline Costos Indirectos & 0 & 0 & 0 & 0 & \\
\hline Gastos Administrativos & 201,008 & 221,071 & 243,677 & 269,185 & 298,314 \\
\hline Gastos de Venta & 191,904 & 201,288 & 211,765 & 195,909 & 208,865 \\
\hline Depreciación Activo Fijo & 1,250 & 1,250 & 1,250 & 1,250 & 500 \\
\hline Amortización de Intangibles & 4,188 & 4,188 & 4,188 & 4,188 & 4,188 \\
\hline Amortización de Pre Operativos & 0 & 0 & 0 & & \\
\hline Costos Fijos & 398,350 & 427,797 & 460,879 & 470,532 & 511,867 \\
\hline Punto de Equilibrio ( $\mathbb{N}^{\circ}$ de Unidades) & 96,185 & 112,334 & 115,654 & 112,931 & 117,552 \\
\hline Punto de Equilibrio (En Soles) & $1,298,500$ & $1,531,677$ & $1,592,717$ & $1,570,759$ & $1,651,383$ \\
\hline
\end{tabular}

\begin{tabular}{|c|c|c|c|c|c|}
\hline Resultados (Costeo Directo) & 2018 & 2019 & 2020 & 2021 & 2022 \\
\hline $\begin{array}{l}\text { Ventas } \\
\text { (-) Costos Variables }\end{array}$ & $\begin{array}{r}1,298,500 \\
(900,151)\end{array}$ & $\begin{array}{r}1,531,677 \\
(1,103,879)\end{array}$ & $\begin{array}{r}1,592,717 \\
(1,131,838)\end{array}$ & $\begin{array}{r}1,570,759 \\
(1,100,227)\end{array}$ & $\begin{array}{c}1,651,383 \\
(1,139,516)\end{array}$ \\
\hline Margen de Contribución & 398,350 & 427,797 & 460,879 & 470,532 & 511,867 \\
\hline (-) Costos Fijos & $(398,350)$ & $(427,797)$ & $(460,879)$ & $(470,532)$ & $(511,867)$ \\
\hline Utilidad Operativa & 0 & 0 & 0 & 0 & 0 \\
\hline
\end{tabular}

FUENTE: ELABORACIÓN PROPIA 


\subsubsection{Principales riesgos del proyecto (cualitativos)}

En todo proyecto de inversión se puede presentar diversos riesgos que se deben tomar en cuenta, en entre los principales riesgos para SENIOR CARE:

- La competencia nueva en el mismo rubro, con años de experiencia en el exterior y decide implementar su expansión y crecimiento en el Perú.

- El entorno económico y político que viene afectando al país actualmente, sobre todo donde la corrupción se encuentra operando en los organismos estatales. Por ende, se produciría una reducción de los ingresos de las personas donde solo cubrirán sus necesidades básicas.

- Carecer de staff de enfermeras en algún momento donde la demanda se encuentre con mayor auge, y no podamos cubrir las necesidades del cliente.

- Si durante el servicio haya una mala práctica de las enfermeras que pueda ocasionar un daño a la salud del paciente sea leve, moderado o grave. Lo que nos dejaría una mala experiencia para el cliente y dejar la imagen de la empresa se vea afectada como empresa y económicamente también.

- Como no hay experiencia entre los socios, se pueda generar un conflicto interno que vaya a interrumpir las actividades normales de la empresa. 


\section{CAPITULO 9: CONCLUSIONES}

\subsection{Conclusiones Grupales}

- Considerando el incremento de la población adulto mayor se va incrementando cada año, existe un mercado insatisfecho para el servicio y atención del cuidado del adulto mayor en el Perú, asimismo, existen muchas alternativas que ofrecen el servicio de cuidado, pero el proceso de envejecimiento es inevitable.

- Se ha podido observar que existe una demanda insatisfecha por un servicio integral para el cuidado del adulto mayor por horas, en SENIOR CARE cuente con profesionales especialistas en diversas ramas de la materia de geriatría que permita plasmar sus conocimientos y experiencia en el servicio del usuario final.

- El negocio de cuidado y la seguridad de las personas de la tercera edad en nuestro país, las familias no cuentan con tiempo disponible para su atención por motivos laborales, paciencia o capacidad necesaria, por ello, surge la idea de negocio de SENIOR CARE que permitirá cubrir las necesidades del cliente no satisfechas.

- Muchos adultos mayores requieren apoyo o acompañamiento en sus propios hogares en forma continua, los mismos que son cuidados por alguna persona o son encargados por sus vecinos pero que no cubren las necesidades en su totalidad. 


\subsection{Conclusiones Individuales}

\section{Sosa Cardenas, Julia Carolina}

- $\quad$ El proyecto de negocio SENIOR CARE, permitirá a muchas familiar que carecen de tiempo suficiente en brindar apoyo y protección al adulto mayor en casa con la atención que ellos merecen.

- Nuestra propuesta de personal especializado en las técnicas de geriatría permitirá que exista un beneficio en el adulto mayor.

- $\quad$ Para el desarrollo del negocio SENIOR CARE, se ha plasmado todos los cursos llevados a cabo en la Universidad, que nos han permitido elaborar el presente trabajo final de negocio SENIOR CARE.

- Luego de analizarlo cuidadosamente podemos decir que el proyecto nos ha demostrado ser rentable y crear una oportunidad de negocio personal en el futuro.

- Para llevar a cabo el proyecto se tomará en cuenta los factores económicos es decir la factibilidad económica y financiera del proyecto.

- $\quad$ El presente estudio se ha abarcado atender las zona 6 y7 de los distritos de Lima Metropolitana, si ponemos en marcha el proyecto se puede cubrir otras zonas adicionales con la finalidad de ir incrementando nuevos clientes potenciales y que el proyecto sea mucho más rentable en el futuro. 


\section{CAPITULO 10: REFERENCIAS BIBLIOGRÁFICAS}

Diario Gestión (GESTION) (2018) (https://gestion.pe/economia/crisis-politica-impactoeconomia-2018-223528) Sitio web oficial del diario GESTION; contiene información política del país (consulta: 11 de abril)..

Diario Perú21 (PERU21) (2018) (https://peru21.pe/economia/inei-situacion-adultomayor-peru-174786) Sitio web oficial del diario PERU 21; contiene información de salud del adulto mayor (consulta: 11 de abril).

Diario Perú21 (PERU21) (2018) (https://peru21.pe/economia/inei-situacion-adultomayor-peru-174786) Sitio web oficial del diario PERU 21; contiene información de salud del adulto mayor (consulta: 11 de abril).

Diario RPP (RPP)

(2018)(https://www.inei.gob.pe/media/MenuRecursivo/boletines/informetecnico poblac ion-adulta-mayor-oct-nov-dic2015.pdf) Sitio web oficial de INEI; contiene datos estadísticos del adulto mayor (consulta: 11 de abril).

Bertoni y Asociados (s.f.). Mentoring. Recuperado el 09 de septiembre de 2017 de http://www.bertoniyasociados.com.ar/detalle.php? $\mathrm{a}=$ Mentoring\& $\mathrm{t}=5 \& \mathrm{~d}=9$

Ipsos Apoyo (IPSOS) (2018) (https://www.ipsos.com/es-pe/perfil-del-adulto-mayor2016) Sitio web oficial de IPSOS; contiene informaciones estadísticas del adulto mayor (consulta: 11 de abril).

Perspectivas Ey Peru (ECOMMERCE)

(2018)(https://perspectivasperu.ey.com/2018/02/12/e-commerce-peru-

desafiostendencias-2018/) Sitio web oficial de ECOMMERCE; contiene información de la tendencia de comercio por internet (consulta: 11 de abril).

Instituto Nacional De Estadística E Informática (INEI) (2017) (https://www.inei.gob.pe/media/MenuRecursivo/boletines/01-informe- 
tecnicon01 adulto-oct-nov-dic2017.pdf) Sitio web oficial de la INEI; contiene información sobre la institución y enlaces de interés (Consulta: 31 de marzo). 


\section{ANEXOS}

Eduardo Román Flores (80 años):

\begin{tabular}{|c|c|c|c|c|c|}
\hline & matara & meramastara & tanot & MEDatarot & Noout \\
\hline Acciones & $\begin{array}{l}\text { Se ducha contemor y toma des ayuno } \\
\text { se ducha con temor y toma des ayuno } \\
\text { se ducha contemor y toma desayuno }\end{array}$ & $\begin{array}{l}\text { Mira television } \\
\text { se va al seguro a solictar cta } \\
\text { Se va al supermercado a comprar }\end{array}$ & $\begin{array}{l}\text { Almuerza solo } \\
\text { Almuerza solo } \\
\text { Ailmuerza solo } \\
\end{array}$ & \begin{tabular}{|l|} 
sale al parque a distraerse \\
se va a sus terapias \\
VIstra a sus hermanas
\end{tabular} & $\begin{array}{l}\text { Cena, mira TV toma sus pastilas y descansa } \\
\text { Cena, mira TV toma sus pastllas y descansa } \\
\text { Cena, mira TV toma sus pastllasy descansa }\end{array}$ \\
\hline $\begin{array}{l}A \\
\hat{L} \\
G \\
R \\
\mathbf{E}\end{array}$ & & & & & \\
\hline $\begin{array}{l}5 \\
5 \\
R \\
1 \\
0\end{array}$ & & & & & \\
\hline $\begin{array}{l}T \\
R \\
R \\
1 \\
S \\
T \\
\\
\end{array}$ & $\begin{array}{l}x \\
x\end{array}$ & & & & \\
\hline
\end{tabular}

Guillermina Jacobo Murillo (75 años):

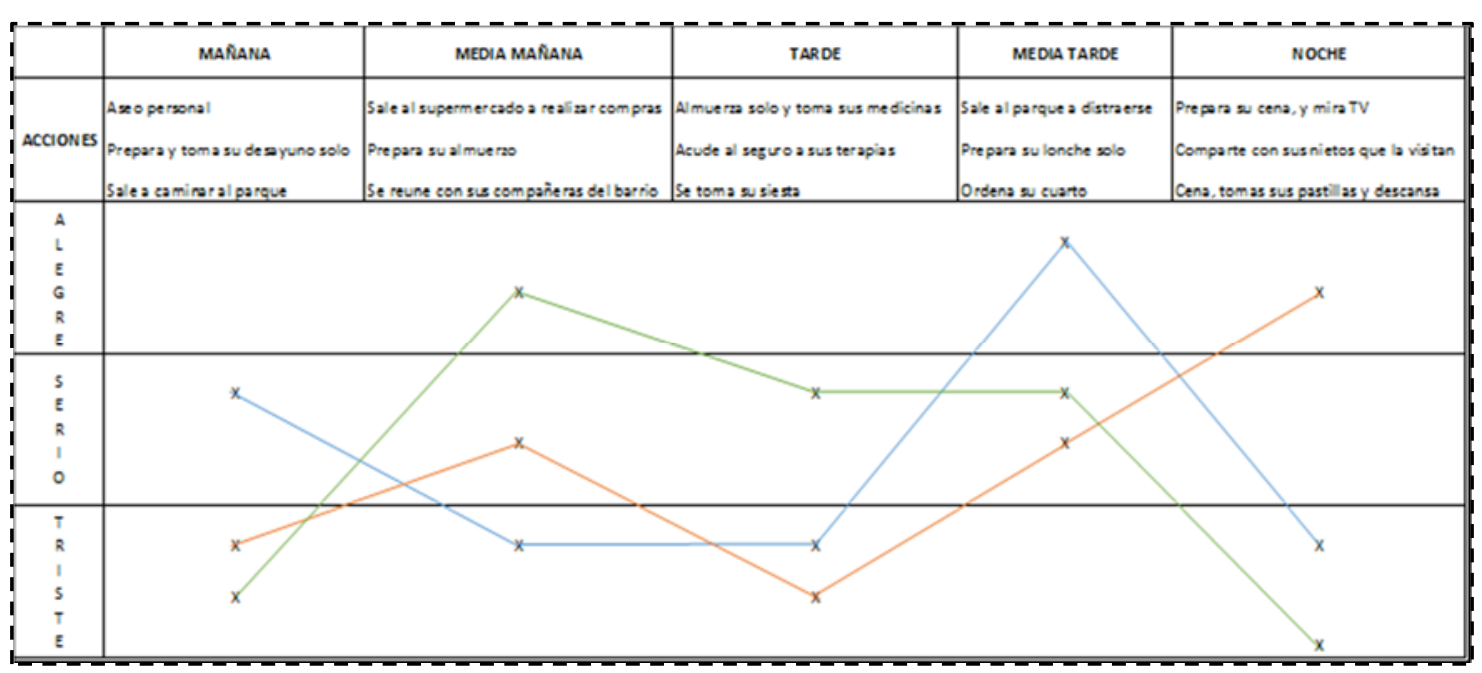

Gloria Vásquez Carrillo (75 años): 


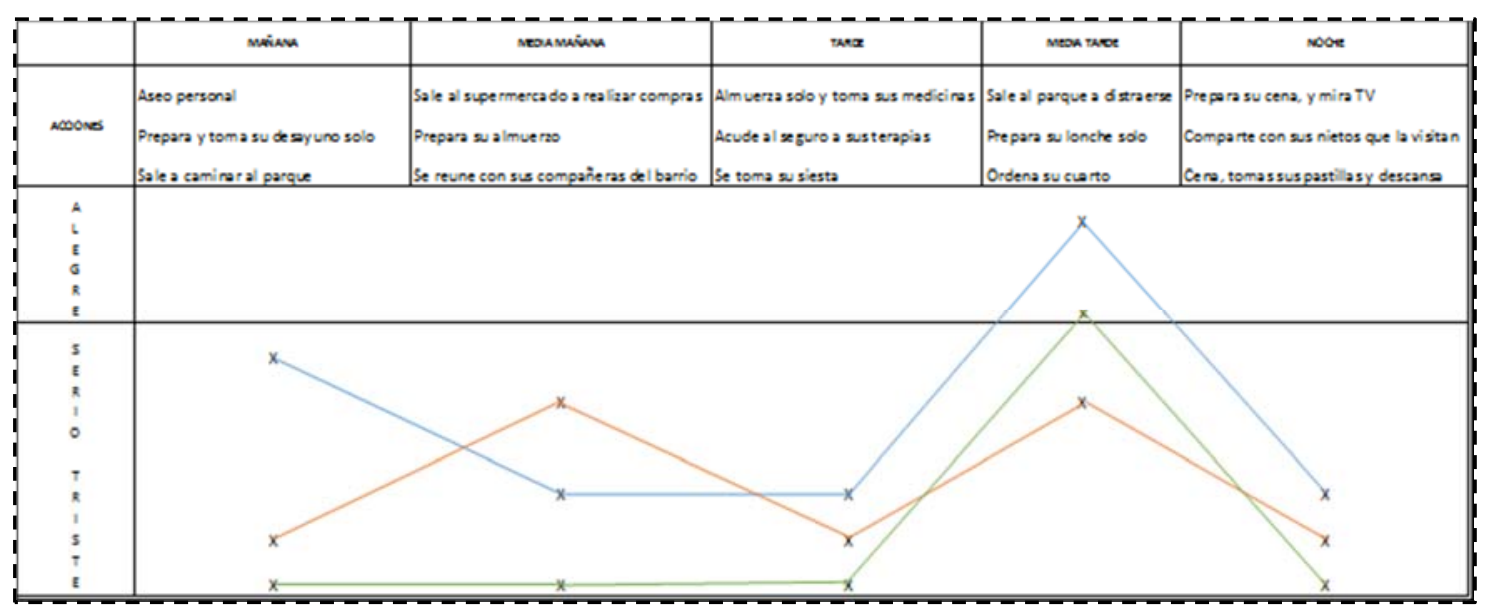

Mercedes Rosado Ugarte (78 años):

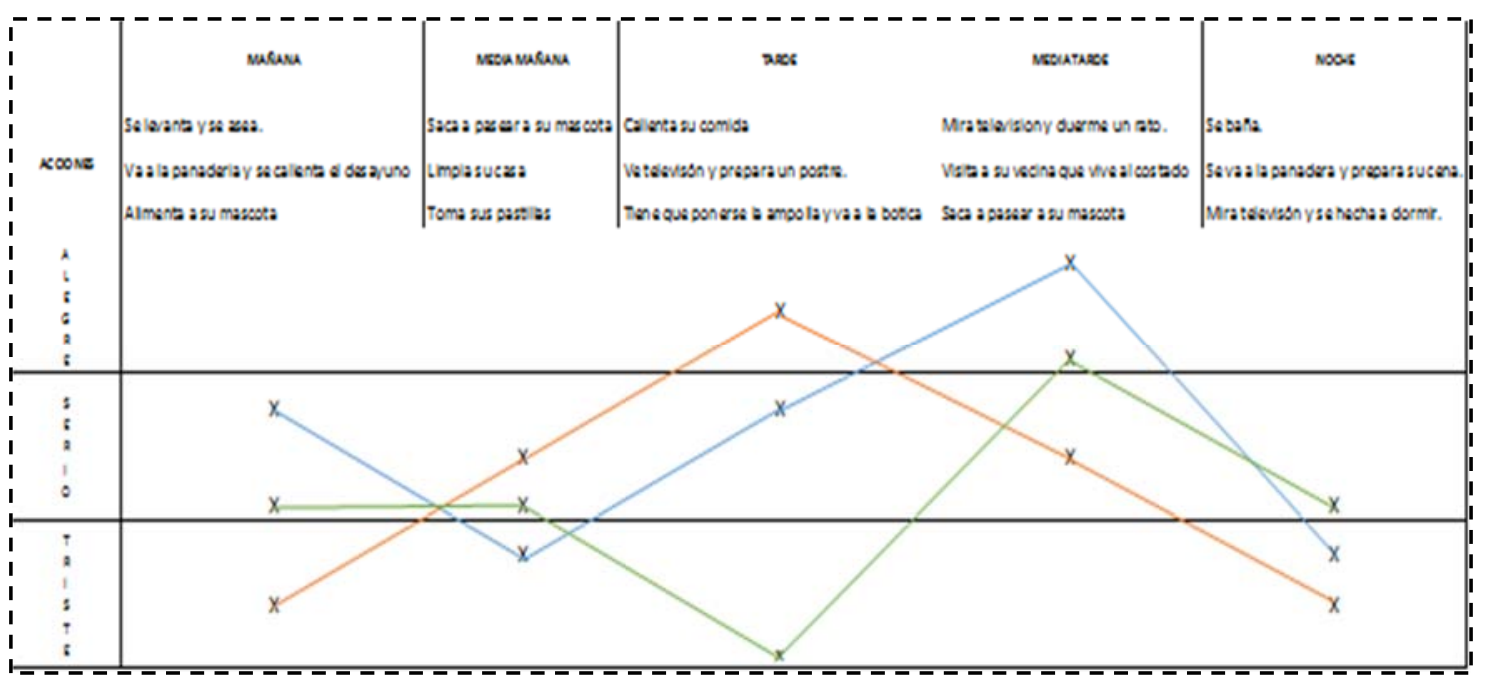

Consuelo Flores Rodríguez (79 años):

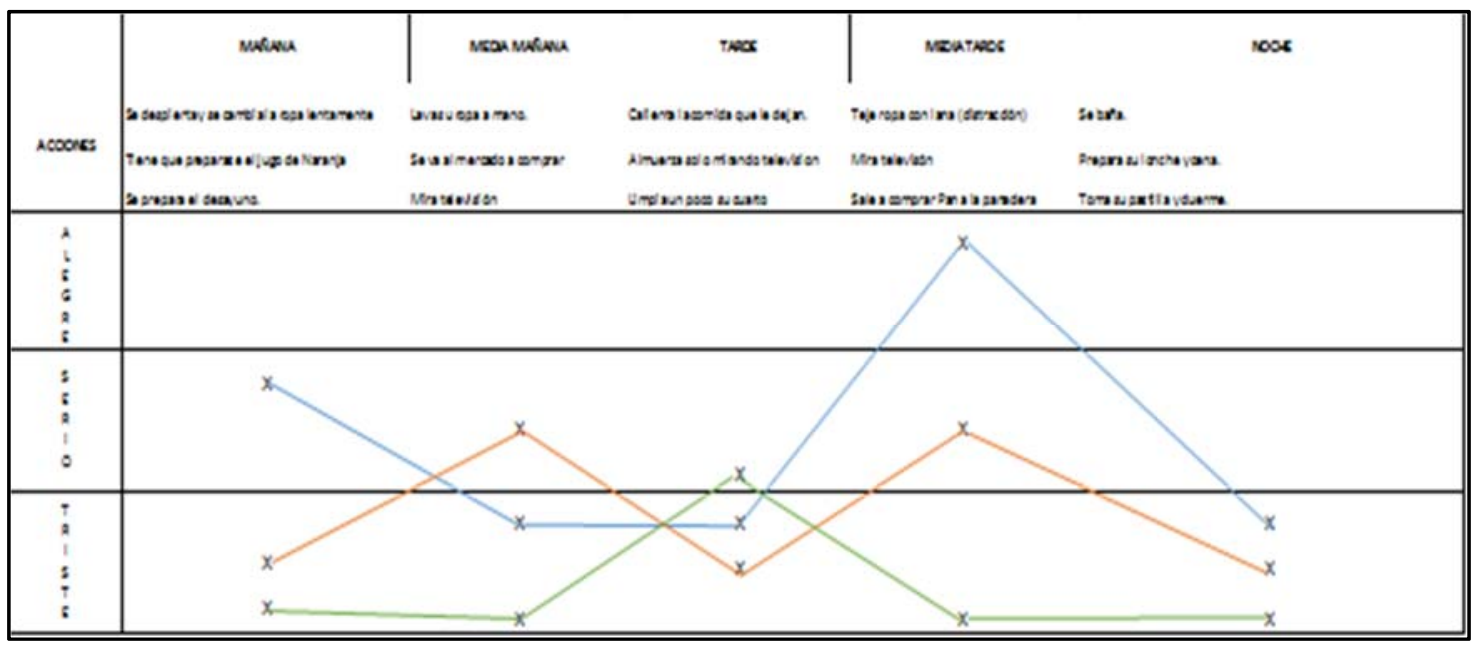

Claudio Pineda Mendoza (72 años): 


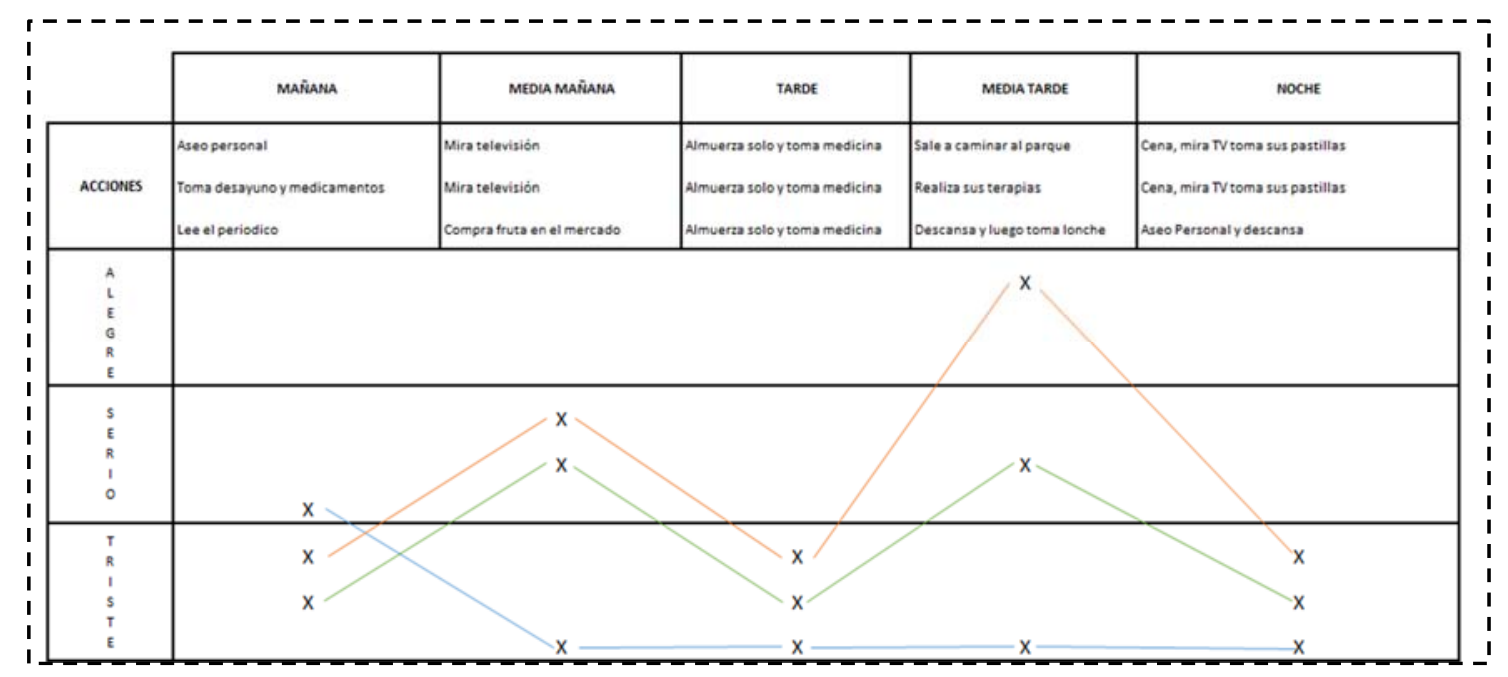

Antonia Caritas Torres (75 años):

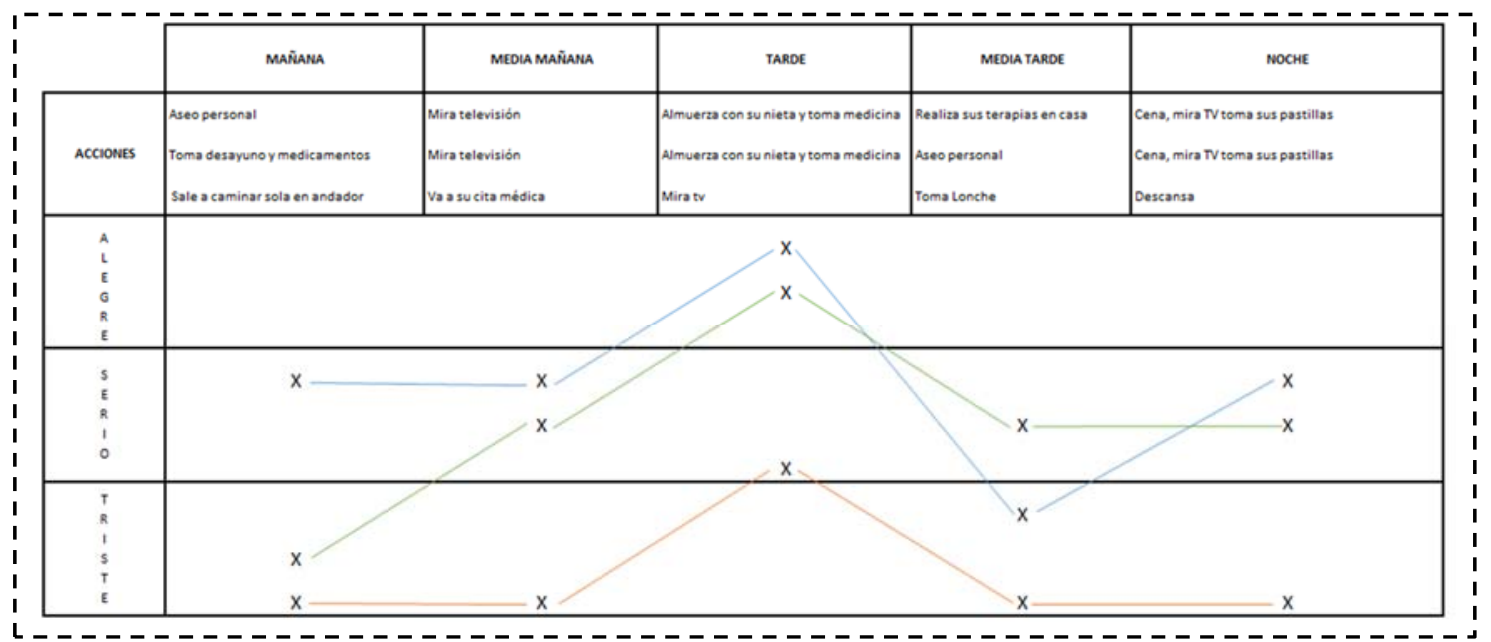

Felicia Navarro De Rojas (67 años):

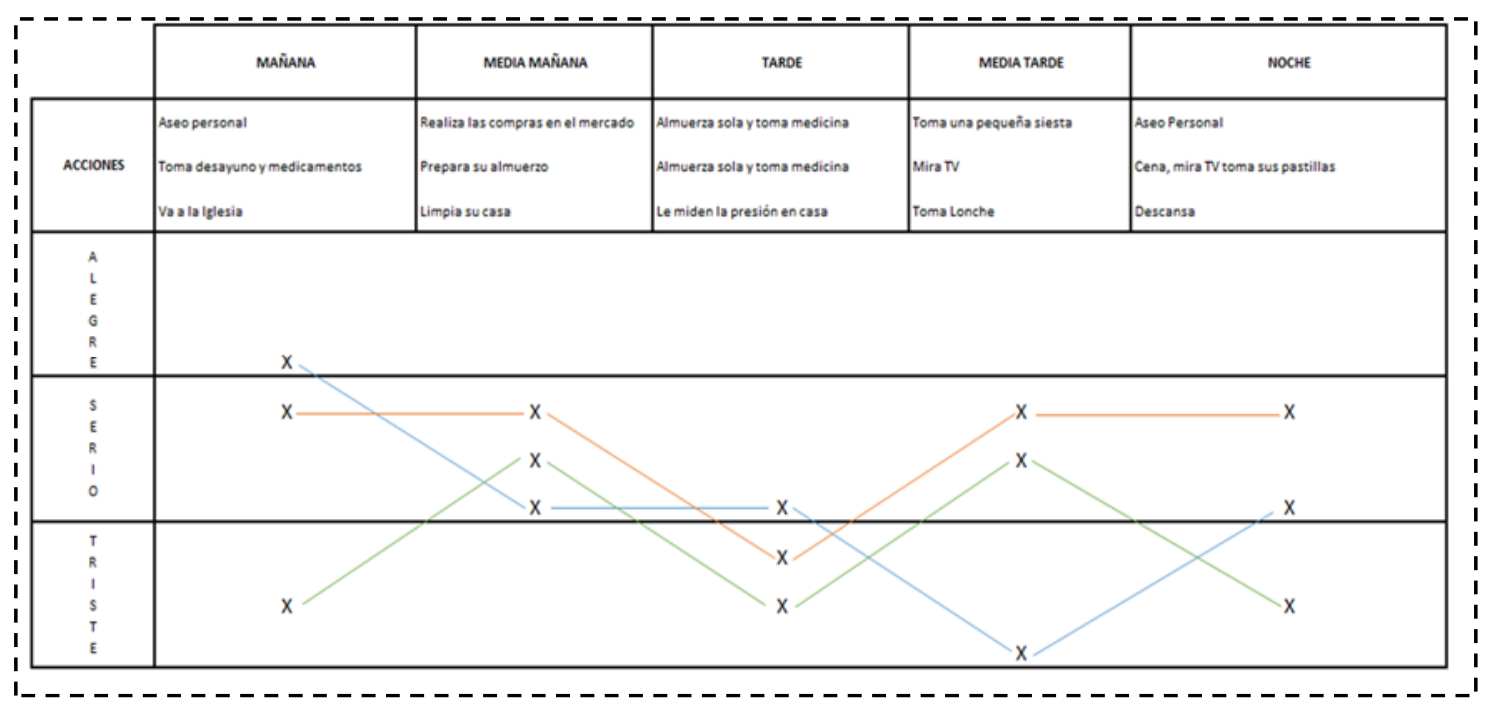

